Portland State University

PDXScholar

Environmental Science and Management

Professional Master's Project Reports

Spring 2019

\title{
Analysis of Toxic Pollutant Sources and \\ Characteristics Contributing to Water Quality Impairments in the Willamette River Basin
}

Melinda Borgens

Portland State University

Follow this and additional works at: https://pdxscholar.library.pdx.edu/mem_gradprojects

Part of the Environmental Monitoring Commons, and the Water Resource Management Commons Let us know how access to this document benefits you.

\section{Recommended Citation}

Borgens, Melinda, "Analysis of Toxic Pollutant Sources and Characteristics Contributing to Water Quality Impairments in the Willamette River Basin" (2019). Environmental Science and Management Professional Master's Project Reports. 55.

https://pdxscholar.library.pdx.edu/mem_gradprojects/55

https://doi.org/10.15760/mem.56

This Project is brought to you for free and open access. It has been accepted for inclusion in Environmental Science and Management Professional Master's Project Reports by an authorized administrator of PDXScholar. Please contact us if we can make this document more accessible: pdxscholar@pdx.edu. 


\section{Analysis of Toxic Pollutant Sources and Characteristics Contributing to Water Quality Impairments in the Willamette River Basin}

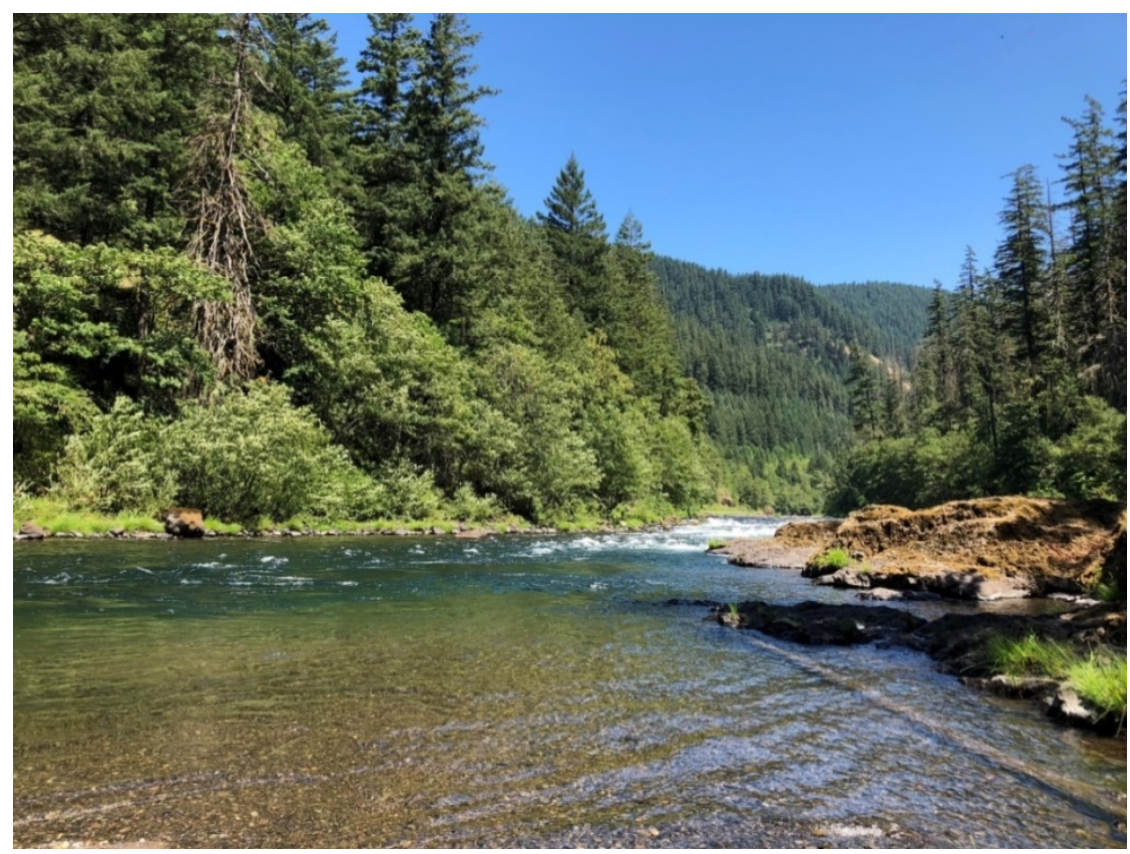

by

Melinda Borgens

A thesis submitted in partial fulfillment of the requirements for the degree of

Master of Environmental Management

School of Environmental Science and Management

Portland State University

June 4, 2019

Thesis Committee:

Dr. Eugene Foster, Oregon Department of Environmental Quality

Dr. Daniel Sobota, Oregon Department of Environmental Quality

Dr. Yangdong Pan, Portland State University

Dr. Joseph Maser, Portland State University 


\section{Acknowledgements}

This Project was completed under the guidance of a Community Partner (the Oregon Department of Environmental Quality (DEQ)) in partial fulfillment of the Master of Environmental Management (MEM) at Portland State University's Environmental Science and Management Department (ESM). This Project provided research support for DEQ's Water Quality Division in the development of Total Maximum Daily Loads for the Willamette River Basin.

I would like to express my sincere gratitude and appreciation to my Community Partner and MEM Committee for all the support and guidance I received during the process of developing and completing my thesis. Thank you to Dr. Eugene Foster for providing me the opportunity and freedom to work on a project of great interest to me, providing invaluable mentoring and guidance on project management, and most importantly, keeping me on track to achieving my personal and Project goals. Thank you to Dr. Daniel Sobota for your technical guidance and for reminding me to keep the intent of my research focused on the Project goals and objectives, helping me understand the importance of scientific writing. Thank you to Dr. Yangdong Pan for your kind patience in helping me understand the complexity and joy of environmental statistical analysis. Thank you to Dr. Joseph Maser for the guidance at the start of my graduate program in developing my project and support during MEM lab group discussions.

I would also like to express my appreciation to students and faculty of the ESM Department as well as to faculty of the College of Engineering at PSU. The knowledge I received from faculty during challenging and complex classwork, and support from fellow students, have been invaluable. Thank you also to my MEM lab group for their constructive criticism, feedback, and support.

I would also like to thank my employer (AECOM) and undergraduate college sorority (Kappa Delta at Oregon State University). The completion of this thesis (and graduate degree) in a three-year period would not have been possible without their financial support.

And last but not least, thank you to my family, friends, and colleagues for their emotional support as I managed graduate school while working full time.

Cover photo: (Melinda Borgens, July 2018) Clackamas River at river mile 40.1. Oregon DEQ, Stream Location Identification Tool interactive map (DEQ, 2018b). 


\section{Abstract}

Point and nonpoint sources contribute toxic pollutants to surface waters, degrading water quality and impairing aquatic and human life. As of 2012, 51 stream segments totaling approximately 6,000 kilometers (3,750 miles) in Oregon's Willamette River Basin (the Basin) were listed as impaired on the Clean Water Act's (CWA) Section 303(d) list with 48 toxic pollutants. These toxic pollutants exceed the Oregon Department of Environmental Quality's (DEQ) state water quality standards, requiring Total Maximum Daily Loads (TMDLs) to restore water quality and protect beneficial uses. Identifying toxic pollutant point and nonpoint sources, and the total loads a waterbody receives, are critical components in TMDL development and a CWA requirement. However, developing a single pollutant TMDL is data- and time-intensive.

In this Project, I investigated: 1) point and nonpoint sources potentially contributing to the Basin's impairments of metals, polycyclic aromatic hydrocarbons (PAHs), volatile organic compounds (VOCs), polychlorinated biphenyls (PCBs), organochlorine insecticides, and organophosphorus insecticides; and 2) developed a strategy for DEQ to approach TMDL modeling based on similarities in geographical source areas (by subbasin) and chemical characteristic similarities among the toxic pollutants $(n=48)$. Characteristics considered included water solubility, vapor pressure, Henry's Law Constant, octanol-water partition coefficient $\left(\mathrm{K}_{\mathrm{ow}}\right)$, and organic carbonwater distribution coefficient $\left(\mathrm{K}_{\mathrm{oc}}\right)$. These characteristics are primary mechanisms influencing environmental behavior and key inputs to surface water quality models used to determine toxic pollutant loads for TMDL allocation. These characteristics were evaluated using multivariate statistical techniques of cluster analysis and Nonmetric multidimensional scaling (NMDS).

Point source analysis of Basin stormwater/wastewater discharges revealed 2,050 national pollutant discharge elimination system (NPDES)-permitted facilities discharging 13 toxic pollutants, 81 NPDES-permitted Department of Geology and Mineral Industries mining sites, and 522 Oregon Department of Transportation outfalls. Nonpoint source analysis of Basin activities revealed 937 toxic pollutant-impacted contaminated waste sites (927 DEQ Environmental Cleanup Site Information sites and 10 Environmental Protection Agency Superfund Sites) and the application of 1.5 million kilograms (3.3 million pounds) of toxic pollutant-containing pesticides (metals, organochlorine and organophosphorus insecticides) to agricultural land (2000 to 2016). The Project results revealed that metals, PAHs, and VOCs can be attributed to both point and nonpoint sources while PCBs, organochlorine insecticides, and organophosphorus insecticides can be attributed to nonpoint sources.

Exploratory analysis of cluster analysis, in conjunction with Analysis of Similarity statistical evaluations, revealed four statistically different toxic pollutant groups discriminated by chemical characteristics (Clusters 1 through 4). NMDS analysis indicated clusters were associated with chemical characteristics and generally not to pollutant class, suggesting similarities in environmental behavior: Cluster 1 toxic pollutants (VOCs and metals) exhibiting soluble behavior, Cluster 2 toxic pollutants (VOCs and metals) exhibiting more volatile behavior, Cluster 3 toxic pollutants (PAHs, organochlorine and organophosphorus insecticides) exhibiting less volatile behavior, and Cluster 4 toxic pollutants (PAHs, organochlorine insecticides, and PCBs) exhibiting hydrophobic behavior. The Project results suggested that statistically evaluating chemical characteristic data for TMDL modeling of multiple pollutants could address multiple surface water impairments concurrently, efficiently meeting CWA requirements and DEQ needs, resulting in improvement of the Basin's water quality. 


\section{Table of Contents}

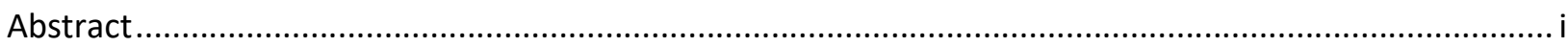

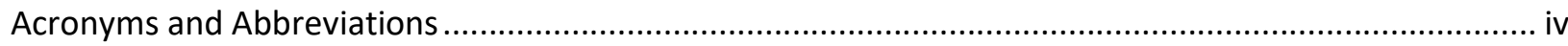

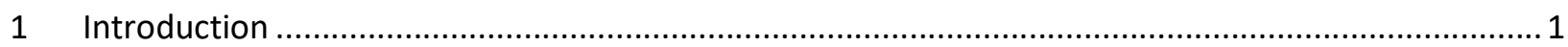

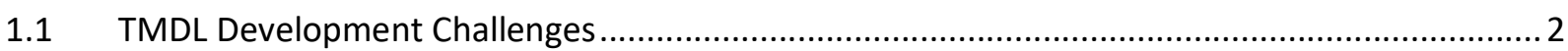

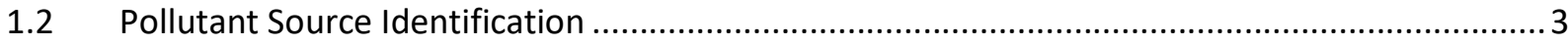

$1.3 \quad$ TMDL Development Strategies …................................................................................

1.4 Project Goals and Purpose

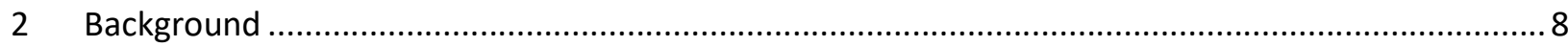

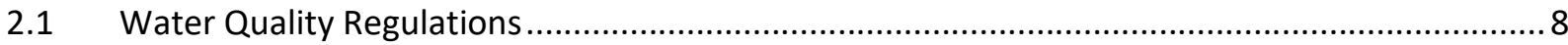

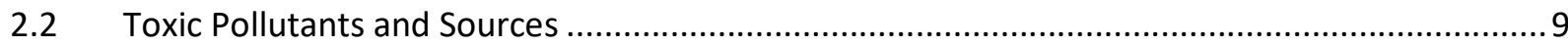

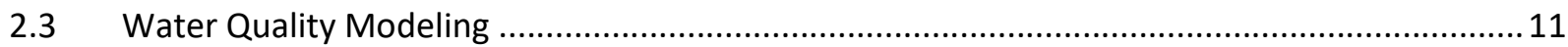

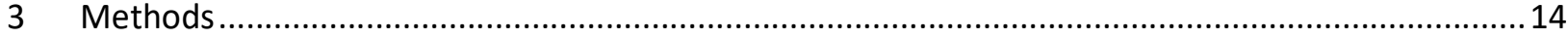

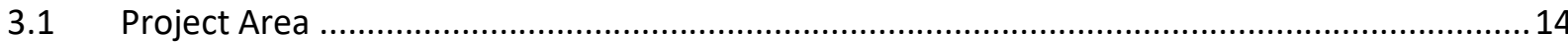

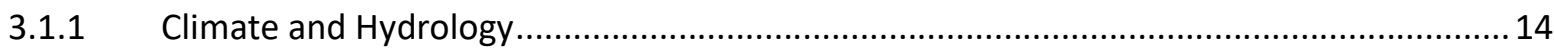

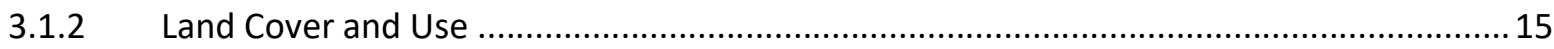

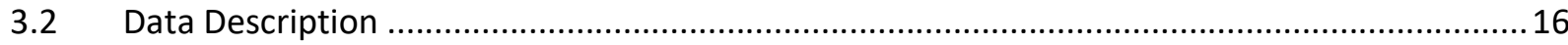

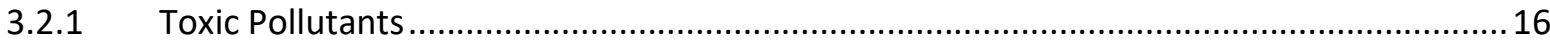

3.2.2 Point and Nonpoint Source Data Acquisition ............................................................ 16

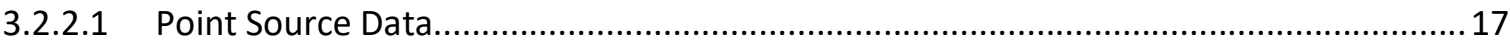

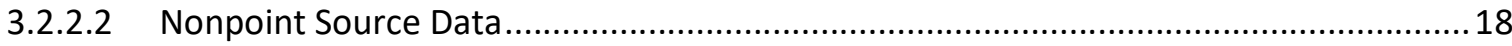

3.2.3 Chemical Characteristic Data Acquisition ...................................................................... 20

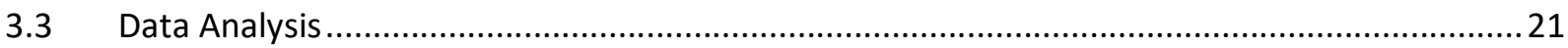

3.3.1 Categorization of Point Sources by Activity ............................................................... 21

3.3.2 Categorization of Sources by Geographical Source Area ...............................................22

3.3.3 Categorization of Toxic Pollutants by Chemical Characteristics .......................................2 23

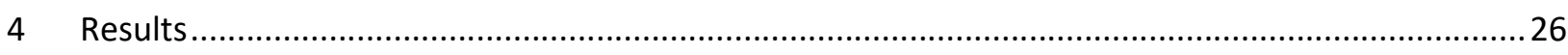

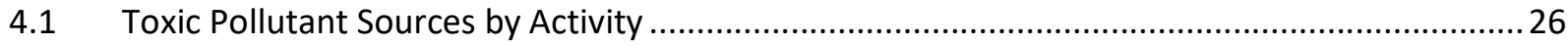

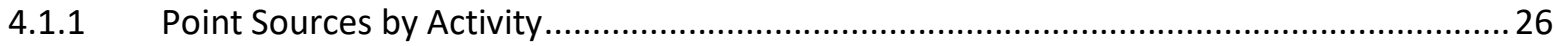

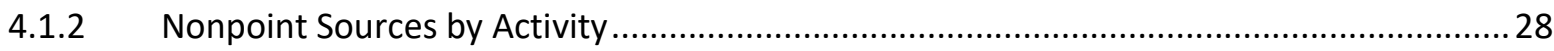


4.2 Toxic Pollutant Sources by Geographic Source Area .........................................................29

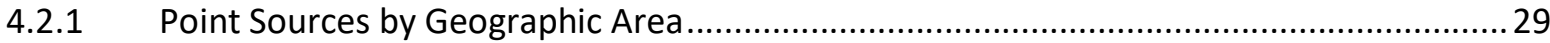

4.2.2 Nonpoint Sources by Geographic Area ................................................................................. 31

4.3 Toxic Pollutant Chemical Characteristics .............................................................................. 34

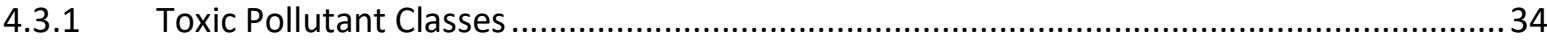

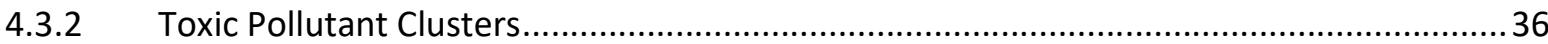

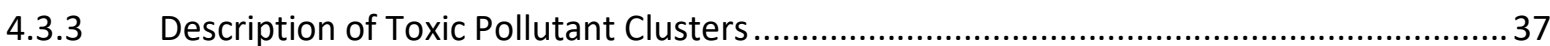

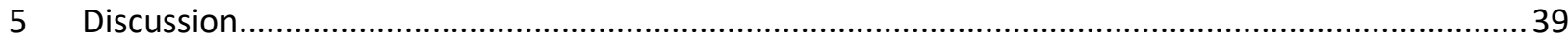

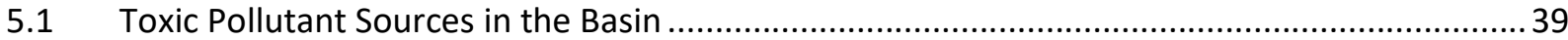

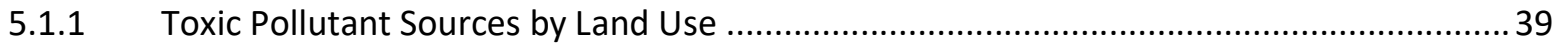

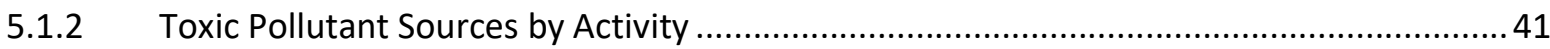

5.1.3 Other Possible Sources of Toxic Pollutants ....................................................................44

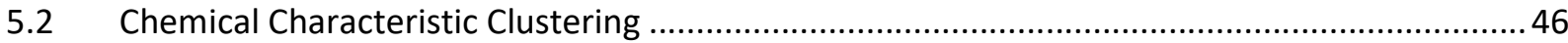

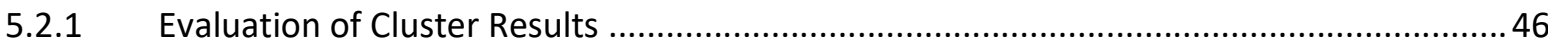

5.2.2 Evaluation of Clustering Applications in Other Studies ................................................. 48

5.2.3 Additional Chemical Characteristics to Consider ........................................................50

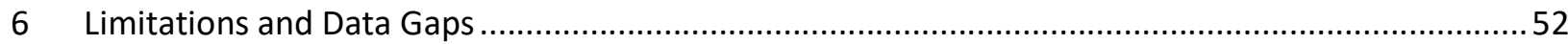

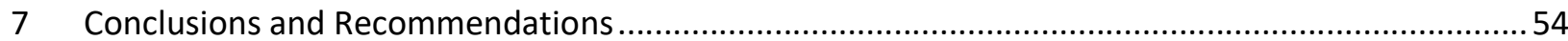

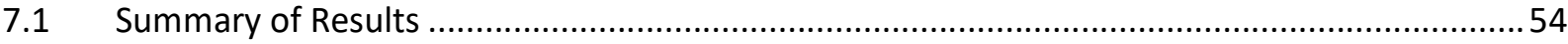

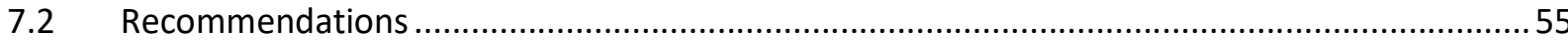

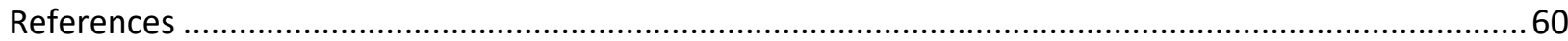

\section{List of Appendices}

Appendix A - Tables

Appendix B - Figures

Appendix C - Subbasin Profiles

Appendix D - Toxic Pollutant Profiles 


\section{Acronyms and Abbreviations}

\begin{tabular}{|c|c|}
\hline$\alpha$ & alpha (statistical significance level) \\
\hline$<$ & less than \\
\hline$>$ & greater than \\
\hline${ }^{\circ} \mathrm{C}$ & degrees Celsius \\
\hline $303(d)$-listed & pollutants listed on the Clean Water Act Section 303(d) list \\
\hline ANOSIM & Analysis of Similarity \\
\hline ANOVA & Analysis of Variance \\
\hline atm- $\mathrm{m}^{3} / \mathrm{mole}$ & cubic meter atmospheres per mole \\
\hline ATSDR & Agency for Toxic Substances and Disease Registry \\
\hline Basin & Willamette River Basin \\
\hline BAF & Bioaccumulation Factor \\
\hline $\mathrm{BCF}$ & Bioconcentration Factor \\
\hline cPAHs & carcinogenic polycyclic aromatic hydrocarbons \\
\hline CWA & Clean Water Act \\
\hline DCE & Dichloroethylene \\
\hline DDD & Dichlorodiphenyldichloroethane (also referred to as p,p-DDD) \\
\hline DDE & Dichlorodiphenyldichloroethylene (also referred to as $p, p-D D E$ ) \\
\hline DDT & Dichlorodiphenyltrichloroethane (also referred to as $p, p-D D T$ ) \\
\hline DDx & sum of DDT, DDD, and DDE \\
\hline DEQ & (Oregon) Department of Environmental Quality \\
\hline DMR & Discharge Monitoring Report \\
\hline DNAPL & Dense Non-aqueous Phase Liquid \\
\hline DOGAMI & Department of Geology and Mineral Industries \\
\hline $\mathrm{ECHO}$ & Enforcement, Compliance and History Online \\
\hline ECSI & Environmental Cleanup Site Information \\
\hline EFDC & Environmental Fluid Dynamics Code \\
\hline EPA & (United States) Environmental Protection Agency \\
\hline EPest & Estimated Pesticides \\
\hline EQC & equilibrium criterion \\
\hline FIPS & Federal Information Processing Standards \\
\hline GIS & Geographic Information System \\
\hline
\end{tabular}




\begin{tabular}{|c|c|}
\hline HUC & Hydrologic Unit Code \\
\hline HSPF & Hydrologic Simulation Program - Fortran \\
\hline $\mathrm{kg}$ & kilograms \\
\hline $\mathrm{K}_{\mathrm{H}}$ & Henry's Law Constant \\
\hline $\mathrm{K}_{\mathrm{OC}}$ & Octanol-water partition coefficient \\
\hline $\mathrm{K}_{\mathrm{ow}}$ & Organic carbon-water distribution coefficient \\
\hline km & kilometers \\
\hline lbs & pounds \\
\hline $\mathrm{mg} / \mathrm{L}$ & milligrams per liter \\
\hline MGD & million gallons per day \\
\hline $\mathrm{mmHg}$ & millimeters of mercury \\
\hline NAICS & North American Industry Classification System \\
\hline NWQA & National Water Quality Assessment \\
\hline NFA & No Further Action \\
\hline NLCD & National Land Cover Dataset \\
\hline NMDS & Nonmetric multidimensional scaling \\
\hline NPDES & National Pollutant Discharge Elimination System \\
\hline OAR & Oregon Administrative Rule \\
\hline ODOT & Oregon Department of Transportation \\
\hline ORS & Oregon Revised Statute \\
\hline OSDL & Oregon Spatial Data Library \\
\hline PAHs & polycyclic aromatic hydrocarbons \\
\hline PCBs & polychlorinated biphenyls \\
\hline PCE & Tetrachloroethylene (also known as perchloroethylene) \\
\hline PLS & Partial Least Squares \\
\hline PNSP & Pesticide National Synthesis Project \\
\hline POTW & Publicly-Owned Treatment Works \\
\hline PRP & Potentially Responsible Party \\
\hline QSAR & Qualitative Structure-Activity Relationship \\
\hline$r^{2}$ & squared correlation coefficient \\
\hline SIC & Standard Industrial Classification \\
\hline sq km & square kilometer \\
\hline sq mi & square mile \\
\hline
\end{tabular}


SWAT Soil and Water Assessment Tool

TCE Trichloroethylene

TMDL Total Maximum Daily Load

TRI Toxic Release Inventory

TSCA Toxic Substances Control Act

TSS total suspended solids

Toxic pollutants Non-conventional pollutants; the 2012 Category 5 303(d)-listed pollutants in the Willamette River Basin

U.S. United States

USDA United States Department of Agriculture

USGS United States Geological Survey

VOCs Volatile Organic Compounds

WASP Water Quality Analysis Simulation Program

WPCF Water Pollution Control Facility 


\section{Introduction}

Managing and improving water quality across large watersheds impaired by multiple pollutants requires significant efforts by stakeholders and regulatory authorities. In the United States (U.S.), several state environmental agencies, including the Oregon Department of Environmental Quality (DEQ), make use of Total Maximum Daily Loads (TMDLs) to address these impairments, required under the Clean Water Act (CWA) Section 303(d) of 1972. A TMDL is a tool environmental regulatory agencies use to implement strategies designed to bring impaired waterbodies into compliance with state water quality standards, based on the relationship between pollutant sources and the water quality conditions. In its simplest form, a TMDL is an allocation of calculated pollutant loads to point and nonpoint sources as a pollutant reduction strategy for water quality standards to be met (EPA, 1991; Younos, 2005).

The initial step, and major component of a TMDL, involves identifying point and nonpoint sources of pollutant-containing stormwater and wastewater discharges contributing to surface water impairments. However, developing a TMDL for each pollutant/impairment is a lengthy process, with an estimated duration ranging from 18 to 24 months, or even longer (EPA, 2001). TMDLs require several components completed in series, including: data compilation and analysis, water quality target identification, pollutant source assessment, source linkage analysis, calculations of loading capacity, and finally allocation analysis (EPA, 2008a). The TMDL development process also involves implementation planning and a public comment period (EPA, 2008a). Furthermore, identifying and applying the most appropriate surface water quality model(s) to toxic pollutant simulations for setting pollutant loads is a time- and data-intensive task. To increase the efficiency of TMDL development, the application of multivariate statistical techniques have been studied in a Texas watershed to identify clusters of similar watersheds based on relationships among nonpoint sources contributing to surface water impairments (Hall, 2012; Paul, 2003). Applying such an approach to TMDL development to address multiple pollutant impairments does not appear to be common practice across state environmental agencies. Nevertheless, results of these studies suggest applying cluster analyses in the development of watershed TMDLs has the potential to reduce the level of effort and time.

Impaired rivers and streams not meeting water quality standards need a TMDL to improve water quality and comply with the CWA. In Oregon, the DEQ identifies these impairments as a "Category 5" 303(d) listing. The DEQ's 2012 Integrated Report for the Willamette River Basin (the Basin) lists approximately 6,000 kilometers $(\mathrm{km})(3,750$ miles) of rivers and streams impaired with 48 Category 5 non-conventional pollutants, referred to here after as "toxic pollutants." These toxic pollutants are comprised of six classes: metals (9 pollutants), polycyclic aromatic hydrocarbons (PAHs) (17 pollutants), total polychlorinated biphenyls (PCBs), volatile organic compounds (VOCs) (8 pollutants), organochlorine insecticides (11 pollutants), and organophosphorus insecticides (2 pollutants) (Figures 1-2, Tables 1-2) (DEQ, 2012b). Existing TMDLs developed for the Basin do not address all of these 48 303(d)-listed toxic pollutants and are not issued for the Basin as a whole. Existing TMDLs throughout the Basin approved by EPA include metals (arsenic and iron) and pesticides (Dichlorodiphenyltrichloroethane [DDT], chlordane, and dieldrin) for the Molalla-Pudding subbasin (issued in 2008), mercury for the Basin (issued in 2006), and ammonia for the Coast Fork subbasin (issued in 1995) (DEQ, 2017b). An update to the Basin's 2006 
mercury TMDL is scheduled to be completed by the end of 2019. Developing TMDLs for the Basin's 48 toxic pollutants could potentially take decades to complete. Developing the TMDLs however, is only the first part, as Implementation Plans must then be developed by the Basin's Designated Management Agencies (and approved by DEQ), identifying actions that will be taken to reduce the toxic pollutant loads according to the TMDL allocations (DEQ, 2018g). Developing TMDLs and Implementation Plans adds to the time that water quality will continue to remain impaired.

The DEQ intends to use one, or a combination, of three water quality models to calculate the Basin's toxic pollutant load reductions: Hydrologic Simulation Program-Fortran (HSPF), Soil and Water Assessment Tool (SWAT), and Water Quality Analysis Simulation Program (WASP) (Bicknell et al., 2001; Neitsch et al., 2002; Shoemaker et al., 2005; Wool et al., 2009). These water quality models simulate pollutant fate and transport within a watershed, with outputs capable of demonstrating point and nonpoint source pollutant loads meeting numerical water quality standards (Tables 3-4). Although these models are capable of simulating fate and transport mechanisms of all the Basin's toxic pollutants, in addition to supporting special water features, these models are extremely time-intensive and require large amounts of data, which can be limited in availability (Shoemaker et al., 2005). While DEQ intends to use HSPF, SWAT, and/or WASP surface water quality models, other state agencies have utilized other models for simulating toxic pollutants (DEQ, n.d.). Environmental Fluid Dynamics Code (EFDC) was utilized by Washington Department of Ecology to simulate metals, PCBs, and PAHs in the Green/Duwamish River watershed in Washington State (WA Ecology, 2014). WASP and other models (including some developed for specific state agencies) were utilized to estimate PCB loads in the PCB TMDL for the Tidal Potomac and Anacostia Rivers of Virginal and Maryland as well as estimating organochlorine pesticide loads in the pesticide TMDL for Los Angeles County (EPA, 2008a).

\subsection{TMDL Development Challenges}

Between the late 1990s and early 2000s, EPA TMDL programs mostly addressed impairments of the least complex TMDLs, owing to the tremendous amount of effort and resources involved in addressing the more complex TMDLs. These complex TMDLS refer to complexities in waterbody type, hydrodynamic features, and characteristics of pollutants of concern. As of the early 2000s, EPA had only approved $25 \%$ of the pollutant impairment listings across the U.S. (Shoemaker et al., 2005). By 2008, due to limited resources and data availability, more than 70,000 TMDLs still needed to be developed across the U.S., totaling over $\$ 1$ billion (roughly $\$ 28,000$ per TMDL) in development costs (EPA, 2008a). EPA categorizes the level of effort for states to develop TMDLs according to the level of difficulty: Level 1 consists of relatively simple TMDLs involving simplified spreadsheet calculations and have limited public interest; Level 2 consists of mid-range TMDLs involving some process-based analysis using simple models; and Level 3 consists of TMDLs requiring detailed analysis using more complex models analyzing physical, chemical, and biological processes and have more public interest (EPA, 2001).

Time requirements for TMDL development increase accordingly with each level of difficulty, as do the associated costs: Level 1 TMDL development efforts are estimated at 1,200 hours, approximately 7.5 work months; Level 2 TMDL development efforts are estimated at 2,396 hours, approximately 15 work months; and Level 3 TMDL development efforts are estimated at 3,954 hours, approximately 24 work months (EPA, 2001). According to EPA's applied hourly rate of $\$ 38.89$, the cost for developing a single 
TMDL at each of the three levels were: $\$ 46,668, \$ 93,180$, and $\$ 153,771$, respectively (EPA, 2001). Today, these costs would be $44 \%$ higher at $\$ 67,380, \$ 134,535$, and $\$ 222,017$, respectively (US Labor Department, 2019). Per pollutant, the national average costs in 2001 for developing a single TMDL was estimated at $\$ 28,000$ (ranging from $\$ 6,000$ to $\$ 154,000$ ). Today, the national average cost would be $\$ 40,425$ (ranging from $\$ 8,662$ to $\$ 222,341$ ) (US Labor Department, 2019). Per waterbody, the national average costs in 2001 for developing a single TMDL was estimated at \$52,000 (ranging from \$26,000 to $\$ 500,000)$ (EPA, 2001). Today, this national average cost would be $\$ 75,076$ (ranging from $\$ 37,538$ to $\$ 721,887)$ (US Labor Department, 2019).

Given the size and complexity of the Basin and its watersheds, in addition to the likely high public interest given the multiple pollutants and beneficial uses impaired, the Basin's 48 toxic pollutant TMDLs would likely fall under EPA's development effort categories of Level 2 or Level 3. Therefore, applying EPA's time and cost estimates for developing all of the Basin's 48 toxic pollutants at Level 2 and Level 3 development efforts to today would result in 60 years and \$6,457,699 and 96 years and $\$ 10,656,821$, respectively (EPA, 2001; US Labor Department, 2019). If water quality throughout the Basin is left unaddressed, there is the potential for aquatic environments throughout the Basin's currently impaired rivers and streams to experience continued and more intense negative effects. To address Category 5 303(d) listings efficiently, a robust and alternative approach is needed to more adequately develop and apply TMDL models for the Basin's toxic pollutants.

\subsection{Pollutant Source Identification}

A critical step in TMDL development is the identification and quantification of all potential point and nonpoint sources contribution to pollutant impairments. To accomplish this watershed characterization step, the activities occurring throughout a watershed and the land use features found throughout a watershed need to be characterized accurately. Activities identified are those related to point sources and nonpoint sources. Point sources refer to discharges and emissions (stormwater/wastewater/air) from a discrete pipe or other outlet that are generally permitted. Nonpoint sources refer to diffuse discharges such as land runoff/drainage, precipitation, seepage, and atmospheric deposition, which are generally not permitted. Another critical component in TMDL development is understanding the pollutants causing impairments and their unique environmental behaviors, which is conducted during linkage analysis for simulating pollutant loads in surface water quality models (EPA, 2008a).

Toxic pollutants are commonly transported with stormwater from point and nonpoint sources (CWP, 2003; EPA, 2008a). For some activities, stormwater discharges are permitted by the National Pollutant Discharge Elimination System (NPDES) program under the CWA (EPA, 2016a). Such activities include industrial and commercial processes and materials handling exposed to stormwater. These exposures contribute toxic pollutants in offsite discharges to surface waters, directly and indirectly (after secondary discharges via treatment systems) (EPA, 2017c). Facilities that contribute metals, PAHs, and VOCs into stormwater include: hazardous waste and treatment sites, metal and mineral mine sites, transportation facilities, bulk petroleum terminals, paper mills, scrap metal recycling, timber products, machinery manufacturing, vehicle maintenance, and transportation (including airports) (EPA, 2017c). Facilities that contribute pesticides into stormwater include: hazardous waste and treatment sites, landfills, timber products, and treatment works (EPA, 2017c). Facilities that contribute cyanide into stormwater include: 
mineral mining/processing and primary metals (EPA, 2017c). Facilities that contribute ammonia into stormwater include: hazardous waste and treatment sites, landfills, metal mines, paper mills, primary metals facilities, treatment works, vehicle maintenance, and airports (deicing) (EPA, 2017c). Facilities that contribute a variety of metals (cadmium, copper, mercury, lead, and zinc) in stormwater include mining sites (copper, lead, zinc, gold, and silver ore mining) associated with mine drainage (EPA, 2011).

In contrast to point sources, PCBs and chlorinated pesticides are legacy nonpoint sources. However, PCBs have recently been included in NPDES discharge permits to monitor their concentrations in stormwater and wastewater effluent, for example in the Lower Willamette subbasin (DEQ, 2014). PCBs in surface waters (and sediment) are attributed to legacy uses and historical releases from a wide variety of industrial, commercial, and residential sources. Additionally, PCBs can be inadvertently generated (and released in effluent) as byproducts during various manufacturing processes (ATSDR, 2000; DEQ, 2003; EPA, 1976).

Toxic pollutant sources in rivers and streams have been linked not only to specific anthropogenic activities but also to specific land features. Land cover plays a considerable role in the transport of pollutants to surface waterbodies. Stormwater runoff contributes pollutants from point and nonpoint sources via direct and indirect pathways. Stormwater is a major contributor of metals concentrations attributed to urbanization, where vegetation is replaced with impervious cover (i.e., buildings and pavement). The hydrologic dynamics of a watershed are negatively altered as impervious land cover increases, causing increased contaminated stormwater runoff. A positive relationship exists between percent imperviousness area and stormwater runoff (Schueler, 2000). However, a negative relationship exist between surface water quality and land use (Carle et al., 2005; Chen et al., 2016; Fitzpatrick et al., 2007; Guzmán et al., 2012). Urban land uses in developed watersheds, in particular, contribute to poor surface water quality: metals concentrations in urban streams increase as the area of urban developed watersheds increases (CWP, 2003). Additionally, indicators of poor water quality (such as aquatic insects and fish communities) generally are present in streams of urban watersheds, particularly those with high levels of impervious cover. Stream water quality is reduced when impervious cover exceeds $10 \%$, which is typical in urban watersheds (CWP, 2003; Schueler, 2000). As the total area of urban land in a watershed increases, the potential for higher volumes and more frequent contributions of toxic pollutant-contaminated stormwater runoff increases.

Forested land and impervious cover, in contrast to urban land, exhibits an inverse relationship. Forested watersheds are often used as reference sites to delineate and compare water quality conditions across watersheds. Studies indicate that water quality can be maintained when forest cover comprises at least $65 \%$ of the land (CWP, 2003). Forested land covers a large area of land in the Basin, yet many streams flowing from and through forested land are impaired by toxic pollutants. In 2000, nonpoint sources of agricultural activities across the U.S. were the leading cause of water quality impacts to rivers, streams, and wetlands whereas point source urban runoff (i.e., storm sewers) was ranked fifth. Irrigation and fertilizer use contributes metals to surface runoff from direct and indirect agricultural applications to the land (EPA, 2003a, 2005a, 2005b). Stormwater runoff from forest land is generally attributed to disturbances within a watershed from activities such as logging, vegetation removal, and road development. Fertilizer/herbicide application and timber harvesting constitute nonpoint source runoff 
from forest land practices (EPA, 2005a). The hydrologic cycle plays an integral role in regulating pollutant loading and fluxes in surface waterbodies within watersheds (Soto-Varela et al., 2015). Pollutants are transported to surface waterbodies as a result of direct application/discharges, stormwater runoff, and atmospheric deposition (EPA, 2003a, 2005b). Additionally, metals in forested soils are distributed dependent on the metal, the concentration, the source, and soil physical/chemical characteristics (Hernandez et al., 2003).

Stormwater is a contributor of pollutant runoff attributed to deforestation, where logging leaves barren land and unvegetated logging roads (EPA, 2005a). Metals-contaminated stormwater runoff is attributed to logging forest practices and mine drainage in forest land (i.e., nonpoint sources), where soil erosion causes contaminants to become mobilized, discharging to surface waters (Nimmo et al., 1990; Vuori et al., 2003). Metals-contaminated stormwater runoff is also attributed to agricultural practices (i.e., nonpoint sources), such as the application of metals-containing pesticides, where overspray application transports metals away from the intended application area, mobilizing and discharging to surface waters (Hernandez et al., 2003). Metals contamination in soil/sediment entrained in stormwater runoff is recognized from forest and agricultural practices (EPA, 2005b, 2005a). Mining practices are also a significant contributor of metals contamination in soil/sediment entrained in stormwater runoff. EPA surveys in the early 2000s indicated only a small quantity of ore mining sites throughout the U.S. were responsible for approximately $90 \%$ of the offsite toxic weighted discharges of various metals (EPA, 2011).

\subsection{TMDL Development Strategies}

Multivariate statistical techniques are used regularly in evaluating complex environmental datasets, in particular water quality data. The application of mathematical and statistical techniques to improve chemical understanding (known as chemometrics) has shown to be useful and scientifically defensible in numerous studies. This allows for pattern recognition, identification of significant differences amongst groups (and environmental media), identification of pollutant sources (associated with clustered variables), and application of cluster results to models for estimating/predicting unknown variables (where there is limited spatial/temporal data) and delineating geographic regions. The method of reducing large datasets and assigning unknown variables to known cluster results (based on similarity relationships) has shown to be advantageous for environmental management and decision making purposes. Cluster analysis is widely used as an unbiased method to display relationships among factors of interest, thus enabling data to be interpreted based on the understanding of environmental variables applied (Gamble \& Babbar-Sebens, 2012; Haggarty et al., 2012; Kim et al., 2005; Lin \& Wang, 2006; Paul, 2003; Servien et al., 2014; Shrestha \& Kazama, 2007; Y. Wang et al., 2013; Wenning \& Erickson, 1994; Wolock et al., 2011). The method of evaluating large sets of chemicals on the sole basis of their individual chemical characteristics has been widely studied (Cronin et al., 2003; Gramatica et al., 2004; D. Mackay et al., 2001; Servien et al., 2014; Webster et al., 2005).

In water quality assessments and management, multivariate data analysis has been used to identify potential pollutant sources and assess spatial and temporal relationships between water quality and watershed attributes (Boyacioglu \& Boyacioglu, 2008; H. Chen et al., 2012; Gamble \& Babbar-Sebens, 2012; Haggarty et al., 2012; McNeil et al., 2005; Plummer \& Long, 2009; Y. Wang et al., 2013). Very few 
studies report on the use of multivariate data analysis in devising a strategy for developing watershed TMDLs for multiple toxic pollutants. However, the need for developing multiple TMDLs for toxic pollutant impairments across large-scale watersheds is long overdue, not only in Oregon but across the U.S. (DEQ, 2012b; EPA, 2008a, 2018a). While these studies describe conventional pollutants, they illustrate the general feasibility of developing watershed TMDLs using multivariate analytical techniques that can be similarly applied to other pollutants.

Many state environmental agencies have issued TMDLs for multiple toxic pollutant impairments to ensure water quality standards are met. A chlorinated pesticides (DDT and dieldrin) and PCB TMDL for the Yakima River and Walla Walla River (southern Washington) linked sources to urban stormwater runoff, wastewater treatment plant effluent, and wastewater effluent from fruit and vegetable packaging facilities (predominantly agricultural regions) (WA Ecology, 2006, 2010). A PCB TMDL for San Francisco Bay (central California coast) linked sources to stormwater outfalls and runoff, municipal and industrial wastewater treatment effluent, wastewater effluent, dredging and soil erosion disturbances (a predominantly urban area) (CRWQCB, 2008). A Mercury TMDL for San Francisco Bay linked sources to historic mines, urban stormwater runoff, wastewater effluent, atmospheric deposition, and resuspension of historic mercury-contaminated sediment (CRWQCB, 2006; EPA, 2015). A dissolved metals TMDL for the Spokane River (northeastern Washington) linked sources of arsenic, cadmium, chromium, lead, and zinc to municipal and industrial wastewater treatment plants (a predominantly forest and agricultural area) (WA Ecology, 1999). Percent impervious cover TMDLs for watersheds in Maine, Ohio, and Connecticut were developed to capture a wide variety of pollutants impairing surface waters attributed to stormwater runoff (from primarily urban areas) (CDEP, 2007; MDEP, 2012; OEPA, 2012).

Multi-pollutant and multi-watershed TMDLs are useful when addressing multiple impairments across a large watershed, which could prove advantageous for the Basin. EPA has no federally-mandated limits on addressing impaired waterbodies (EPA, 2018d). EPA does promote the development of watershed TMDLs to reduce costs and address more pollutant-waterbody combinations efficiently. A watershed TMDL can provide an evaluation of impairments encompassing all relative impacts and potentially related source areas (and sources). With this added management approach, pollutant loading allocations can be optimized and sources can be targeted to effectively attain water quality standards and maintain the most sensitive beneficial uses, contributing to the benefits of DEQ's adaptive management program (an integral part of DEQ's TMDL process) (EPA, 2008a).

\subsection{Project Goals and Purpose}

This Project will provide DEQ TMDL developers with an overview of the potential sources and chemical characteristics of the 2012 303(d)-listed toxic pollutants impairing the Basin's waterbodies, a critical first step in TMDL development that is consistent with CWA requirements. Understanding the technical considerations for selecting appropriate modeling approaches early in the TMDL process allows for efficient allocations of toxic pollutant loads. Management of pollutant-contributing sources and assessments of surface water quality conditions can be improved with a holistic understanding of the watershed. 
The goal of the Project is to develop a strategy for developing toxic pollutant TMDL groups for the Basin on the basis of geographic source area and chemical characteristic similarities. The chemical characteristics evaluated include those key to environmental fate and transport processes: solubility, vapor pressure, Henry's Law Constant, octanol-water partition coefficient $\left(\mathrm{K}_{\mathrm{ow}}\right)$, and organic carbonwater distribution coefficient $\left(\mathrm{K}_{\mathrm{oc}}\right)$. These characteristics were assessed using multivariate statistical techniques to determine which characteristics are most useful in assembling the toxic pollutant groups. The Project consists of three specific objectives (Figure 3): categorizing point sources contributing toxic pollutants based on similar activities (Objective 1), categorizing point and nonpoint sources contributing toxic pollutants based on similar geographic areas (at the subbasin level [Hydrologic Unit Code] 8) (Objective 2), and classifying toxic pollutants into clusters based on similar chemical characteristics (Objective 3). Achieving these three objectives will enable DEQ to simulate toxic pollutant groups during TMDL modeling analysis, rather than simulating individual toxic pollutants, potentially reducing the time and effort required given the size of the Basin and the quantity of impairments needing to be addressed. 


\section{Background}

\subsection{Water Quality Regulations}

The 1972 federal CWA requires states to identify surface waters that do not meet or are not expected to meet state-designated water quality standards, when current pollution control technologies are inadequate to prevent point and nonpoint source pollutants discharging to surface waters. These surface waters are considered impaired or "water quality-limited," impairing state-designated beneficial uses. States are required to report these impairments to EPA on the CWA's Section 303(d) list. This list establishes the development of TMDLs for those impairments, required by Section 303(d) of the CWA (EPA, 1991, 2017f; Younos, 2005).

The CWA requires a TMDL be developed for each pollutant (or groups of pollutants) that identify: 1 ) water quality-limited segments and each applicable state water quality standards for the impaired pollutants, 2) assessment of the physical and chemical characteristics of the pollutants, and 3) the likely sources contributing to the pollutant(s) impairments (DEQ, 2012b, 2017d; EPA, 1991). Identifying point and nonpoint sources and estimating toxic pollutant loads (as best as the data allows) is a required element of Oregon's Administrative Rules (OARs) (DEQ, 2017a). TMDLs include several elements: characterization of the waterbody, pollutant source assessment (i.e., identification of point and nonpoint sources), source linkage analysis (i.e., surface water quality modeling linking the source to the impairment), loading capacity calculation, and allocation analysis (EPA, 2008a). These steps are conducted in succession, in order for a TMDL to be appropriately developed.

Beneficial uses describe the designated use of a waterbody for fish, aquatic life, and humans and are one of three components comprising water quality standards (the other two being numeric/narrative water quality criteria and anti-degradation policies) (DEQ, 2006c). The most sensitive beneficial use to toxic pollutant impairments must be addressed in a TMDL (DEQ, 2011). Beneficial uses throughout the Basin include contact recreation, water supplies, aesthetic, and fish/aquatic life criteria (Table 5). Water quality standards are either numeric or narrative criteria (established for the state by the environmental state agencies and approved by EPA) based on the needs of protecting beneficial uses. The criteria can specify the total allowable concentration of a toxic pollutant (numeric) for aquatic and human life or it can specify unwanted conditions (narrative) (Table 6). The goal of setting water quality standards is to attain good water quality at or above the criteria, which is achieved through TMDL implementation. These goals may take several years to achieve for both point and nonpoint sources, depending on the activity and control technologies implemented (DEQ, 2006c). Where numeric water quality standards are not identified for a toxic pollutant, a water quality standard is calculated based on applicable environmental indicators.

Point sources are those facilities subject to regulation under the NPDES program, specifically for industrial and municipal wastewater and stormwater discharges. NPDES permits are part of the implementation process of a TMDL that set attainment limits for point source discharges (EPA, 2008a). The NPDES program covers discharges to surface waterbodies from construction, industrial, municipal, 
transportation, oil and gas, pesticide applications, and vessel incidental discharges. Stormwater is regulated from municipal storm sewer systems (MS4s), construction activities, and industrial activities. Wastewater is regulated from industrial and municipal activities (EPA, 2018b). Nonpoint sources are not subject to regulation under a NPDES permit. A NPDES permit is issued to limit effluent from point sources, serving as the implementation of technology-based and water quality-based controls (EPA, 2017e, 2018d).

\subsection{Toxic Pollutants and Sources}

The presence of Category 5 toxic pollutants throughout the Basin is attributed to historical and presentday stormwater and wastewater discharges, direct releases from point and nonpoint sources, and atmospheric deposition, where in-stream concentrations exceed the water quality standards (Table 6). The Basin's toxic pollutants include many that exhibit complex fate and transport mechanisms influencing their unique behavior in the environment. These complex pollutants are generally organics (such as PCBs, PAHs, and chlorinated pesticides) and some metals (notably lead and mercury). These metals are capable of transforming into organometallic compounds under certain conditions that can be toxic to human and aquatic life (ATSDR, 1999, 2007c; Walker, 2001b, 2001f, 2001c, 2001d). Understanding the unique chemical characteristics exhibited by the Basin's toxic pollutants is necessary for selecting and applying appropriate surface water quality models that will effectively simulate pollutant loads to calculate pollutant reductions and ultimately achieve water quality standards.

A total of 51 stream segments totaling approximately 6,000 river $\mathrm{km} \mathrm{(3,750} \mathrm{miles)} \mathrm{are} \mathrm{listed} \mathrm{for} \mathrm{aquatic}$ and human life impairments throughout the Basin, impairing beneficial uses, and failing to meet numeric water quality standards (Table 1, Figure 1). In terms of total impaired stream length by toxic pollutant class, the Basin's impairments primarily consist of metals $(75 \%)$, organochlorine insecticides (13\%), VOCs (5.0\%), organophosphorus insecticides (3.3\%), PCBs (2.6\%), and PAHs (1.3\%) (Figure 2) (DEQ, 2012b). These toxic pollutants are considered toxic and priority pollutants under the CWA, with one of the organophosphorus insecticides (chlorpyrifos) named as a "pesticide of concern" (DEQ, 2018a; EPA, 2014). In terms of total impaired stream length by location, the majority of the impaired streams are located in the western portion of the Basin, primarily in the Tualatin (22\%), Upper Willamette (20\%), and Middle Willamette (14\%) subbasins (DEQ, 2012b).

Many of the Basin's toxic pollutants are legacy pollutants that discharged into surface waters from historical use, including PCBs, organochlorine insecticides (aldrin, dieldrin, chlordane, DDE/DDT, endosulfan, endrin aldehyde, and hexachlorobenzene), and organophosphorus insecticides (guthion), in addition to being distributed from atmospheric deposition (Table 7). These pollutants, however, remain in the environment today, attached to soil/sediment since their release and remobilizing from hydrologic processes and their ability to cycle through the environment. These unique features are attributed to the unique chemical characteristics that a pollutant exhibits. Present-day point sources of stormwater, wastewater, and airborne discharges contribute metals and organics to the Basin's surface waterbodies from industrial and commercial processes, albeit authorized under NPDES permits.

Metals are natural elements existing as the element themselves or as compounds combined with other elements. Metals are released to the environment from industrial and commercial processes, 
contributing to contaminated stormwater and wastewater discharges, including mining, metallurgy, electronics manufacturing, and many other point sources (ATSDR, 1990, 1992, 1999, 2004b, 2005, 2007a, 2007c, 2012; Walker, 2001b).

Organochlorine insecticides are man-made organic compounds historically produced for various purposes, but primarily for agricultural use. Organochlorine insecticides include DDT (and its related compounds Dichlorodiphenyldichloroethane (p,p-DDD)) and Dichlorodiphenyldichloroethylene (p,pDDE)) and cyclodienes. These toxic pollutants are legacy pollutants as they are no longer manufactured and used in the U.S. (ATSDR, 1994b, 1996b, 2002a, 2002b, 2007b, 2015; Walker, 2001f). As a result of their moderate to high sorption and low solubility characteristics, these toxic pollutants have persisted in the environment (Walker, 2001f, 2001c). Organochlorine insecticides are released to the environment from agricultural, industrial, and commercial processes through contaminated stormwater and wastewater discharges (ATSDR, 1994b, 1996b, 2002a, 2002b, 2007b, 2015; Walker, 2001f).

Organophosphorus insecticides are man-made organic compounds historically produced for various purposes, but primarily for agricultural use similar to organochlorine insecticides. Former uses of organophosphorus insecticides have been cancelled/phased out in the U.S. (ATSDR, 1997, 2008). As a result of their moderate to high sorption and low solubility characteristics, these pollutants have persisted in the environment (Walker, 2001f, 2001c). Organophosphorus insecticides are released to the environment from agricultural, industrial, and commercial processes contributing contaminated stormwater and wastewater discharges (ATSDR, 1997, 2008).

PAHs are hydrocarbons that can be complex mixtures, expressed as total PAHs comprised of 17 individual constituents (ATSDR, 1996c; Walker, 2001e). PAHs are released to the environment from industrial and commercial processes contributing contaminated stormwater and wastewater discharges, as well as from vehicle combustion and incineration contributing contaminated emissions to the air (ATSDR, 1996c; Walker, 2001e).

PCBs are a group of man-made organic chemicals where up to 209 different chlorinated congeners exist. PCBs refer to the entire class, or any subset, of one or more congeners (ATSDR, 2000; EPA, 2003b; Erickson D., 1997). PCBs are legacy pollutants as they are no longer manufactured since EPA's Toxic Substances Control Act (TSCA) PCB Rule in 1979, which banned the manufacturing, processing, and distribution of PCBs in the U.S. (ATSDR, 2000; Erickson D., 1997). Because specific congeners exhibit specific chemical characteristics, PCBs are ubiquitous in nature, accumulating at varying magnitudes of concentrations in soil, air, and water around the globe (ATSDR, 2000; Meijer et al., 2003; Walker, 2001d). PCBs were historically released to the environment from industrial, commercial, and residential processes, contributing contaminated stormwater and wastewater discharges as well as directly to the environment. PCBs are a continual source of environmental contamination from legacy deposits, including atmospheric deposition, sediment transport, and riverbank erosion (ATSDR, 2000; Erickson D., 1997).

VOCs are a group of man-made organic compounds with many existing as dense non-aqueous phase liquids (DNAPLs) and used primarily as industrial solvents. Many VOCs are produced as byproducts of manufacturing processes or are breakdown products of their parent compound (ATSDR, 1994a, 1996a, 2004a, 2006, 2014a, 2014b). VOCs are released to the environment from industrial, commercial, and 
residential processes through stormwater and wastewater discharges. One notable toxic pollutant is perchloroethylene (PCE), a dry cleaning solvent known for its historical releases to the environment from dry cleaning operations (ATSDR, 1994a, 1996a, 2004a, 2006, 2014a, 2014b).

\subsection{Water Quality Modeling}

Surface water quality models are used in developing TMDLs to conduct the required linkage analysis, establishing relationships between pollutant sources and their water quality standards. In obtaining accurate model outputs capable of quantifying waterbody responses, TMDL developers must have a scientific understanding of the fate and transport properties of the pollutants causing the impairment in addition to an understanding of the waterbody characteristics and hydrodynamics. This knowledge drives the selection of an appropriate surface water quality model(s) to adequately calculate load allocations in a TMDL (EPA, 2008a; Shoemaker et al., 2005).

Five primary intrinsic chemical characteristics are the mechanisms responsible for influencing toxic pollutant fate and transport in the environment, driving tendencies to partition between water, soil, and air. These characteristics include: water solubility, vapor pressure, Henry's Law Constant, octanol-water partition coefficient $\left(\mathrm{K}_{\mathrm{ow}}\right)$, and organic carbon-water distribution coefficient $\left(\mathrm{K}_{\mathrm{oc}}\right)$. The first three characteristics are related to a chemical's ability to partition to water and air, respectively. The last two characteristics are related to a chemical's ability to partition to soil and sediment. These chemical characteristics are important inherent properties widely used in quantifying a chemical's behavior in the environment through modeling and are considered the key properties involved in fate and transport processes (Hemond \& Fechner-Levy, 2000; Donald Mackay et al., 1997; Webster et al., 2005). Environmental behaviors can range from simple to complex, depending on the pollutant, and are simulated in surface water quality models through mass balance equations (and other processes) to calculate pollutant loads. Understanding these chemical characteristics facilitates efficient assessments and to approach the development of fate and transport models.

Chemical thermodynamic processes have been extensively studied in the literature, with environmental fate and transport behaviors described for various toxic pollutant classes (Hemond \& Fechner-Levy, 2000; Donald Mackay et al., 1997, 2006, 1993; Schwarzenbach et al., 2017; Webster et al., 2005). The behaviors of organic pollutants can be described by mathematical relationships as a function of their chemical characteristics when parameters cannot be analyzed in the field. For instance, unlike water solubility and vapor pressure, $K_{o w}$ and $K_{o c}$ can be difficult to measure and values for these characteristics are typically estimated in the laboratory. Such mathematical relationships use the partition coefficients of $\mathrm{K}_{\mathrm{ow}}$ and $\mathrm{K}_{\mathrm{oc}}$ to estimate a chemical's partitioning into soil-water and sedimentwater phases. $\mathrm{K}_{\mathrm{ow}}$ is widely used to estimate $\mathrm{K}_{\mathrm{oc}}$ (Hemond \& Fechner-Levy, 2000; Schwarzenbach et al., 2017; Webster et al., 2005).

$\mathrm{K}_{\mathrm{OW}}$ is widely used as a measure of a chemical's hydrophobicity, which describes a chemical's partitioning behavior to fats (lipids) and its biological uptake in the food chain (Hemond \& Fechner-Levy, 2000; Schwarzenbach et al., 2017). $\mathrm{K}_{\mathrm{ow}}$ is one of the more dominant characteristics used in modeling contaminant transport (Miller et al., 1985; Walker, 2001a; Wania \& Mackay, 1998). 
$\mathrm{K}_{\mathrm{Oc}}$ is widely used as a measure of a chemical's soil sorption capacity, describing not only a chemical's preference to attach to soil particles but also its mobility in groundwater. $\mathrm{K}_{\mathrm{oc}}$ is correlated with soil organic matter content, thus the sorption capacity a chemical exhibits varies by soil type (among other factors) (Hemond \& Fechner-Levy, 2000; Piwoni \& Keeley, 1990; Webster et al., 2005).

Understanding the fate and transport mechanisms of chemicals to make reasonable predictions on the basis of chemical class, rather than an individual chemical, is well-studied having real-world applications. Qualitative Structure-Activity Relationship (QSAR) is a technique used in risk assessment to estimate and predict aquatic toxicological effects and environmental behaviors that certain classes of chemicals exhibit. Specifically, the application of QSAR is used in predicting toxicological effects of new chemical substances developed in the pharmaceutical industry where data does not yet exist. The classes are assigned according to similarities in chemical structures, defined by specific physicochemical characteristics exhibiting similar fate and transport behaviors and modes of toxicity. The main assumption is based on the knowledge of chemical structures, that similar molecular structures have the tendency to produce similar toxicological effects. QSAR is essentially a tool for interpreting unknown chemical structures according to known information about another; predicting effects for chemicals with characteristics from one class to chemicals of a different class is not appropriate (Cronin et al., 2003; Verhaar et al., 1992).

Assessing the environmental behavior of chemicals on the basis of partitioning preferences based on unique chemical characteristics exhibited, has its application in environmental modeling. The application of the equilibrium criterion (EQC) model uses input data associated with chemical classes to make predictions on chemical fate and transport behavior in the environment (Donald Mackay et al., 1996). The EQC model is based on the understanding of a chemical's partitioning preference(s) to specific environmental compartments (i.e., air, water, or soil), which is controlled by the chemical's unique characteristics that govern its environmental behavior. Chemical classes are defined by groupings of similar chemical characteristics and similar partitioning preferences. The EQC model includes three levels of complexity (Levels I, II, and III) to simulate chemical mass balances dependent on desired outputs (Donald Mackay et al., 1996). The use of chemical characteristics in environmental modeling applications is advantageous to predict and extrapolate other chemicals and their behavior based on similar structures and properties (Donald Mackay et al., 1997, 2006, 1993).

Numerous surface water quality models are available for use in TMDL development to simulate watershed hydrology and water quality. Surface water quality models are capable of predicting waterbody responses from point and nonpoint source pollutant inputs. The most commonly used models for TMDLs include WASP, HSPF, and SWAT, although there are over 20 other models available (Shoemaker et al., 2005). These models are capable of simulating the Basin's toxic pollutants and supporting several different land and water features at varying levels of complexity and time steps (Tables 3-4). These models (as well as others) require many input parameters to calculate mass balances for the simulation of pollutant fate and transport and receiving waterbody responses. Model outputs are used to calculate a reduction in pollutant loads (compared against each individual pollutant's water quality standard) and ultimately calculate a loading capacity allocated to point and 
nonpoint sources (Shoemaker et al., 2005). The DEQ intends to use at least one of these three models to calculate loading capacities for each of the 48 toxic pollutants.

In the WASP surface water quality model, simple transport processes of non-organics are simulated using only sorption (defined by sorption and adsorption coefficients) and volatilization; organic pollutants are simulated using only sorption and a limited set of transformation processes (degradation and reaction rates) (Wool et al., 2009). In the HSPF surface water quality model, pesticides are simulated considering transport and reaction processes through degradation and adsorption properties (Bicknell et al., 2001). In the SWAT surface water quality model, a database of pesticide parameters is used for reference in the model simulations. Parameters in this database include $\mathrm{K}_{\mathrm{OC}}$, water solubility, and halflife (Neitsch et al., 2002).

During the linkage analysis step of TMDL development, the objective of surface water quality modeling is to support informed decision making for allocating pollutant reductions that will meet water quality standards and achieve beneficial uses (Reckhow et al., 2001). This decision making should be made efficiently and economically on the basis of sound science without relying on overly complex tools where information can be lost and misinterpreted. 


\section{Methods}

\subsection{Project Area}

The Basin is located in the west/central portion of the state of Oregon, covering an area of approximately 29,784 square kilometers (sq km) (11,500 square miles (sq mi)). The Basin is bordered by the Cascade Mountains to the east, the Coast Range to the west, and the Columbia River to the north (Figure 4). Considering the full river/stream network, approximately 26,000 kilometers (16,000 miles) of rivers and streams flow through the Basin (DEQ, 2006c; NRCS, 2007). The main stem Willamette River, approximately $483 \mathrm{~km}$ (300 miles) in length, begins south of Eugene where the Coast Fork River and the Middle Fork River meet. The Willamette River generally flows from south to north and is a tributary to the Columbia River, eventually flowing into the Pacific Ocean. (Uhrich \& Wentz, 1999).

The Basin is comprised of 12 subbasins, defined as the 8-digit fourth level United States Geological Survey (USGS) Hydrologic Unit Code (HUC) 8. From south to north, the subbasins include: Coast Fork Willamette, Middle Fork Willamette, McKenzie, South Santiam, Upper Willamette, North Santiam, Clackamas, Molalla-Pudding, Middle Willamette, Yamhill, Tualatin, and Lower Willamette (Figure 4) (NRCS, 2007; OSDL, 2017). Total land area of the subbasins range from 1,100 square kilometers (sq km) (400 sq mi) (Lower Willamette) up to 5,000 sq km (1,800 sq mi) (Upper Willamette) (Figure 5, Appendix C) (OSDL, 2017). The Project area encompasses the entire Basin with exception for the South Santiam subbasin, which has no toxic pollutant impairments (DEQ, 2012b).

\subsubsection{Climate and Hydrology}

Precipitation throughout the Basin is driven by the season and elevation differences (Figure 6). Generally, precipitation occurs during the winter rainy season (October through March). Precipitation in the Basin during the driest months (July and August) is less than $5 \%$ of the total annual precipitation received. As elevation increases, precipitation increases. In lower elevations (i.e., the Willamette Valley floor), the Basin may receive between 1 and 1.3 meters (40 and 50 inches) of precipitation annually, while higher elevations (i.e., the Cascade Mountain range) may receive up to 5 meters (200 inches). Precipitation in the High Cascades is primarily in the form of snow while precipitation in the West Cascades and Coast Mountains is primarily in the form of rain with occasional snow (DEQ, 2006c).

The Basin's Coastal Mountain ecoregion has a high density of perennial streams: three to five km of streams per sq km of land (two to three miles of steams per sq mi of land). The Western and High Cascade ecoregions have a lower density of streams: up to one $\mathrm{km}$ of streams per sq $\mathrm{km}$ of land (two miles of streams per sq mi of land). Perennial streams are found in the northern portion of the Basin and intermittent streams are found in the southern portion (Uhrich \& Wentz, 1999). Surface water runoff throughout the Basin is correlated with precipitation; the majority of runoff (60 to $85 \%$ ) occurs during the winter rainy season (October through March) and less than $10 \%$ runoff occurs during the drier months (July and August). Surface water runoff from the Cascade Mountains occurs during the spring months as a result of the winter snowpack melting. From 1961 to 1990, annual mean discharge of 
surface water runoff was greater in the Cascade Mountains compared to the Coastal Mountains (Uhrich \& Wentz, 1999).

Surface water flow within the Basin is modified by dam and reservoir operations for flood control, navigation, hydroelectric power, and water storage (for irrigation and recreation during summer months). A total of 11 dams with reservoirs and two regulating dams were constructed on major tributaries within the Basin between 1941 and 1969 by the US Army Corps of Engineers, primarily for flood control. An additional 350 dams were constructed throughout the Basin for irrigation purposes. In the late summer and early fall months, reservoirs are drawn down to provide flood storage capacity for the coming winter month's precipitation. Dams throughout the Basin, however, have altered the natural flow patterns of the Willamette River by reducing peak flows during the winter months and artificially increasing low flows during the summer months. These alterations have caused changes in stream temperature and the timing of when high and low stream temperatures occur (DEQ, 2006c).

\subsubsection{Land Cover and Use}

The Basin is comprised of various land features, such as forest, agriculture, urban land, and many waterbodies (rivers, lakes, and wetlands) (Figure 7). Forest land is the most predominant land feature of the Basin, comprising $68 \%$ of the total land cover. Forest land is primarily found in the higher elevations to the foothills of the Coastal Mountain and Cascade Mountain ranges. Agriculture land uses are the largest land uses in the lowlands and the second most predominant land cover feature in the Basin, comprising $20 \%$ of the total land cover. The remaining land features of the Basin consist of urban (8.1\%), wetlands $(1.7 \%)$, open water $(0.9 \%)$, barren land $(0.87 \%)$, and perennial snow/ice $(0.003 \%)$ (Figure 8 ) (OSDL, 2011; Uhrich \& Wentz, 1999).

The Basin is comprised of five ecoregions associated with physiographical attributes, including climate, soils, vegetation, and land use: the Coastal Mountains ( $8 \%$ of total basin land cover area), the Willamette Valley Plains (22\%), the Willamette Valley Foothills (20\%), the Western Cascades (44\%), and the High Cascades (6\%). The Coastal Mountains are found along the western boundary of the Basin; the High Cascades are found along the eastern boundary of the Basin; the Western Cascades are found throughout the majority of the eastern Basin area (west of the High Cascades); and the Willamette Valley Foothills flank the east and west sides of the Willamette Valley Plains throughout the center of the Basin (Figure 4) (Uhrich \& Wentz, 1999).

Land uses throughout the Basin vary and can be generally associated with the land features. Agriculture is the predominant industry, followed closely behind by timber harvesting/production, and mining. The Basin consists of the most diverse and economically valuable agriculture areas in the state, with agricultural activities contributing to the Basin's (and Oregon's) economy since the mid-1800s (DEQ, 2006c; Uhrich \& Wentz, 1999). The Basin's farms harvest between 3,500 and 196,590 acres of crops. Approximately $46 \%$ of the Basin's farm lands are harvested. The majority of the harvested cropland occurs in Marion (69\%), Polk (64\%), and Linn (58\%) counties, located across several subbasins (USDA, 2012f, 2012e).

Crops harvested throughout the Basin include: grass/legume seeds, hay, grains, field crops, tree fruits/nuts, small fruits/berries, vegetables, and nurseries/Christmas trees (Uhrich \& Wentz, 1999). 
Crops are diverse throughout the Basin, however, with more agricultural activities occurring in the northern portion compared to the southern. The Basin's northern portion consists of row crops such as orchards, vineyards and nurseries. The Basin's southern portion costs of grains, hay, and grass and legume seeds (USGS, 1996). Animal feeding operations throughout the Basin include: cattle, sheep, hogs, and chickens (Uhrich \& Wentz, 1999). The Basin produces the most timber for the state. Mining activities throughout the Basin produces various metals (gold, copper, silver, lead, zinc, and mercury) as well as aggregates (sand, gravel, and rocks) (DEQ, 2006c; Uhrich \& Wentz, 1999).

Land ownership and management throughout the Basin consists primarily of private land (private owners and industry) (61\% of the total area), forest land services (32\%), federal (6.1\%), local government and state departments (1.2\%), military (0.57\%), and tribal (0.02\%) (Figure 9) (OSDL, 2015b). Forest lands throughout the Basin are managed by the US National Forests, Bureau of Land Management, the Oregon Department of Forestry, and private timber companies (DEQ, 2006c).

Since settlement of the Basin in the mid-1800s, the population has increased steadily, with the majority of increases historically occurring in the counties of Multnomah, Washington, and Clackamas. In the mid-1990s, Oregon's population increased at twice the rate of the national average because of the rate of growth in major metropolitan cities (Portland, Salem, Eugene) in the Basin (Uhrich \& Wentz, 1999). Between 2010 and 2017, population in the Basin (which consists of 13 counties) has increased $8 \%$ (2.9 million to 3.2 million). Currently, the highest populated county in the Basin is Multnomah County $(807,555)$ (U.S. Census Bureau, 2019). These high population counts throughout the Basin add to the increased urban land cover.

\subsection{Data Description}

\subsubsection{Toxic Pollutants}

DEQ's 2012 Integrated Report Assessment Database and 303(d) List was queried to obtain a full list of Category 5 pollutants in the Basin. The query results returned a Microsoft Excel ${ }^{\circledR}$.csv file that included both conventional and toxic pollutant parameters. Only the toxic pollutant parameters were chosen, resulting in 27 toxic pollutants in six pollutant classes: metals, PAHs, PCBs, VOCs, organochlorine insecticides, and organophosphorus insecticides (Table 1). Not included in the list were toxic pollutants classified as PAHs, PCBs, and dichlorethylenes (a VOC). The full list of toxic pollutants in these chemical classes was obtained from the literature, primarily the Toxicological Pollutant Profiles published by ATSDR, to result in the total of 48 toxic pollutants (ATSDR, 1996c, 2000, 2015; EPA, 2008b).

The toxic pollutants on DEQ's 2012 303(d) list were spatially mapped in ArcGIS using DEQ's 2012 Integrated Report Geographic Information System (GIS) geodatabase (DEQ, 2012a).

\subsubsection{Point and Nonpoint Source Data Acquisition}

Publicly available information from various state and federal agency websites was reviewed to compile an inventory of point and nonpoint source data (Table 8). All point source information was downloaded as Microsoft Excel ${ }^{\circledR}$ spreadsheets. Geographic information systems (GIS) programming (ArcMap version 10.5.1) was used to display facility coordinate locations in the Basin at the HUC 4 level and a geospatial 
processing technique (intersecting) was applied to further determine subbasin locations at the HUC 8 level (ESRI, 2017).

\subsubsection{Point Source Data \\ $\underline{\text { DEQ - Wastewater Permit database }}$}

This database identifies industrial, commercial, and treatment facilities (i.e., Water Pollution Control Facility [WPCF], also known as a Publicly Owned Treatment Works [POTW]) permitted to discharge stormwater and wastewater (DEQ, 2017c).

This database was queried to obtain results only for facilities located in the Basin at the HUC 4 level (HUC 1709) and only the active permits. The query results returned Microsoft Excel ${ }^{\circledR}$.csv files and were uploaded into ArcMap to plot the facility coordinates in the Basin (ESRI, 2017).

EPA - Enforcement Compliance History Online (ECHO), Water Pollutant Loading Tool, Water Pollution Search database

This database identifies industrial, commercial, and treatment facilities permitted to discharge stormwater and wastewater that also report TRI discharges annually to EPA (EPA, 2017g). Facilities in EPA's database are categorized as a minor discharger (i.e., discharges less than 1.0 million gallons per day [MGD]) or a major discharger (discharges greater than $1.0 \mathrm{MGD}$ ). Pollutant loads reported by facilities to EPA are maintained in the Discharge Monitoring Report (DMR) and Toxics Release Inventory (TRI) section of the database and organized by reporting year.

This database was queried to obtain results only for facilities located in the Basin at the HUC 4 level (HUC 1709) and only for the Basin's toxic pollutants. Further, EPA's database was queried in both the DMR and TRI sections to obtain results for reporting years 2007 through 2016 and 2007 through 2015, respectively. The query results returned Microsoft Excel ${ }^{\circledR}$ files and were uploaded into ArcMap to plot the facility coordinates in the Basin (ESRI, 2017). At the time of download, the most recent reporting year (2016) did not yet have a complete set of data (i.e., 12 months) and was therefore, not included. Total flow and pollutant loads are important for DEQ to quantify toxic pollutant loads during simulation of toxic pollutants in surface water quality models and to calculate pollutant reductions.

\section{Oregon Department of Geology and Mineral Industry (DOGAMI) - Mining Permit Viewer}

This database identifies mining sites and the commodities mined (DOGAMI, 2017). Mining site locations are identified by county. DOGAMI issues three different surface mining permits, based on the type of mining activity and the quantity/acreage of the activity: 1) Operating Permit, 2) Exploration Permits, and 3) Exclusion Certificates (DOGAMI, 2018a). Two types of water quality permits are issued to aggregate mining operations: 1) WPCF 1000 permit and 2) NPDES 1200A permit. A WPCF 1000 permit is issued if water is used for processing and there is no offsite discharge. A NPDES 1200A permit is issued if water is used for processing and there is offsite discharge. The NPDES 1200A permit also covers water used for processing if process water remains onsite (DOGAMI, 2018b). The DEQ requires these water quality permits for mining operations (DEQ, 2018f). Point source discharges from mining sites include mine drainage and process wastewater that may or may not include stormwater runoff (EPA, 2011). 
The permit viewer is available as a searchable database; however, sites are identified by county and not by watershed (i.e., HUC levels). Instead, the permit viewer results were downloaded as a list in a Microsoft Excel ${ }^{\circledR}$ spreadsheet and uploaded into ArcMap to plot the facility coordinates in the Basin (ESRI, 2017).

Oregon Department of Transportation (ODOT) - Stormwater Outfall Inventory Management

This database identifies outfalls along state highways permitted to discharge stormwater. ODOT discharges stormwater from highways throughout the state under a NPDES MS4 permit, issued by the DEQ. A requirement of their permit, ODOT has located and inventoried over 700 stormwater outfalls within the NPDES permitted areas of the state that DEQ has identified as "high risk" for stormwater impacts to receiving waters. These "high risk" areas refer to major cities located within urban growth boundaries (ODOT, 2016). ODOT only inventoried outfalls in priority cities at the time this database was acquired.

ODOT's inventory was not available as a searchable database. Instead, information was downloaded in a Microsoft Excel ${ }^{\circledR}$ file and was uploaded into ArcMap to plot the facility coordinates in the Basin (ESRI, 2017).

\subsubsection{Nonpoint Source Data}

$\underline{\text { DEQ - Environmental Cleanup and Site Information (ECSI) database }}$

This database identifies contaminated hazardous waste sites throughout the state that DEQ tracks with known, suspected, or cleaned up hazardous substance contamination, since 1989 (DEQ, 2018c). The ECSI database maintains an inventory identifying contaminants impacting soil, sediment, and groundwater, investigative/remedial status, and cleanup recommendations for further action (or no further action [NFA] status). Facilities are primarily industrial and commercial, but some highly contaminated residential properties and larger study areas are also included. This database does not include facilities with leaking underground storage tanks. Facilities in the ECSI database also include those that no longer pose risks to human health/environment, but continue to be listed for historical reference (DEQ, 2018c).

This database was queried to obtain results only for facilities located in the Basin at the HUC 4 level (HUC 1709) and only for the Basin's toxic pollutants. The query results returned Microsoft Excel ${ }^{\circledR}$ files and were uploaded into ArcMap to plot the facility coordinates in the Basin (ESRI, 2017).

EPA - National Priorities List and Superfund Alternative Approach Sites database

This database identifies contaminated hazardous sites listed as Superfund Sites (EPA, 2018e). The Comprehensive Environmental Response, Compensation, and Liability Act (CERCLA), commonly referred to as Superfund, is a Federal statue enacted in 1980 by Congress (and amended in 1986 as the Superfund Amendments and Reauthorization Act [SARA]) that addresses cleanup of sites where there has been a release or threat of a release of hazardous substances. Sites are prioritized by EPA on the National Priority List (NPL) using a hazard ranking system focused on human health and environmental risk effects to guide EPA in determining which sites require further investigation. 
This database was queried to obtain results only for facilities located in the Basin at the HUC 4 level (HUC 1709) and only for the Basin's toxic pollutants. The query results returned Microsoft Excel ${ }^{\circledR}$ files and were uploaded into ArcMap to plot the facility coordinates in the Basin (ESRI, 2017).

USGS - National Water Quality Assessment (NWQA), Pesticide National Synthesis Project (PNSP)

This database identifies annual pesticide applications compiled by the USGS sourced from the USDA's farm surveys identified at the county level (USGS, 2017). Pesticide applications in the U.S. are reported at the multi-county Crop Reporting District level (a collection of contiguous counties within each state). The harvested-crop acreage data are compiled by the USDA National Agricultural Statistics Service, Census of Agriculture (USDA, 2012d). The USDA applies the harvested rates to the harvest acreage of each crop for all counties, resulting in a pesticide-use rate estimate by county (USGS, 2015). The USGS implemented the NAWQA PNSP in 1991 to collect information about non-point source pesticide use in agricultural and urban (primarily residential) settings to understand the occurrence and behavior of pesticides in streams and groundwater for ambient water quality management and policy.

The NAWQA provides a comprehensive national-scale analysis of pesticide occurrence and concentrations in streams and groundwater throughout the U.S. Beginning in 1991, the Basin is the only watershed in Oregon that the USGS included in the PNSP survey (USGS, 2007). The PNSP reports total pesticide use (in kilograms) by county as an "estimated pesticide use" (EPest) rate for each crop by year from thousands of crop operations. This EPest rate is determined by the surveyed pesticide use data in conjunction with the county annual harvested-crop acres reported by the USDA Census County Agricultural Production Survey. The USDA's Economic Research Service separates the U.S. into 'Farm Resources Regions' based on the types of farm commodities produced in similar geographic areas (USGS, 2015).

Tabulating pesticide applications only for Oregon counties relied on the Federal Information Processing Standards (FIPS) codes reported in the compiled survey results, which are codes assigned to every county in the U.S. (US Census Bureau, 2010). Tabulating pesticide applications containing only the Basin's toxic pollutants was based on review of the 333 pesticide names identified in the compiled results, evaluated for the years 2000 to 2016 (Table 9) (USGS, 2017). The reported pesticide chemical structures were reviewed online in EPA's Registered Pesticide Search Database and the National Library of Medicine PubChem database. Only pesticides with ingredients containing toxic pollutants were included in the final results (EPA, 2016b; NLM, 2017). The pesticide applications (high estimate) were summed and converted from kilograms to pounds. The search results were presented as text values, which were copied and pasted into Microsoft ${ }^{\circledR}$ Notepad for transfer into a Microsoft Excel ${ }^{\circledR}$ spreadsheet.

The majority of the pesticides applied throughout the Basin were reported as dormant oil (54\%). Dormant oil is a petroleum oil that is comprised of total petroleum hydrocarbons (TPH), which is not a toxic pollutant for this Project (OSU, 2018; USGS, 2017; WSU, 2015). Therefore, dormant oil applications were not included in the evaluation of nonpoint sources of pesticide applications. 


\subsubsection{Chemical Characteristic Data Acquisition}

Chemical characteristic data for the Basin's 48 toxic pollutants were obtained from several publicly available data sources, including online databases and the literature. Data were compiled into a Microsoft Excel ${ }^{\circledR}$ spreadsheet to generate a database (Table 10) (EPA, 2017a; NLM, 2017).

- Water solubility (in milligrams per liter $[\mathrm{mg} / \mathrm{L}]$ ) - defined at equilibrium, as the maximum concentration of a chemical in solution (aqueous solubility), at 25 degrees Celsius $\left({ }^{\circ} \mathrm{C}\right.$ ).

- Vapor pressure (in milligrams of mercury [mmHg]) - defined as the pressure exerted by a chemical's gases in the vapor phase at equilibrium with its pure phase (solid or liquid) (solubility in air), at $25^{\circ} \mathrm{C}$. The vapor pressure governs the air-water interface exchange of a chemical's gases through Henry's Law Constant.

- Henry's Law Constant ( $\mathrm{K}_{\mathrm{H}}$, in atmospheres-cubic meter per mole $\left.\left[\mathrm{atm}-\mathrm{m}^{3} / \mathrm{mol}\right]\right)$ - defined at equilibrium as the ratio of a chemical's vapor pressure (concentration in air) to its aqueous solubility (concentration in water), at $25^{\circ} \mathrm{C} . \mathrm{K}_{\mathrm{H}}$ describes the partitioning tendency of a volatile chemical between air and water and is thus temperature dependent, defined by vapor pressure and solubility of a chemical, respectively.

- Octanol-water partition coefficient ( $\mathrm{K}_{\mathrm{ow}}$, unitless, presented as a logarithmic value) - defined as the ratio of a chemical in octanol to water at equilibrium, at $25^{\circ} \mathrm{C}$. $\mathrm{K}_{\mathrm{ow}}$ is a measured estimate of hydrophobicity (i.e., partitioning preferences).

- Organic carbon-water distribution coefficient ( $\mathrm{K}_{\mathrm{oc}}$, unitless, presented as a logarithmic value) defined as the ratio of a chemical concentration in organic carbon to water at equilibrium, at $25^{\circ} \mathrm{C}$. $\mathrm{K}_{\mathrm{OC}}$ is calculated using the chemical's soil adsorption coefficient $(\mathrm{Kd})$ and percent organic carbon. Soil sorption occurs mostly to organic matter; therefore, $\mathrm{K}_{\mathrm{oc}}$ is a more useful expression. $\mathrm{K}_{\mathrm{oc}}$ describes a chemical's mobility in soil and is thus dependent on the soil type.

While metal compounds exist in different valence states (e.g., $\mathrm{Cu}[(+1]$ and $\mathrm{Cu}[+2] ; \mathrm{Pb}[0], \mathrm{Pb}[+2]$, and $\mathrm{Pb}[+4] ; \mathrm{Zn}[0]$ and $\mathrm{Zn}[+2]$ ), the chemical characteristics of the common elemental metal found under ordinary environmental conditions $\left(\right.$ at $25^{\circ} \mathrm{C}$ ) reported in the databases and literature were compiled.

EPA - Chemistry Dashboard database

This database compiles scientific information on hundreds of thousands of chemicals from various public sources for research purposes. Information reported includes: chemical structures and chemical property data in addition to toxicological health exposure risk data (EPA, 2017a).

National Library of Health - National Institutes of Health, PubChem (Compound and Substance) database

This database is an open public repository that compiles scientific information on hundreds of thousands of chemicals from various public sources (and hundreds of contributors) for research purposes. Information reported includes: chemical structures and chemical property data in addition to toxicological health exposure risk data (NLM, 2017). 
Agency for Toxic Substances \& Disease Registry (ATSDR) - Toxicological Profiles

The ATSDR publishes Toxicological Profiles, which are peer-reviewed reports compiling scientific information on individual chemical compounds, including chemical characteristics, toxicological and epidemiological effects (ATSDR, 2017).

Syracuse Research Corporation (SRC) - FatePointers Search Module, PhysProp database

This database compiles scientific information on hundreds of thousands of chemicals for research purposes. Information reported includes: chemical structures, physical, and chemical property data (SRC, 2013).

\subsection{Data Analysis}

Data were compiled in alignment with the Project's objectives, relying on various methodologies according to data availability (Table 8). Sources of toxic pollutants were categorized by activity (Objective 1) and geographical source area (Objective 2) and toxic pollutants were evaluated and categorized by chemical characteristic data (Objective 3). The compiled data were categorized for manageability and to facilitate attainment of the Project's objectives for understanding the Basin's impairments.

\subsubsection{Categorization of Point Sources by Activity}

Point sources evaluated by industry activity included DEQ's ECSI and Wastewater Permit databases.

\section{$\underline{\text { DEQ ECSI Sites }}$}

The ECSI Sites were evaluated to determine the primary activities conducted onsite contributing to the reported contamination, indicating the types of pollutants handled onsite. A total of 19 categories were created, based on review of the ECSI database that identified historical operations and general facility descriptions (Table 11). For example, sites operating as dry cleaners were included in the category of "dry cleaner/laundromat" and sites described as a spill with no actual facility information were included in the category of "spill." This provided for a generalized assessment of the industries comprising the list of contaminated properties impacted by toxic pollutants.

\section{DEQ NPDES-Permitted Facilities}

Facility information in DEQ's and EPA's databases includes the Standard Industrial Classification (SIC) and/or North American Industry Classification System (NAICS) codes, which identify activities conducted onsite. These codes were used to evaluate the types of industries contributing discharges to the Basin and to categorize industries for Objective 1 . Since 2006, the TRI program requires facilities to report NAICS codes instead of SIC codes on discharge monitoring/pollutant reporting forms. Furthermore, not all NAICS coded-facilities are required to report pollutant discharges (EPA, 2016c). Because only NAICS codes were identified for facilities in the DMR section of EPA's and DEQ's Wastewater permit databases, the corresponding SIC codes were obtained from a NAICS-SIC codes look up table (NAICS, 2018). Typically, a facility is assigned a single SIC/NAICS code. However, it is common for facilities to be involved in multiple types of activities, resulting in being assigned multiple SIC/NAICS codes (NAICS, 
2018). Where multiple NAICS codes are associated with an SIC code, the following methodology was applied.

- SIC code 3728 corresponds to NAICS codes 332912, 336411, 336413, and 541713. Each of these NAICS codes involves different types of manufacturing (i.e., NAICS group 33), while the last code involves research/development in nanotechnology (i.e., NAICS group 54).

- The NAICS description (for each NAICS code) was given a generalized industry title to create the generalized industry categories for this Project.

The NAICS group codes of 33 were grouped into a single industry title category of "Manufacturing." The NAICS code of research/development in nanotechnology remained in the "Manufacturing" category, given that the SIC code was the same for the other associated manufacturing NAICS descriptions. All reported pollutant discharges for facilities in the "Manufacturing" categories were summed.

This methodology was applied to each of the facility activity categories created, resulting in a total of 12 categories (Table 12) (DEQ, 2017c; EPA, 2017g; NAICS, 2018). The second column in Table 12 lists the NAICS code descriptions for each of the NAICS codes associated with each of the DEQ and EPA facilities identified in their respective databases. The fourth column of Table $\mathbf{1 2}$ lists the industrial activity categories developed for this Project, based on the original NAICS descriptions.

The facilities assigned to each of the Project categories were deemed representative of that category name, based on facility information reported in EPA's ECHO database, combined with industry knowledge (EPA, 2017b). The "utilities" industry category includes POTWs (wastewater and sewage treatment facilities) and non-POTWs (public electric utility providers, cities/municipalities, and remediation sites). The "waste management" category includes landfills. The "administrative/service" category includes analytical research labs, other service providers, and a prison. The "state/county transportation roadway management" category was created for this Project, as two facilities identified in DEQ's wastewater permit database did not have SIC/NAICS codes reported. These facilities are associated with stormwater discharges from ODOT state highway outfalls and are considered a "mobile source", and thus, do not have a physical location.

\subsubsection{Categorization of Sources by Geographical Source Area}

Geographical locations of point and nonpoint source data (Objective 2) was evaluated using geospatial processing techniques in ArcGIS version 10.5.1 (ESRI, 2017). The geographical source area is defined as the subbasin at the HUC 8 level. Facility coordinates for point and nonpoint sources retrieved from online databases were plotted in ArcGIS and intersected with subbasins at the HUC 8 level. The subbasins are identified in the 'Watershed Boundary Dataset' data layer retrieved from the Oregon Spatial Data Library (OSDL) (OSDL, 2017).

Geographical locations of the nonpoint source pesticide applications were geospatially referenced based data reported at the county level. The evaluation of total pesticides applied by subbasin was calculated in Microsoft Excel ${ }^{\circledR}$ based on the total pesticide applications reported at the county level. The total pesticide applications were only evaluated on agricultural land uses, similar to USGS' methodology 
(Section 3.2.2). The total subbasin pesticide applications were calculated proportionally to the total county-level pesticide applications, using the total land area of the county and associated subbasin. The total land area of the counties and subbasin were retrieved from the 'Watershed Boundary Dataset' and 'Oregon Counties' data layers of the OSDL (OSDL, 2015a, 2017). Calculating the estimated total mass of pesticides applied in each of the subbasins was based on a simple mathematical equation. Table 13 shows an example of the calculation performed for quantifying the total pesticides applied in the Tualatin and Lower Willamette subbasins, according to totals reported for the county the that these subbasins reside in (Columbia County).

\subsubsection{Categorization of Toxic Pollutants by Chemical Characteristics}

Multivariate statistical analyses were performed on the chemical characteristic dataset to determine relationships among the Basin's toxic pollutants and their respective chemical characteristics. This approach determined the significance chemical characteristics had in the toxic pollutant clustering. All data analyses were conducted using $R$ (version 3.5.1) ( $R$ Development Core Team, 2016). R packages used for the cluster and NMDS analyses included: 'vegan' (version 2.5-4), 'envfit' (version 2.4-2), 'MASS' (version 7.3-51.3), 'dplyr' (version 0.7.8), 'factoextra' (version 1.0.5), and 'ggplot2' (3.1.0). Box plots were generated in $\mathrm{R}$ to visualize statistical results.

Exploratory data analysis (cluster analysis) and ordination techniques (NMDS) were utilized to discriminate the Basin's 48 toxic pollutants into clusters based on their chemical characteristic values (Objective 3). Ordination examines relationships in the dataset to reduce dimensionality while maintaining all the necessary information. Cluster analysis is a classification technique by which the toxic pollutants were segregated into distinguishable groups based on similarities in the chemical characteristics for each toxic pollutant $(n=48)$. Clustering and NMDS are both methods that facilitate the recognition of patterns and trends. Similarities and dissimilarities of the toxic pollutants according to chemical characteristic data were explained by the NMDS analysis in an NMDS plot, where the toxic pollutants sharing similarities were located closer together and toxic pollutants with dissimilarities were located further apart (Gotelli \& Aaron, 2013; McCune \& Grace, 2002).

Because three of the five chemical characteristics (solubility, vapor pressure, and Henry's Law Constant) have values reported in different units ( $\mathrm{K}_{\mathrm{ow}}$ and $\mathrm{K}_{\mathrm{oc}}$ are unitless values reported in a logarithmic scale), the chemical characteristic data were transformed to the standardized normal with a scale of negative one to positive one. Standardizing repositioned the data into similar scales of magnitude for comparison and application in NMDS distance measurements (McCune \& Grace, 2002). Interpretation of chemical characteristic data for the toxic pollutants was based on the literature to identify the governing fate and transport behaviors (Figure 10). These behaviors generally describe a pollutant's partitioning preference to air, water, or soil, based on the chemical characteristic exhibited (D. Mackay et al., 1992; Schwarzenbach et al., 2017). The chemical characteristic data were interpreted according to established criteria in the literature that divides ranges of values for each chemical characteristic into general classifications (EPA, 2012; Rand, 1995). For example, water solubility is divided into five solubility classifications: negligible solubility $(<0.1 \mathrm{mg} / \mathrm{L})$, slight solubility ( $>0.1$ to $100 \mathrm{mg} / \mathrm{L})$, moderate solubility (>100 to $1,000 \mathrm{mg} / \mathrm{L})$, soluble $(>1,000$ to $100,000 \mathrm{mg} / \mathrm{L})$, and very soluble $(>100,000 \mathrm{mg} / \mathrm{L})$. The 
remaining four chemical characteristics were interpreted similarly: volatile classifications for vapor pressure and Henry's Law Constant, sorption classification for $\mathrm{K}_{\mathrm{OC}}$, and hydrophobic classifications for Kow.

Hierarchical agglomerative cluster analysis determined relatively similar groups of toxic pollutants using the Bray-Curtis dissimilarity index (Clarke \& Warwick, 2001; Gotelli \& Aaron, 2013; McCune \& Grace, 2002). Hierarchical grouping is a useful tool in classification to organize datasets for use in other applications (Ward Jr., 1963). The Ward's minimum variance method was used in the cluster analysis to minimize within-cluster sum of squares. This method is common and frequently used in environmental data analysis, yielding satisfactory classification results (Clarke \& Warwick, 2001; Gotelli \& Aaron, 2013; McCune \& Grace, 2002). Cluster analysis results generated a dendrogram where toxic pollutants are presented on the $x$-axis and the similarity level at which two variables (or clusters) are branched are presented on the $y$-axis. Toxic pollutants sharing similar chemical characteristics are grouped exclusively together and toxic pollutants of dissimilarity are grouped apart (Clarke \& Warwick, 2001). Generally, primary clusters form smaller clusters at lower levels of similarity (i.e., subgroups) (Clarke \& Warwick, 2001). Therefore, the main goal of hierarchical agglomerative cluster analysis is to maximize similarities within a group and minimize similarities between groups (Kalkstein et al., 1987). The Elbow method, a supportive and efficient cluster selection approach driven by the dataset itself, was evaluated in $\mathrm{R}$ that revealed four clusters as the optimum number for analysis to best explain the variance among the chemical characteristic data (Kingrani et al., 2017; McCune \& Grace, 2002; Zambelli, 2016).

To test if there were significant differences among the clusters, Analysis of Similarity (ANOSIM) was used based on permutation testing (999 times) of among- and within-cluster similarities. ANOSIM is a nonparametric rank-based index of relative within-cluster dissimilarity that measures how far each toxic pollutant cluster is from one another (Clarke \& Warwick, 2001; McCune \& Grace, 2002). Testing the null hypothesis that there are significant differences among the clusters was determined using a significance level $(\alpha)$ of 0.05 , where $p$-values less than the significance level were considered significant. To examine the effects of the toxic pollutant chemical characteristics on each cluster (because ANOSIM only identified the presence or absence of significant differences among clusters), pairwise comparisons were tested between each cluster (6 pairs). Testing the null hypothesis that there are no significant differences between the pair of clusters was determined using the Bonferroni-correction factor ( $\alpha_{\text {altered }}=$ $0.5 / 6=0.01$ ) to conservatively evaluate the significance, where the p-values less than the altered significance level were considered significant (McCune \& Grace, 2002). To examine the variance in chemical characteristic data among the clusters, Analysis of Variance (ANOVA) was used (Gotelli \& Aaron, 2013). Testing the null hypothesis that chemical characteristic data are significantly different among the clusters was determined using the Bonferroni-correction factor $\left(\alpha_{\text {altered }}=0.05 / 4=0.0125\right.$ ) to conservatively evaluate the significance, where the $p$-values less than the altered significance level were considered significant (McCune \& Grace, 2002).

NMDS was performed to display clusters and visualize the location of the toxic pollutants according to their dissimilarities. NMDS plotted toxic pollutants into a chemical characteristic-defined space of ordination with two dimensions ( $x$ and $y$ ) based on their ranked dissimilarity. NMDS is often a chosen 
ordination technique in multivariate data analysis to graphically represent multiple complex relationships in small dimensional spaces (Clarke \& Warwick, 2001; K. R. Clarke, 1993; McCune \& Grace, 2002). NMDS preserved the similarity rankings of the toxic pollutants using the Bray-Curtis dissimilarity matrix (Clarke \& Warwick, 2001). A goodness-of-fit regression for the NMDS projection was measured as a stress value that quantified the difference from a monotonic relationship between the distance among toxic pollutants in the Bray-Curtis dissimilarity matrix and the distance among toxic pollutants in the NMDS plot (Clarke \& Warwick, 2001). A stress value less than 5 indicates an excellent representation of data compressed in the two-dimensional ordination space (Clarke \& Warwick, 2001). The NMDS analysis was used to assess how each of the toxic pollutants differed among the clusters, with differences related to their respective chemical characteristics (i.e., the explanatory variables) using the "envfit" function (version 2.4-2) in the "vegan" package (version 2.5-4) of $R$ ( $R$ Development Core Team, 2016). This function fit the chemical characteristics in the two-dimensional ordination space defined by the toxic pollutants. The importance of each chemical characteristic was assessed using a squared correlation coefficient $\left(r^{2}\right)$. 


\section{Results}

\subsection{Toxic Pollutant Sources by Activity}

A total of 3,710 point sources with authorized stormwater and wastewater discharges to surface waters were located throughout the Basin (Table 14). Facilities in DEQ's wastewater permit database consisted of $55 \%$ of the total point sources, facilities in EPA's pollutant loading database with reported toxic pollutant discharges consisted of $3 \%$, DOGAMI mining sites consisted of $27 \%$, and ODOT outfalls consisted of $14 \%$.

A total of 13,751 nonpoint sources were located throughout the Basin (Table 14). Farms harvesting crops with reported toxic pollutant-containing pesticide applications consisted of $93 \%$ of the nonpoint sources, contaminated sites in DEQ's ECSI database consisted of $6.7 \%$, and EPA Superfund Sites consisted of $0.07 \%$.

\subsubsection{Point Sources by Activity}

DEQ NPDES-Permitted Facilities

A total of 2,050 active facilities operating under NPDES discharge permits were located throughout the Basin (Table 15). These facilities operate under 2,153 NPDES permits (103 of the facilities operate two or three different permits each). Of the permitted facilities, 1,521 were industrial dischargers (74\%), 86 were POTWs $(4.2 \%), 16$ were covered under MS4 permits $(0.78 \%)$, and the remaining $430(21 \%)$ had unidentified discharge class sizes. Of the industrial dischargers, 1,516 (99\%) were minor and $5(0.33 \%)$ were major. Of the POTWs, 66 (76\%) were minor and 20 (23\%) were major.

A total of 623 facilities (30\% of the total) were active in manufacturing and mining activities while 1,427 facilities (70\%) were active in other activities (administration, professional services, agricultural, transportation, warehousing, utilities, and waste management). Surface water discharges were mostly for construction (711 total, 33\%), manufacturing (603 total, 28\%), and transportation/warehousing (137 total, $6 \%$ ) categories. The utility industry category comprises sewage treatment facilities (POTWs), water supply/irrigation systems, and power generation/distribution. The POTWs comprise $87 \%$ (219 facilities) of the total facilities in the utility industry category.

Of the total facilities, $85 \%$ were authorized to discharge to surface waters (1,819 total), while the remainder were authorized to discharge onsite (245 total facilities, 11\%) or to sewage systems ( 89 total facilities, 4.1\%) (Figure 11). The authorized surface water discharges were comprised of stormwater (1,481 total facilities, 69\%), domestic (326 total facilities, 15\%), and industrial wastewater (346 facilities (16\%) (Figure 11).

\section{EPA NPDES-Permitted Facilities}

A total of 123 actively-permitted facilities were identified in EPA's water pollution search database (Tables 16-17) (EPA, 2017g). Of the total 2,050 facilities identified in DEQ's Wastewater permit database, only 39 facilities (1.9\%) were identified in EPA's database (EPA, 2017g). Wastewater discharges included remediated groundwater, cooling water, domestic, non-process, sewage treatment, 
and general industrial. Of the permitted facilities, 85 were industrial dischargers (69\%) and 38 were POTWs (31\%). Of the industrial dischargers, 72 (85\%) were minor and $13(15 \%)$ were major. Of the POTWs, 25 (66\%) were major and 13 (34\%) were minor.

Facilities reporting to the EPA include industrial, commercial, and sewage/wastewater treatment facilities (POTW). A total of 85 facilities (69\%) were non-POTWs and 38 facilities (31\%) were POTWs. The total daily flow of the reported discharges (2007 to 2016) totaled $1.8 \times 10^{-02} \mathrm{MGD}$, equating to an annual daily flow of $2.1 \times 10^{-03} \mathrm{MGD}$. The POTWs discharged $99 \%$ of the total reported flow volume $\left(1.8 \times 10^{-02}\right.$ MGD)and the non-POTWs discharged the remaining $1.0 \%\left(2.6 \times 10^{-04} \mathrm{MGD}\right)$. Non-POTW facilities included utilities and manufacturing categories.

The 123 facilities were reported discharging 67 toxic pollutants in their waste streams to surface waters. However, pollutant masses were only reported for 13 of the 48 pollutants ( $27 \%$ of the total) including: VOCs (ammonia, cyanide, and trichloroethylene), PAHs (benzo(g,h,i)perylene)), and metals (arsenic, cadmium, chromium, copper, lead, methyl mercury, mercury, silver, and zinc). Most of the toxic pollutant loads were reported for ammonia (32 million kilograms (kg) [70.8 million lbs], 99\%)), with far lesser amounts reported for metals, with the most metals reported as zinc $(64,537 \mathrm{~kg}$ [142,279 lbs], $0.20 \%)$ and copper $(9,941 \mathrm{~kg}[21,916 \mathrm{lbs}], 0.031 \%)(\mathrm{EPA}, 2017 \mathrm{~g})$. The remaining toxic pollutant loads reported in offsite discharges totaled less than $1,179 \mathrm{~kg}(2,600 \mathrm{lbs},<0.0036 \%)$.

Of the seven categories of industry activities, only three reported masses of toxic pollutants in offsite stormwater/wastewater discharges: utilities (including POTW and non-POTW) reported 31.2 million $\mathrm{kg}$ (68.8 million lbs, 97\%), manufacturing reported 1 million $\mathrm{kg}$ (2.21 million lbs, 3.1\%), and real estate/retail reported $375 \mathrm{~kg}$ (827 lbs, 0.0012\%) (EPA, 2017g).

Of the seven categories of industry activities, only two reported total daily flow volumes (2007 to 2016) in offsite stormwater/wastewater discharges: utilities (including POTW and non-POTW) reported 1.8X10 ${ }^{02}$ MGD (98\%) and manufacturing reported 3.5X10-04 MGD (2.0\%) (EPA, 2017g). Of the total daily flow volumes reported, $99 \%$ of the volume was reported by major POTW facilities $\left(1.8 \times 10^{-02} \mathrm{MGD}\right)$ compared to $1.0 \%$ reported by major non-POTW facilities $\left(2.6 \times 10^{-04} \mathrm{MGD}\right)$. No daily flow volumes were reported by minor discharge facilities.

\section{DOGAMI Mining Sites}

A total of 715 mining sites were located throughout the Basin (Table 18) with aggregate mining commodities varying from metal ores to aggregates. The mining commodities were comprised of the following percentages, in order from the most to least sites producing those items: rock/shale $(42.6 \%$ of the total sites), sand and gravel (28\%), unidentified material (20\%), borrow/fill/top soil (4.7\%), clay (1.9\%), bar run (0.9\%), and copper (0.14\%) (DOGAMI, 2017).

Of the 715 mining sites, a total of 81 mining sites (11\%) were authorized to discharge process water offsite under a NPDES permit (NPDES 1200A permit). The remaining 22 mining sites (3\%) were not authorized to discharge process water offsite, operating under a different NPDES permit (WPCF 1000). Of the 715 mining sites, 612 mining sites (85\%) do not operate with a water quality permit. A total of 87 mining sites (12\%) have a permitted water quality permit status, 30 mining sites (4\%) have a terminated status, and one mining site $(0.1 \%)$ has only an application status. A total of 597 mining sites have an 
unknown water quality permit status (83.5\%) (DOGAMI, 2017). Pollutant loads were not reported for the mining sites.

\section{ODOT Outfalls}

A total of 522 ODOT outfalls were located throughout the Basin (Table 19). Stormwater discharges from highways were primarily received in unidentified features (24.5\%), streams (23.6\%), open fields (22\%), and rivers (13\%). Other discharge receiving features include sloughs (6\%), ditches (3.6\%), wetlands (3.5\%), storm drain systems (2.5\%), and ponds (1\%) (ODOT, 2016). Pollutant loads were not reported for ODOT outfalls.

\subsubsection{Nonpoint Sources by Activity}

\section{Pesticide Applications}

A total mass of 1.5 million $\mathrm{kg}$ ( 3.3 million $\mathrm{lbs}$ ) of 13 different toxic pollutant-containing pesticides were applied on agricultural land from 2000 to 2016 throughout the Basin (Table 20). Metals-containing pesticides were applied the most at approximately 1.1 million $\mathrm{kg}$ ( 2.5 million lbs, 77\%), compared to organophosphorus insecticide-containing at over $303,000 \mathrm{~kg}(668,000 \mathrm{lbs}, 20 \%)$, and organochlorine insecticide-containing at over $36,700 \mathrm{~kg}(81,000 \mathrm{lbs}, 2.5 \%)$ (USGS, 2017). The most metals-containing pesticides applied were copper at over 839,000 million $\mathrm{kg}$ ( 1.85 million lbs, $73 \%$ ) compared to zinc at over $313,000 \mathrm{~kg}(691,000 \mathrm{lbs}, 27 \%)$. The most organphosphorus insecticide-containing pesticide applied was chlorpyrifos at over $263,000 \mathrm{~kg}(581,000 \mathrm{lbs}, 87 \%)$, compared to azinphos-methyl at over $39,000 \mathrm{~kg}$ $(87,000 \mathrm{lbs}, 13 \%)$. The only organochlorine insecticide-containing pesticide applied was endosulfan at over $36,000 \mathrm{~kg}(81,000 \mathrm{lbs})$.

Seven categories of crops received pesticide applications in the Basin including alfalfa, corn, orchards/grapes, pasture/hay, vegetables/fruit, wheat, and other crops (Figure 12). Orchards/grapes comprise the majority of the crops receiving pesticide applications in the Basin (62\%), followed by vegetables/fruit (32\%), and wheat (1.6\%) (USDA, 2012a, 2012b, 2012c).

\section{DEQ ECSI Sites}

A total of 927 contaminated sites were located throughout the Basin, impacted by 55 toxic pollutants (Tables 21-22). These sites have toxic pollutant contamination in soil, sediment, and groundwater including metals, pesticides/insecticides, PAHs, PCBs, and VOCs. Several sites were impacted by a single toxic pollutant while a single property is impacted by 31 toxic pollutants (DEQ, 2018c). The activities associated with the ECSI sites consisted mostly of industrial/manufacturing (353 total, $38 \%$ of total), dry cleaner/laundromat $(89,9.6 \%)$, and non-specific industries categorized as "study areas" (68, 7.3\%) categories (DEQ, 2018c).

Toxic pollutants impacting the ECSI sites varied but included all toxic pollutant classes with exception for organophosphorus insecticides (Table 22). A total of 346 sites (37\%) were impacted by metals, 323 sites (35\%) were impacted by VOCs, 125 sites (13\%) were impacted by PAHs, 89 sites (9.6\%) were impacted by PCBs, and 44 sites (4.8\%) were impacted by organochlorine insecticides. Most of the sites impacted by metals, PAHs, and VOCs were each associated with industrial/manufacturing (180 total, 37 total, and 116 total, respectively) (Figure 13). Most sites impacted by PCBs were associated with utilities (36 total). Most sites impacted by organochlorine insecticides were associated with agricultural (21 total). 


\section{EPA Superfund Sites}

A total of 10 EPA Superfund Sites were located throughout the Basin (Table 23). These sites were impacted by all toxic pollutants, operating historically and currently as varying industrial activities. Evaluation of toxic pollutants at EPA Superfund Sites is based on geographic location, refer to Section 4.2.2.

\subsection{Toxic Pollutant Sources by Geographic Source Area}

Most point sources were located in the southeastern and northwestern subbasins of the Basin: Yamhill (17\%), Tualatin (16\%), and McKenzie (14\%) (Figure 14). The remaining subbasins comprised $12 \%$ or less of the total point sources (Table 14).

Most nonpoint sources were located in the western subbasins of the Basin: Upper Willamette (30\%), Middle Willamette (19\%), and Tualatin (14\%) (Figure 15). The remaining subbasins comprised less than $10 \%$ of the total nonpoint sources (Table 14).

Many of the point and nonpoint sources could be related to specific land uses. Approximately $63 \%$ of the point sources were located on urban land, whereas $18 \%$ were located on agricultural land, followed by $13 \%$ located on forest land (Table 24, Figure 16). Point sources were primarily located in the Upper Willamette (24\% of the total sources), the Middle Willamette $(15 \%)$, and the Tualatin (14\%) subbasins.

Most nonpoint sources were located on agricultural land at $93 \%$ of the total, whereas only $6.2 \%$ were located on urban land, followed by $0.25 \%$ located on forest land (Table 14, Figure 16). These quantities do not include total masses of pesticide applications. Nonpoint source contaminated properties (DEQ ECSI Sites and EPA Superfund Sites) were located mostly in the McKenzie subbasin (481 total, 51\% of total), the Tualatin $(139,15 \%)$, and the Yamhill $(119,13 \%)$ subbasins. Nonpoint source toxic pollutantcontaining pesticide applications by subbasin were mostly in the Upper Willamette at approximately $499,000 \mathrm{~kg}$ (1.1 million Ibs, 34\%), the Middle Willamette at over 374,000 kg (826,000 lbs, 23\%), and the Yamhill at over $155,000 \mathrm{~kg}(342,000 \mathrm{lbs}, 11 \%)$ subbasins (Table 20).

\subsubsection{Point Sources by Geographic Area DEQ Permitted Facilities}

Facilities with NPDES discharge permits were located in all 11 subbasins. Most NPDES-permitted facilities in the Basin authorized to discharge stormwater and wastewater offsite were located in the Lower Willamette (488 total, $24 \%$ ), the Middle Willamette (380 total, 19\%), and the Upper Willamette (345 total, 17\%) subbasins (Table 26, Figure 17) (DEQ, 2017c).

Of the 12 categories of industry activities, most NPDES-permitted facilities in the Basin were in the construction category (714 total, 35\%), with the most located in the Middle Willamette (176 total, 25\%). The second most NPDES-permitted facilities in the Basin were in the manufacturing category, with the most located in the Upper Willamette (134 total, 25\%). The third most NPDES-permitted facilities in the Basin were in the utilities category (246 total, $12 \%$ ), with the most located in the Lower Willamette (36 total, $15 \%)$. 
Of the 12 categories of industry activities with permitted stormwater/wastewater discharges, 7 were found in all 11 subbasins: accommodation/food/recreation, administration/services, agriculture, construction, manufacturing, mining, and utilities (Figures 18-19). The remaining industry activity categories with permitted stormwater/wastewater discharges were found in 10 subbasins or less: the retail/wholesale trade category were found in 10 subbasins; the transportation/warehousing industry were found in 8 subbasins; the real estate industry were found in 7 subbasins; the roadway management industry were found in two subbasins; and the waste management industry were found in one subbasin (Figures 18-19).

Most of the Basin's facilities were minor industrial dischargers located in all of the subbasins, with most located in the Lower Willamette (436 total in this subbasin, 89\%) (Figures 20, 23). Only five major industrial dischargers were located in four of the 11 subbasins, with most located in the Middle Willamette (3 total in this subbasin, 60\%) (Figures 21, 23). Most of the Basin's POTWs were minor POTWs located in all of the subbasins, with most located in the Upper Willamette (17 total in this subbasin, 4.9\%) (Figures 20, 23). Only 20 major POTWs were located in 8 of the 11 subbasins, with most located in the Middle Willamette (4 total in this subbasin, 1.05\%) (Figures 21, 23). The Basin's MS4permitted facilities were located in 6 of the 11 subbasins, with most located in the Middle Willamette (5 total in this subbasin, 1.3\%) (Figures 22-23).

NPDES-permitted facilities were located mostly on urban land at $70 \%$ of the total, whereas $18 \%$ were located on agricultural land and $8.4 \%$ were located on forest land (Table 24, Figure 16).

\section{EPA Discharge Reporting Facilities}

Facilities with NPDES discharge permits reporting discharges to EPA were located in all 11 subbasins. Most of the NPDES-permitted facilities in the Basin reporting offsite stormwater/wastewater discharges and pollutant loads to EPA were located in the Tualatin (32 total, 26\%), the McKenzie (29 total, 24\%), and the North Santiam (17 total, 13\%) subbasins (Tables 26-27, Figures 18-21, 23). The remaining subbasins consisted of less than $9 \%$ of the total each (EPA, 2017g).

Most of the Basin's facilities reporting discharges were minor industrial dischargers located in 8 of the 11 subbasins, with most located in the Lower Willamette (24 total in this subbasin, 83\%) (Figures 20, 23). Only 13 major industrial dischargers were located in three of the 11 subbasins, with most located in the Upper Willamette (7 total in this subbasin, 22\%) (Figures 21, 23). Most of the Basin's POTWs were major POTWs located in nine of the 11 subbasins, with most located in the Middle and Lower Willamette (5 total in each subbasin) (Figure 21). Only 13 minor POTWs were located in five of the 11 subbasins, with most located in the Upper Willamette (5 total in this subbasin, 16\%) (Figures 20, 23).

Non-POTWs were located mostly in both the Upper Willamette (24 facilities, 28\%) and the Lower Willamette (24 facilities, $28 \%$ ), the Middle Willamette (12 facilities, 14\%), and the Molalla-Pudding ( 8 facilities, 9.4\%) subbasins (Figures 20-21). The remaining subbasins consisted of non-POTWs at less than $10 \%$ of the total each. POTWs were located mostly in the Upper Willamette (8 facilities, 21\%), the Lower Willamette (5 facilities, 13\%), the Yamhill (5 facilities, 13\%), and the Middle Willamette (5 facilities, 13\%), and the Tualatin (4 facilities, 10\%) subbasins (Figures 20-21). The remaining subbasins consisted of quantities of POTWs at less than $10 \%$ of the total each (EPA, 2017g). 
Facilities reporting the most total daily flow volume (2007 to 2016) of offsite stormwater/wastewater discharges were located mostly in the Tualatin $\left(1.0 \times 10^{-02} \mathrm{MGD}, 69 \%\right)$, the Middle Willamette $\left(1.3 \times 10^{-03}\right.$

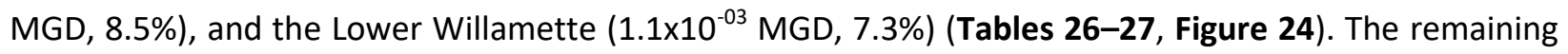
subbasins consisted of total flow volumes at less than $7 \%$ of the reported total each (EPA, 2017g).

Facilities reporting the most mass of toxic pollutant loads in offsite stormwater/wastewater discharges by subbasin were mostly in the Lower Willamette (over 7.4 million $\mathrm{kg}$ [16.5 million lbs], $27.3 \%$ of the total), the Tualatin (over 7.3 million kg [16.1 million lbs], 26.5\%), and the Middle Willamette (over 7.2 million kg [15.9 million Ibs], 26.2\%) (Tables 26-27, Figure 24). The remaining subbasins consisted of pollutant masses at less than $15 \%$ of the total each (EPA, 2017g).

Industry categories reporting the most discharges were manufacturing (61 total facilities, 50\%), with the most located in the Upper Willamette (19 total) (Figure 25). The industry category reporting the second most discharges were utilities (48 total facilities, 39\%) and the third most discharges were administrative/service ( 6 total facilities, 4.9\%). The remaining industry categories comprised less than $1.6 \%$ of the total categories each.

EPA-reporting facilities were located mostly on urban land at $84 \%$ of the total, whereas $6.5 \%$ were located on agricultural land, followed by $4.1 \%$ located on forest land (Table 24, Figure 16).

\section{DOGAMI Mining Sites}

Mining sites, and mining sites with NPDES permits authorized to discharge offsite, were located in all 11 subbasins. DOGAMI mining sites authorized to discharge stormwater and wastewater offsite (under a NPDES 1200-A discharge permit) were located mostly in the Middle Willamette (3\%), the Upper Willamette (2\%), and the Molalla-Pudding (1\%) subbasins (Table 28, Figures 26-27) (DOGAMI, 2017).

Mining sites were located on forest land at $35 \%$ of the total, whereas $25 \%$ were located on agricultural land, followed by $19 \%$ at urban land (Table 24, Figure 16).

\section{ODOT Outfalls}

ODOT outfalls were located in eight of 11 subbasins. ODOT outfalls authorized to discharge stormwater from roads/highways were located mostly in the Tualatin (173 total outfalls, 33\% of the total), the Lower Willamette $(128,24 \%)$, and the Upper Willamette $(112,21 \%)$ subbasins (Table 29, Figures 28-29) (ODOT, 2016).

ODOT outfalls were located mostly on urban land at $92 \%$ of the total, whereas $2.1 \%$ of the total were located on forest land, followed by $1.1 \%$ located on agricultural land (Table 24, Figure 16).

\subsubsection{Nonpoint Sources by Geographic Area}

\section{Pesticide Applications}

Toxic pollutant-containing pesticide applications (2000 to 2016) were reported across 13 counties in all 11 subbasins. The most mass of pesticides applied by subbasin were in the Upper Willamette (over $498,000 \mathrm{~kg}$ [1.1 million Ibs], 34\% of the total), the Middle Willamette (over 351,000 kg [774,000 lbs], 23\%), and the Yamhill (over 169,000 kg [374,000 lbs], 11\%) (Table 20, Figures 30-33) (USGS, 2017). 
Pesticides applied in the remaining subbasins were in quantities less than $10 \%$ of the total in each subbasin.

Most of the metals-containing pesticide applications by subbasin were in the Upper Willamette (over $372,000 \mathrm{~kg}[822,000 \mathrm{lbs}]$, the Middle Willamette (over 276,000 kg [610,000 lbs]), and the Yamhill (over $134,000 \mathrm{~kg}[296,000 \mathrm{lbs}])$. Most of the organophosphorus insecticide-containing pesticide applications by subbasin were also in the Upper Willamette (over 115,000 kg [254,000 lbs]), the Middle Willamette (over 65,000 kg [144,000 lbs]), and the Yamhill (over 30,000 kg [68,000 lbs]). The organochlorine insecticides (only reporting endosulfan) applications by subbasin were also in the Upper Willamette (over 12,000 kg [27,000 lbs]), the Middle Willamette (over 9,000 kg [20,000 lbs]), and the Yamhill (over $4,000 \mathrm{~kg}[9,000 \mathrm{lbs}])$.

\section{$\underline{\text { DEQ ECSI Sites }}$}

ECSI Sites were located in all 11 subbasins. ECSI sites were located primarily in the Lower Willamette (481, 52\%), the Upper Willamette $(139,15 \%)$, and the Tualatin $(118,13 \%)$ subbasins (Table 30, Figure 34). The remaining subbasins comprise less than $10 \%$ of the total ECSI sites each. Of the 927 contaminated sites in DEQ's ECSI database, 215 sites (23\% of the total) were located within $0.3 \mathrm{~km}$ (1,000 feet) of a river (DEQ, 2018c).

As previously described in Section 4.1.2, the industry activities associated with the ECSI sites were diverse, grouped into 19 industry categories. Most ECSI sites were associated with industrial/manufacturing at 353 total (38\%), with 213 (60\%) located in the Lower Willamette (Figure 35). The second most ECSI sites were associated with dry cleaners/laundromats at 89 total (9.6\%), with 36 total (40\%) located in the Lower Willamette. The third most ECSI sites were associated with the general category of "study area" at 68 total (7.3\%), with 31 total (45\%) located in the Lower Willamette.

Most sites impacted by metals, PAHs, PCBs, VOCs, and organochlorine insecticides were located in the Lower Willamette (at 195 total, 81 total, 145 total, 42 total, and 18 total, respectively) (Figure 35). The second and third most sites impacted by metals, PAHs, and VOCs were located in the Upper Willamette and Tualatin, respectively. The second and third most sites impacted by organochlorine insecticides were located in the Tualatin and Middle Willamette. The second and third most sites impacted by PCBs were located in the Middle Willamette and the Upper Willamette.

ECSI sites were located mostly on urban land at $91 \%$ of the total, whereas $3.6 \%$ were located on forest land, followed by $3.5 \%$ located on agricultural land (Table 24, Figure 16).

\section{EPA Superfund Sites}

Superfund Sites were located in four of 11 subbasins. Most Superfund Sites were located in the Lower Willamette subbasin (seven, 64\% of total) (Table 23, Figure 36). The Portland Harbor Superfund Site (Portland Harbor) in the lower portion of the Willamette River covers $16 \mathrm{~km}$ (10 miles) is the largest of these sites and is characterized with the most variety of toxic pollutants, including metals, PAHs, PCBs, VOCs, and pesticides (EPA, 2018c) (EPA, 2017d). 
All ten Superfund Sites were identified with contamination in (and contaminant pathways discharging to) waterbodies of the Basin. Nine of the Superfund Sites have discharge pathways to the Willamette River. Several sites have cleanup and remediation completed (NFA status), while others were still undergoing investigation. Over 150 Potentially Responsible Parties (PRPs) were identified as potential contributors of toxic pollutants to the Willamette River of the Portland Harbor Superfund Site (EPA, 2017d).

Superfund Sites were located mostly on urban land at $82 \%$ of the total, whereas $9.1 \%$ were located on forest land and in-water (Table 24, Figure 16). 


\subsection{Toxic Pollutant Chemical Characteristics}

\subsubsection{Toxic Pollutant Classes}

The chemical characteristics for each of the Basin's toxic pollutants varied among each of the pollutant classes (Table 31).

- High values of Henry's Law Constant were exhibited by VOCs $\left(1.9 \times 10^{-01} \mathrm{~atm}-\mathrm{m}^{3} / \mathrm{mol}\right)$, with the lowest values exhibited by organophosphorus insecticides $\left(3.7 \times 10^{-09} \mathrm{~atm}-\mathrm{m}^{3} / \mathrm{mol}\right)$ (Figure 37).

- High values of solubility were exhibited by metals $(623,500 \mathrm{mg} / \mathrm{L})$, with the lowest values exhibited by PCBs (5 mg/L) (Figure 38).

- High values of vapor pressure were exhibited by VOCs $(7,508 \mathrm{mmHg})$, with the lowest values exhibited fairly similarly by the remaining classes (PAHs $\left[9.6 \times 10^{-11} \mathrm{mmHg}\right], \mathrm{PCBs}\left[7.6 \times 10^{-09}\right.$ $\mathrm{mmHg}]$, metals $\left[3.9 \times 10^{-09} \mathrm{mmHg}\right]$, organochlorine insecticides $\left[3.7 \times 10^{-08} \mathrm{mmHg}\right.$, and organophosphorus insecticides $\left[2.2 \times 10^{-07} \mathrm{mmHg}\right]$ ) (Figure 39).

- High values of $\mathrm{K}_{\mathrm{oc}}$ were exhibited by PAHs (6.7), PCBs (6.2), and organochlorine insecticides $(6.0)$, with the lowest values exhibited by organochlorine insecticides $\left(3.9 \times 10^{-07}\right)$ and metals $\left(-6.7 \times 10^{-01}\right)$ (Figure 40).

- High values of $\mathrm{K}_{\mathrm{ow}}$ were exhibited by PCBs (9.6), with the lowest values exhibited by metals $\left(-7.7 \times 10^{-01}\right)$ and VOCs $\left(2.3 \times 10^{-01}\right)$ (Figure 41).

A negative relationship exists between water solubility and $\mathrm{K}_{\mathrm{ow}}$, where $\mathrm{K}_{\mathrm{ow}}$ decreases as solubility increases and a positive relationship exists between water solubility and Henry's Law Constant, where Henry's Law Constant increases as solubility decreases (Figure 42).

The metals classification is comprised of nine toxic pollutants (Table 10, Appendix D). Varying by each compound, metals are non-organic, existing in several oxidation states as a solid or a liquid (temperature dependent). Generally, water solubility is very low to very high (negligible to very soluble), vapor pressures are very low to high (less to very volatile), $\mathrm{K}_{\mathrm{ow}}$ values are very low, and $\mathrm{K}_{\mathrm{oc}}$ values are very low (negligible sorption capacity), making them highly lipophilic with rapid groundwater migration. Based on their vapor pressures and solubility values, the Henry's Law Constant values indicate volatile tendencies. These chemical characteristics indicate metals partition to solid matter but also to the air phase (Table 31). Both lead and mercury (in addition to arsenic) are unique metals in that they are capable of forming covalent bonds with non-polar organic chemical groups, resulting in decreased hydrophobicity (lower $\mathrm{K}_{\mathrm{OW}}$ values) and increased mobility in the environment under certain environmental conditions (ATSDR, 1990, 1992, 1999, 2004b, 2005, 2007a, 2007c, 2012; Walker, 2001b).

The organochlorine insecticides classification is comprised of 11 toxic pollutants (Table 10, Appendix D). Generally, water solubility is fairly low (generally negligible), vapor pressures are moderate (generally slow volatility to volatile), $\mathrm{K}_{\mathrm{ow}}$ values are moderate to high, and $\mathrm{K}_{\mathrm{oc}}$ values are very low to very high (negligible to very strong sorption capacity), making them moderately to super hydrophobic with varying degrees of groundwater migration (rapid to negligible). Based on their vapor pressures and solubility values, the Henry's Law Constant values indicate nonvolatile to slightly volatile tendencies. These chemical characteristics indicate organochlorine insecticides partition to the solid phase. However, 
chemical characteristics vary among each of the constituents (ATSDR, 1994b, 1996b, 2002a, 2002b, 2007b, 2015; Walker, 2001f).

The organophosphorus insecticides classification is comprised of two toxic pollutants (Table 10, Appendix D). Generally, water solubility is fairly low (negligible), vapor pressures are low to moderate (generally slow volatility to volatile), $\mathrm{K}_{\mathrm{ow}}$ values are moderate to high, and $\mathrm{K}_{\mathrm{oc}}$ values are moderate to high (moderate to strong sorption capacity), making them moderately to super hydrophobic but slow to migrate in groundwater. Based on their vapor pressures and solubility values, the Henry's Law Constant values indicate nonvolatile to moderately volatile tendencies. These chemical characteristics indicate organophosphorus insecticides partition to the solid phase (Table 31) (ATSDR, 1997, 2008).

The PAHs classification is comprised of 17 toxic pollutants (Table 10, Appendix D). PAHs are hydrocarbons structured with carbon and hydrogen and classified as either an aromatic or nonaromatic. The aromatic group contains a benzene ring system while the non-aromatics (also known as aliphatic and alicyclic) do not (i.e., alkenes and alkynes). PAHs are complex mixtures, most notably in the aromatic group, consisting of fused rings (i.e., benzo[a]pyrene)). PAHs have a rigid structure and are non-polar. Generally, PAHs exhibit low water solubility (negligible), low to high vapor pressure (less to very volatile), $\mathrm{K}_{\mathrm{ow}}$ values are moderate to high, and $\mathrm{K}_{\mathrm{oc}}$ values are low to very high (negligible to very strong sorption), making them moderately to highly hydrophobic with moderate to negligible migration in groundwater. Based on their vapor pressures and solubility values, the Henry's Law Constant values indicate nonvolatile to volatile tendencies. These chemical characteristics indicate PAHs partition mostly to the water phase (Table 31) (ATSDR, 1996c; Walker, 2001e).

The PCB classification is comprised of 209 congeners represented as total PCBs (Table 10, Appendix D). PCBs consist of carbon, hydrogen, and chlorine atoms (i.e., chlorinated hydrocarbons). A total of one to 10 chlorine atoms can be attached to a biphenyl molecule (an aromatic hydrocarbon) composed of two six-carbon atom phenyl rings, for a total of 12 carbons (with six double carbon-carbon bonds). The number and location of the chlorines attached to the biphenyl rings determines the physical/chemical properties, and toxicity, of the congener. PCB molecules can be either coplanar (more toxic) or noncoplanar. (ATSDR, 2000; EPA, 2003b; Erickson D., 1997). PCBs are non-polar, exhibiting high $\mathrm{K}_{\text {ow }}$ values making them highly to super hydrophobic. PCBs prefer binding to carbonaceous materials with high total organic carbon content in soils and sediments as well as fatty tissues in fish and other animals. Coplanar PCBs sorb to soil stronger than nonplanar congeners with the same degree of chlorination. PCBs are generally insoluble in water but solubility tends to decrease with increasing levels of chlorination (i.e., PCBs are less likely to dissolve as the number of chlorines on the biphenyl rings increases). Based on their vapor pressures and solubility values, the Henry's Law Constant values indicate slightly volatile to volatile tendencies. These chemical characteristics indicate PCBs partition mostly to the solid phase; however, chemical characteristics vary among each of the congeners (Tables 10, 31) (ATSDR, 2000; Erickson D., 1997).

The VOCs classification is comprised of eight toxic pollutants (Table 10, Appendix D). VOCs include certain compounds of carbon. Although ammonia does not contain carbon, ammonia is included in the VOC classification because it is a gas at room temperature and exhibits volatility (ATSDR, 2004a). Cyanide (an inorganic nonmetal anion) is included in the VOC classification because many cyano 
compounds are gases at room temperature and cyanide can form complexes with metals and some gases (i.e., hydrogen cyanide or copper cyanide) or is a breakdown product of a VOC parent compound (i.e., acetonitrile) (ATSDR, 2006). VOCs generally exhibit moderate to high solubility, low to very high values of vapor pressure, Kow values are low to moderate, and Koc values are very low (negligible to low sorption), making them highly lipophilic to moderately hydrophobic with rapid to moderate migration in groundwater. Based on their vapor pressures and solubility values, the Henry's Law Constant values indicate moderate to volatile tendencies. These chemical characteristics indicate VOCs partitioning mostly to the air; however, chemical characteristics vary among each of the constituents (Tables 10, 31). Cyanide is very water soluble and thus, highly lipophilic; these chemical characteristics indicate cyanide partitions to the water phase (Tables 10, 31) (ATSDR, 1994a, 1996a, 2004a, 2006, 2014a, 2014b).

\subsubsection{Toxic Pollutant Clusters}

The dendrogram suggests that the Basin's 48 toxic pollutants could be grouped into four toxic pollutant classes defined by their chemical characteristics (Figure 43). A total of four (8\%) toxic pollutants were grouped in Cluster 1, a total of $13(27 \%)$ were grouped in Cluster 2, a total of 17 (35\%) were grouped in Cluster 3, and a total of 14 (29\%) were grouped in Cluster 4 . The nine metals were distributed across two clusters: three (33\%) were grouped in Cluster 1 and six (67\%) were grouped in Cluster 2. The 17 PAHs were distributed across two clusters: nine (53\%) were grouped in Cluster 3 and eight (47\%) were grouped in Cluster 4. The eight VOCs were distributed across two clusters: one (13\%) was grouped in Cluster 1 and seven (88\%) were grouped in Cluster 2. The 11 organochlorine insecticides were distributed across two clusters: six (55\%) were grouped in Cluster 3 and five (45\%) were grouped in Cluster 4 . The two organophosphorus insecticides and one PCB were each grouped in a single cluster: two in Cluster 3 and one in Cluster 4, respectively.

The box plots for each of the clusters show trends in the distribution of toxic pollutants defined by their chemical characteristics.

- Henry's Law Constant values are similar for toxic pollutants in Clusters 1 and 2 but decrease by Clusters 3 and 4, with toxic pollutants in Cluster 4 exhibiting a wider range of values (Figure 44).

- Solubility values decrease from Clusters 1 to 4 , with toxic pollutants in Cluster 1 exhibiting a much smaller range of values compared to the other three clusters (Figure 45).

- Vapor pressure values increase from Cluster 1 to 2 but decrease from Cluster 2 to 4 , with toxic pollutants in Cluster 2 exhibiting a wide range of values (Figure 46).

- Koc values increase from Cluster 1 to 4 , with toxic pollutants in Cluster 1 exhibiting a much smaller range of values and toxic pollutants in Cluster 3 exhibiting more range of values (Figure 47).

- Kow values increase from Cluster 1 to 4 , with toxic pollutants in Clusters 1 and 4 exhibiting a smaller range of values (even smaller in Cluster 1 ) and toxic pollutants in Cluster 2 exhibiting a wider range of values (Figure $\mathbf{4 8}$ ).

The ANOSIM test ( $R$ test statistic $=0.859 ; p=0.001$ ) revealed there were significant differences among each of the four clusters). This indicated toxic pollutants in a single cluster were more similar to each other than toxic pollutants in other clusters. The pair-wise ANOSIM tests revealed each of the four 
clusters were significantly different from each other, based on the Bonferroni-corrected significance level ( $\alpha_{\text {altered, }} p=0.01$ ) (Table 32). The ANOVA tests revealed there were significant differences in variance among the clusters for solubility $(p=0.00000133)$ and $K_{O C}(p=0.00102)$, while there were no significant differences in variance among the clusters for $K_{o w}(p=0.219)$, vapor pressure $(p=0.0242)$, and Henry's Law Constant $(p=0.129)$ based on the Bonferroni-corrected significance level $\left(\alpha_{\text {altered, }} p=0.0125\right)$ (Table 33).

The NMDS plot revealed the 48 toxic pollutants located in proximity to each other that share similarities in chemical characteristics and are further away from each other that do not share similarities (Figure 49). The ordination stress value (0.08742) indicated the NMDS plot provided a sound representation of two dimensional space with limited prospect of misinterpretation. Thus, the NMDS plot represented relationships among toxic pollutants and chemical characteristics corresponding to the four clusters identified by the cluster analysis. The NMDS axis I revealed environmental behavior variation, shifting from water soluble toxic pollutants (Cluster 1 ) (-3 on the x-axis) to hydrophobic toxic pollutants (Cluster 4) ( 1 and 2 on the $x$-axis). Similarly, the NMDS axis 2 revealed environmental behavior variation, shifting from more volatile toxic pollutants (Cluster 2 ) (-1 on the $y$-axis) to less volatile toxic pollutants (Cluster 3 ) (-2 and -3 on the $y$-axis). The chemical characteristics that significantly correlated with the NMDS ordination space defined by the toxic pollutants (in order from most to least significant) included: solubility $\left(r^{2}=0.35, p=0.001\right)$ and $K_{O C}\left(r^{2}=0.42, p=0.001\right)$, Henry's Law Constant $\left(r^{2}=0.15, p=0.019\right)$, and vapor pressure $\left(r^{2}=0.12, p=0.034\right)$ (Table 34). The chemical characteristic $K_{\text {ow }}$ did not show a significant correlation with the NMDS ordination space $\left(r^{2}=0.046, p=0.29\right)$.

\subsubsection{Description of Toxic Pollutant Clusters}

The cluster analysis dendrogram showed Cluster 1 and 2 toxic pollutants within the same primary group but each in their own subgroup (Figure 43). Likewise, Cluster 3 and 4 toxic pollutants were within the same secondary group but each in their own subgroup (and within each subgroup were additional subgroups).

Cluster 1 toxic pollutants exhibit soluble behavior

This cluster includes VOCs $(n=1)$ and metals $(n=3)$ (Table 35, Figure 43). In the dendrogram, two of the three metals (copper and zinc) are in their own subgroup. The toxic pollutant behaviors in this cluster exhibit high solubility, and thus are highly lipophilic with negligible sorption, yet exhibit a range of volatility from low to high. Low sorption values indicate a high degree of mobility in groundwater. Ammonia is the only VOC pollutant in this cluster as it shares more similar characteristics with the clustered metals (high solubility), as compared to the remaining VOC pollutants in Cluster 2 (low solubility). Likewise, metals in this cluster share more similar characteristics (low $\mathrm{K}_{\mathrm{OW}}, \mathrm{K}_{\mathrm{OC}}$, vapor pressure, and Henry's; thus high solubility) as compared to the remaining metals in Cluster 2 (high Kow, $\mathrm{K}_{\mathrm{oc}}$, vapor pressure, and Henry's; thus low solubility). Ammonia is included in its own branch whereas the three metals are branched together. Thus, this cluster is predominantly driven by solubility. 


\section{Cluster 2 toxic pollutants exhibit more volatile behavior}

This cluster includes VOCs ( $n=7)$ and metals $(n=6)$ (Table 35, Figure 43). In the dendrogram, the majority of the VOCs are in the left subgroup and the metals are in the right subgroup; one of the metals is subgrouped with the VOCs (left) and one of the VOCs is sub-grouped with the metals (right); and cyanide is in the right subgroup (with metals) in its own subgroup. The toxic pollutant behaviors in this cluster indicate a range of solubility from negligible to very soluble, and thus ranging from highly lipophilic to moderately hydrophobic with negligible to low sorption, and exhibit some volatility. Low sorption values indicate a high degree of mobility in groundwater. The toxic pollutants in this cluster exhibit higher values (and higher range) of vapor pressure. This cluster is predominantly driven by vapor pressure.

Cluster 3 toxic pollutants exhibit less volatile behavior

This cluster includes PAHs ( $n=9)$, organochlorine insecticides $(n=6)$, and organophosphorus insecticides $(n=2)$ (Table 35, Figure 43). In the dendrogram, the majority of the PAHs are in the left subgroup and the organochlorine insecticides are in the right subgroup; one organochlorine is sub-grouped with the PAHs (left) and two of the PAHs are sub-grouped with the organochlorines (right); the organophosphorus insecticides are in the left and right subgroups, in their own subgroup. The toxic pollutant behaviors in this cluster indicate negligible solubility, and thus are moderately to super hydrophobic, yet exhibiting a range of sorption from negligible to high, and also exhibit a range of volatility from low to high. Low to high sorption values indicate a high to low degree of mobility in groundwater. PAHs in this cluster share more similar characteristics (lower $\mathrm{K}_{\mathrm{ow}}$ and $\mathrm{K}_{\mathrm{oc}}$; higher solubility, vapor pressure, and Henry's) as compared to the remaining PAHs in Cluster 4 (higher $\mathrm{K}_{\mathrm{ow}}$ and $\mathrm{K}_{\mathrm{oc}}$; lower solubility, vapor pressure, and Henry's). Likewise, organochlorine insecticides in this cluster share more similar characteristics (lower $\mathrm{K}_{\mathrm{OW}}, \mathrm{K}_{\mathrm{OC}}$, vapor pressure, and Henry's; higher solubility) as compared to the remaining PAHs in Cluster 4 (higher $\mathrm{K}_{\mathrm{ow}}, \mathrm{K}_{\mathrm{oc}}$, vapor pressure, and Henry's; lower solubility). The toxic pollutants in this cluster exhibit lower values (and lower range) of vapor pressure. This cluster is predominantly driven by vapor pressure.

\section{Cluster 4 toxic pollutants exhibit hydrophobic behavior}

This cluster includes PAHs ( $n=8)$, organochlorine insecticides $(n=5)$, and PCBs (Table 35, Figure 43). In the dendrogram, PAHs are evenly distributed amongst the left and right subgroups; the majority of the organochlorine insecticides are in the left subgroup, with one organochlorine in the right subgroup; and $\mathrm{PCBs}$ are in the right subgroup (with PAHs and a single organochlorine) in their own subgroup. The toxic pollutant behaviors in this cluster indicate negligible solubility, and thus are highly to super hydrophobic with very strong sorption, yet exhibit a range of volatility from low to high. Low to high sorption values indicate a high to low degree of mobility in groundwater. This cluster is predominantly driven by $\mathrm{K}_{\mathrm{oc}}$ and Kow to some extent. 


\section{Discussion}

\subsection{Toxic Pollutant Sources in the Basin}

Identifying all potential point and nonpoint sources throughout a watershed as large as the Basin is challenging given limitations in data availability, the diffuse (and non-regulated) nature of nonpoint source discharges, and the legacy status of many toxic pollutants (i.e., PCBs and pesticides). Review of Oregon's and other environmental state agency's existing TMDLs and literature characterizing toxic pollutant sources based on land use in watersheds provides additional and supporting information on known or potential toxic pollutant sources in the Basin. Nevertheless, the source identification conducted in this Project demonstrates that the six toxic pollutant classes are attributed to a variety of point and nonpoint sources, released historically and presently, from a variety of land uses and industries.

\subsubsection{Toxic Pollutant Sources by Land Use}

The Basin's point and nonpoint sources can be attributed to land use practices (Wilson, 2015; Yong \& Chen, 2002). An expected observation gathered from the identification of sources was the location of sources related to the use of the land. Point sources were mostly located on urban land (63\%) and nonpoint sources were mostly located on agricultural land (93\%) (Table 24, Figure 16). However, because the total quantity of nonpoint sources consisted of farms harvesting crops (with pesticide applications) only in agriculture land uses, this skewed the results. When evaluating only the contaminated sites in the Basin (DEQ ECSI Sites and EPA Superfund Sites), urban land contained the most nonpoint sources at $91 \%$, followed by forest land at $3.6 \%$, and agricultural land at $3.4 \%$, which was a more expected result. When assessing the Basin as a whole, however, forest land comprises $68 \%$ of the total land area, followed by agricultural land at $20 \%$, and urban land at $8.1 \%$. The majority of the developed areas with nonpoint sources, however, are located in the non-forest land areas.

Heavy metals (copper and zinc) are typically associated with urban land use runoff (CWP, 2003; Fitzpatrick et al., 2007). While urban land constitutes only $8 \%$ of the total Basin land area (ranking third after forest and agriculture), the Basin's urban streams are impacted by toxic pollutant impairments the most. The majority of the state's population is found in the Basin and urban development (of industrial and residential uses) contribute contaminated discharges to surface waters (DEQ, 2009, 2015). Evidence of human impacts to water quality is supported by a 2009 study on the biological condition of the Basin's streams. This 2009 study characterized disturbances of various stressors, indicating significantly less disturbance in streams of forest land compared to streams of urban and agricultural land; more disturbances were identified for urban streams (DEQ, 2009).

In the early 1990s, a USGS study correlated toxic pollutant concentrations in surface waters of the Basin to specific land uses, attributing stormwater runoff as a transport pathway of toxic pollutants from upland areas (USGS, 1996). Stream samples collected throughout Basin were analyzed for toxic pollutants such as metals, VOCs, and chlorinated compounds (pesticides and PCBs). Metals exceeded water quality criteria from more urban areas (residential and industrial) compared to agricultural or 
mixed-use areas. Copper, lead, and zinc exceeded water quality criteria in over 50 percent of the samples, with copper most frequently detected in agricultural and mixed-use areas and zinc exceeding water quality criteria only in urban areas. Metals concentrations were higher in industrial samples, characterized with higher concentrations of suspended sediment, compared to residential samples. A total of 14 VOCs were detected in commercial or industrial urban areas with several toxic pollutants exceeding water quality criteria (primarily 1,1-dichloroethylene and PCE). No comparison to nonurban areas was made because nonurban samples were not collected: the authors deemed VOCs to be not important at nonurban sites. Organochlorine insecticides, including dieldrin, DDx (sum of DDT, DDD, and $\mathrm{DDE}$ ), endosulfan, and heptachlor, and PCBs were detected at 14 of 39 sample locations. Dieldrin and DDx were most frequently detected in agricultural and urban areas. The highest concentrations of dieldrin were detected at an agricultural area. DDx was more frequently detected in urban than agricultural areas. PCBs followed closely behind with frequent detections in urban areas. Almost all organochlorine insecticides and PCBs exceeded water quality criteria. The USGS study indicated that the distribution of toxic pollutant detections reflected episodic conditions dependent on streamflow at the time of sampling, and may not have accurately represented Basin-wide concentrations. For example, detections of hydrophobic pollutants were correlated with high suspended sediment concentrations in water samples collected during high flow events (USGS, 1996). Many of the detected pesticides are legacy pollutants, yet are still being transported in stormwater runoff and into streams as a result of their hydrophobic characteristics. These pesticides remain sorbed to soils from historic pesticide use on upland surfaces (DEQ, 2015). While DEQ's 2015 Statewide Water Quality Toxics Assessment Report reported the most pollutant detections throughout the state to be associated with agricultural land, the largest variety of pollutant detections (including the Category 5 toxic pollutants) were reported in the Basin, associated with urban areas (DEQ, 2015).

Stormwater runoff from urban watersheds is a well-known contributor of toxic pollutants impairing surface water quality. Washington Department of Ecology's 2007 Spokane River PCB TMDL Stormwater Loading Analysis reported PCBs in stormwater discharging from stormwater outfalls and combined sewer overflows connected to upland urban areas of the City of Spokane. PCB concentrations showed a positive correlation to total suspended solids concentrations (WA Ecology, 2007b). A study on salmon spawning mortality in the Seattle Puget Sound identified discharges of PAHs (both low and high molecular weight) and metals (cadmium, copper, lead, and zinc) from highway runoff in urban areas of Seattle (Spromberg et al., 2016). The Seattle Puget Sound study correlated runoff concentrations of the toxic pollutants to impervious surface cover, attributed to exhaust, oil leaks, and break pad/tire abrasion from motor vehicles. It has been estimated that a range of 5 to $20 \%$ of pollutants released from vehicles (associated with abrasion from the road, tires, and brake pads, in addition to vehicle fluid releases) reach stormwater, with the remaining percentage drifting into the surrounding area by wind. Tire abrasion releases chromium, copper, lead, and zinc; brake pad abrasion releases chromium, copper, iron, and lead; incomplete combustion from engines and spills of oils and fuels releases PAHs (Göbel et al., 2007). A 2008 study of urban roads in a major German metropolitan city identified metals in stormwater runoff, reporting zinc as the most abundant toxic pollutant, followed by copper and lead, respectively (Helmreich et al., 2010). The German study attributed zinc concentrations in the stormwater to tire and brake pad wear, as well as leaching from galvanized surfaces located along the 
roadway, such as crash barriers and street signs (Helmreich et al., 2010). The German study identified a significant correlation between metals concentrations and suspended solids and identified higher metals concentrations in samples collected during cold seasons compared to warm seasons (resulting from the increased application of gravel during winter months).

Although toxic pollutant discharges from ODOT's state roadway outfalls were not quantifiable from available data sources, the detections of toxic pollutants (particularly PAHs and metals) in urban stormwater runoff from global studies can help to explain their presence in the Basin's streams where urban land uses prevail. For example, the Lower Willamette Basin is impaired with PAHs; urban land covers $45 \%$ of this subbasin with the Willamette River and many of its tributaries flowing through major metropolitan areas. Furthermore, all of the subbasins are impaired with metals; although the Basin as a whole is comprised of only $8.1 \%$ urban land, some individual subbasins are comprised of more urban land (e.g., 20\% in the Middle Willamette) and major metropolitan areas are located in the vicinity of the Willamette River and its tributaries. Thus, there is a high potential for toxic pollutants such as PAHs and metals to be discharged into the Basin's streams from ODOT's state roadway outfalls.

\subsubsection{Toxic Pollutant Sources by Activity}

Based on the evaluation of toxic pollutant loads reported from NPDES-permitted facilities throughout the Basin, an interesting observation was gathered (Figure 50). Most of the toxic pollutant impairments in the Basin cannot be explained by the NPDES-permitted facilities reporting annual toxic pollutant discharges (2007 to 2016) to the EPA's DMR and TRI program. Only three of the six toxic pollutant classes were reported by facilities in offsite discharges: metals, VOCs, and PAHs. All of the subbasins with metals impairments (nine toxic pollutants) can be partially explained by eight of the nine metals reported in discharges (thallium was not reported in discharges). Of these subbasins, the Clackamas had the most reported discharges of metals (seven) and the Molalla-Pudding had the least reported discharges of metals (three). The single subbasin with PAH impairments (Lower Willamette) can only be partially explained by some of the reported discharges of PAHs that consisted of only two toxic pollutants PAHs (of the 17 total PAHs): benzo(g,h,i)perylene and naphthalene. The three subbasins with VOC impairments (Upper Willamette, Tualatin, and Lower Willamette) can be explained by reported discharges of ammonia but can only be partially explained by reported discharges of two other constituents (of the eight total): cyanide and TCE. Reported discharges of cyanide were from facilities in three subbasins: Upper Willamette, Clackamas, and Lower Willamette. Reported discharges of TCE were from facilities in one subbasin: Upper Willamette.

The remaining toxic pollutants of the VOC and PAH toxic pollutant classes not reported in offsite discharges from NPDES-permitted facilities located in subbasins with impairments of PAHs and VOCs could be attributed to one of two scenarios (or both): a) the toxic pollutants are absent from the industrial activities and materials handled (Appendix D); and/or b) the facilities did not report these toxic pollutants to the DMR/TRI program (because not all industries are required to report pollutant discharges) (EPA, 2016c). These toxic pollutants could therefore be associated with nonpoint sources. For example, PCE loads were not reported by any of the identified permitted facilities, yet it is a known constituent in industrial processes, and most notably in dry cleaning operations (ATSDR, 2014a). Dry cleaning facilities in the Basin were not identified in EPA or DEQ databases, but this was expected given 
that dry cleaning facilities do not operate with NPDES permits. However, dry cleaning facilities were identified in DEQ's ECSI database as contaminated properties. This is an example of a toxic pollutant that can be associated with nonpoint sources. PCE is a TRI-listed and reportable pollutant (EPA, 2014, 2016c). Another example, PAHs were not reported in discharges by any of the identified permitted facilities, with exception for two of the 17 total, yet PAHs are known to be discharged in stormwater from various industrial activities (EPA, 2017c). Industries known to discharge PAHs in stormwater are the paper products and timber products industries and the mineral mining industries. PAHs (in addition to heavy metals) are constituents in oils and greases as well as diesel and gasoline fuels used during facility activities (EPA, 2006c, 2006b, 2006a). These facilities were identified in EPA's Water Pollution Search, DEQ's Wastewater permit, and the DOGAMI Mining Permit Viewer databases; however, pollutant loads of PAHs were not reported.

The remaining toxic pollutant classes not reported in offsite facility stormwater/wastewater discharges (PCBs, organochlorine insecticides, and organophosphorus insecticides) to the Basin's surface waters was an expected result. These toxic pollutants are typically not monitored for in NPDES permits, the majority are legacy pollutants, and pesticides are typically not associated with point source facilities with permitted stormwater/wastewater discharges, unless facilities process and/or manufacture pesticides. In the Lower Willamette River, however, PCB monitoring is a requirement of NPDES discharge permits issued to some point sources (DEQ, 2014). PCB discharges from point sources were not identified in EPA's pollutant reporting database. In the Basin, two pesticide manufacturing facilities were identified operating under NPDES permits: one pesticide chemical manufacturing facility was located in the Lower Willamette with permitted industrial wastewater discharges and one nitrogenous fertilizer/pesticide manufacturing facility was located in the Molalla-Pudding subbasin with permitted stormwater discharges. The toxic pollutants potentially discharged from these facilities are not known; they were not identified in EPA's pollutant reporting database. Other than the USGS PNSP results for the Basin and toxic pollutant-impacted Superfund Sites, no other toxic pollutant-containing pesticide sources were identified in the literature.

An unexpected observation gathered from the identification of Basin point sources was the number by subbasin. The top three subbasins with the most point sources were Yamhill (17\%), followed by Tualatin (16\%), and McKenzie (14\%). In terms of the most urban land use (coinciding with high populations), the Upper, Middle, and Lower Willamette subbasins would have been expected to have the most point sources, but they were ranked with the sixth (7.7\%), eighth (5.8\%), and fifth (8.4\%) most of the Basin's total quantity of point sources, respectively. The McKenzie subbasin is located in the southeastern portion of the Basin, which is predominantly forest land use (92\% of total land area), while the Yamhill and Tualatin subbasins are located in the northwestern portion of the Basin, a mix of forest (between $48 \%$ and 56\%), agriculture (between 26\% and 34\%), and urban (between $6 \%$ and 20\%) land uses (Appendix C). However, when looking at the individual NPDES-permitted facilities discharging stormwater/wastewater, the Tualatin subbasin had the most facilities (15\%), compared to the Yamhill (6\%) and McKenzie subbasins (2\%). The subbasins that did not have the most point sources actually had the most NPDES-permitted facilities: the Lower Willamette (24\%), Middle Willamette (19\%), and Upper 
Willamette (17\%) subbasins. These minor discrepancies could be related to the density of industrial and commercial facilities distributed in the specific areas of the Basin.

Direct and indirect discharges of toxic pollutants from the identified DOGAMI mining sites throughout the Basin could not be determined. Metals extraction via mining is a well-known contributor of toxic pollutant metals to receiving streams downhill from mining sites (Moore \& Luoma, 1990). Mining ore from the earth results in the production of tailings, slag, waste rocks, sediment, and air pollution that can contaminate surface waters in the immediate vicinity or downstream of the site and even at greater distances as a result of contaminants mobilized via dust to the air. Depending on the type of ore extracted, mine tailings contain some of the largest deposits of metals, including arsenic, copper, lead, silver, and zinc. Fisheries in Montana have been affected by metals contamination in surface waters (in sediment and solutes) as a result of nearby mining operations (Moore \& Luoma, 1990). The Black Butte Mine in Lane County (Coast Fork Willamette subbasin) is one such mine in the Basin with known contamination, identified as a Superfund Site for mercury and methylmercury contamination in soil, sediment, surface water, and groundwater. This mine was the largest mercury mine in Oregon, historically in operation from the late 1890s to the late 1960s, producing mercury-contaminated tailings immediately adjacent to a creek susceptible to erosion and downstream transport (DEQ, 2019). Although loads of toxic pollutant discharges from DOGAMI's mine sites were not quantified from available sources, the known association of toxic pollutants to mining activities in other geographic locations provide for an explanation of the presence of toxic pollutants in the Basin's streams downstream of historical mine operations. Thus, there is a high potential for toxic pollutant metals to have been discharged into the Basin's streams from historical (as well as currently active) DOGAMI mine sites.

Direct and indirect discharges of toxic pollutants from the identified contaminated sites (DEQ ECSI and EPA Superfund Sites) throughout the Basin could not be determined. Contaminated waste sites are potential contributors of toxic pollutants to surface waters, through direct and indirect transport pathways. Toxic pollutant contamination in soil and groundwater is found at numerous sites throughout several subbasins as a result of historical releases and require cleanup under DEQ and EPA cleanup programs. Many Superfund Sites located throughout the Basin, however, do have known offsite discharges of toxic pollutants. For example, within the 10-mile stretch of the lower Willamette River in the Lower Willamette subbasin, toxic pollutants (including PCBs, PAHs, VOCs, DDx, and metals) have been linked to industries and activities that historically operated upland and contributed contaminated inputs through multiple transport pathways (airborne, direct, and stormwater discharges). These facility activities include: shipyards (paint and other materials handled during construction repair, and breaking), pulp and paper mills, chemical wood treating facilities, railyards, industrial manufacturing facilities, electrical equipment repair facilities, chemical storage and hazardous waste sites, steel metal scrapping facilities, as well as natural riverbank erosion and urban stormwater runoff (DEQ, 2014; EPA, 2017d). Results obtained in this Project identified many of these types of facilities as point source NPDES-permitted facilities.

Other notable Superfund Sites with PCB contamination attributed to similar legacy industrial activities handling PCBs in similarly urbanized and industrialized areas include: the Lower Fox River, Wisconsin 
(notably from historical carbonless copy paper recycling plants); Green/Duwamish Waterway in Seattle, Washington (from various historical point and nonpoint sources); and Lower Hudson Bay in New York/New Jersey (from historical electrical equipment and pigment manufacturers) (Imamoglu \& Christensen, 2002; Rodenburg \& Ralston, 2016; Velleux \& Endicott, 1994; WA Ecology, 2014). In these cases, industrial and municipal wastewater treatment effluent was the primary source of PCBs to surface waters. PCB studies in the Houston Ship Channel (southeastern Texas) characterized all 209 PCB congeners and indicated higher concentrations of PCBs in outfall samples collected from wastewater treatment plant effluent (higher in industrial than municipal) compared to effluent samples representative of industrial facilities. The Texas study results were attributed to differences in treatment processes and the presence of suspended particles that PCBs sorbed to (Balasubramani et al., 2014). These cases demonstrate the magnitude of PCB distribution in waters across the U.S. attributed to the long history of industrialization of urban areas, similar to that found in the Basin.

In Oregon, several TMDLs have been issued for some of the Basin's toxic pollutants, revealing commonalities in sources, even across differing geographic regions. Many of these commonalities were obtained in the results of this Project. An ammonia TMDL for the Coast Fork Willamette subbasin linked sources to wastewater treatment plants (DEQ, 1995). A pesticides (DDT, aldrin, and dieldrin) TMDL for the Lower Willamette subbasin linked sources to historical agricultural insecticide uses, riverbank soil erosion, urban stormwater, and atmospheric deposition (DEQ, 2006b). A mercury TMDL for the Basin linked sources to industrial and municipal wastewater treatment plants, but mostly to nonpoint sources including legacy mines, sediment resuspension, historic mercury-sorbed soil erosion, stormwater runoff, and atmospheric deposition (DEQ, 2006a). An arsenic TMDL in the Molalla-Pudding subbasin linked sources to naturally occurring arsenic in rock and soil, but also to nonpoint sources including historic mining, wood preservation, and pesticide manufacturing and use (DEQ, 2008b). A pesticides TMDL (DDT, chlordane, and dieldrin) for the Molalla-Pudding subbasin linked sources to legacy agricultural applications that transported pesticides in sediment during stormwater runoff (DEQ, 2008a).

\subsubsection{Other Possible Sources of Toxic Pollutants}

Atmospheric deposition is likely a contributing factor to the Basin's toxic pollutant impairments. Pollutants emitted to the air from anthropogenic point and nonpoint sources, both locally and globally, can be deposited with washout from local and global sources directly onto surface water or onto land, mobilizing into stormwater runoff under certain conditions, and discharging into streams (ATSDR, 2000; Hernandez et al., 2003; Hope, 2008; Nicholson et al., 2006). A stormwater study within a Los Angeles, California watershed concluded that atmospheric deposition potentially contributed 57 to $100 \%$ of the mass loading of metals (chromium, copper, lead, and zinc) in stormwater runoff within the study area (Sabin et al., 2005). A PCB study of contamination in the Basin suggested that atmospheric deposition could be contributing high PCB concentrations in the Willamette River (primarily within the Portland Harbor Superfund Site), postulating emissions from industrialized Asian countries have contributed PCB particulates as a result of their ability to undergo long-range transport across the Pacific Ocean and fallout in dry or wet deposition (Hope, 2008). PCB emissions in Oregon between 1988 and 2005 identified no local releases, supporting the stance on global inputs of PCBs (Hope, 2008). Spray drift from local pesticide spraying applications and atmospheric deposition from local and global sources are 
known processes that contribute (and distribute) pesticides to surface waters, while their ultimate impact to the water is dependent on factors unique to their chemical characteristics (Holvoet et al., 2007).

Erosion of contaminated soils could be contributing toxic pollutants to the Basin's surface waters. Metals content of fertilizers in Oregon is strictly controlled by the Oregon Department of Agriculture (ODA, 2019). The DEQ regulates land applications of pretreated biosolids generated from municipal wastewater treatment plants (DEQ, 2018e). Although the application of fertilizers and pretreated sewage sludge onto agricultural land can be beneficial to crops for additional organic matter and nutrient content, toxic pollutants can inadvertently be added, becoming susceptible to release into the Basin's surface waters from stormwater runoff and riverbank erosion. Studies in China have shown toxic pollutant metals (including lead, copper, and zinc) at higher concentrations in soils amended with sewage sludge than in control soils (X. Wang et al., 2008). In apportioning sources of pollutants in China, fertilizer inputs was identified to be a potential source of mercury in agricultural soils (Huang et al., 2015). A European study analyzing phosphorus fertilizers collected from numerous countries identified arsenic, chromium, lead, and zinc at varying concentrations correlated to the concentration of phosphorus. The European study reported inputs of these metals to soils from fertilizer applications in the United Kingdom were similar to and even higher than inputs from atmospheric deposition (Nziguheba \& Smolders, 2008). Studies in Poland have also shown concentrations of PCBs in municipal sewage sludge (Dabrowska \& Rosińska, 2012). Pesticides historically applied to agricultural land in the Walla Walla Basin were identified by Washington Department of Ecology to be the primary source of chlorinated pesticides (DDE, DDD, dieldrin, chlordane, hexachlorobenzene, and heptachlor epoxide) in the Walla Walla River (WA Ecology, 2006). The 2006 Walla Walla River Chlorinated Pesticides and PCBs $T M D L$ reported a correlation between high concentrations of chlorinated pesticides and suspended sediment loads in surface water which coincided with high stream flow and sediment load (January to June) (WA Ecology, 2006). Soil erosion has also been identified as a primary source of DDT, dieldrin, and chlordane concentrations in surface waters of the Molalla-Pudding subbasin, attributed to historical pesticide applications on agricultural land (DEQ, 2008a).

Nonpoint sources of toxic pollutants can be identified in a watershed by conducting seasonal sampling. Washington Department of Ecology's 1999 evaluation of dissolved metals in the Spokane River indicated the presence of metals were attributed to seasonal variation, with higher concentrations of dissolved metals found in the spring from high river flows (WA Ecology, 1999). DEQ's 2015 Statewide Water Quality Toxics Assessment Report reported similar results, with higher metals concentrations found in samples collected during rainy spring and fall months compared to drier summer months (DEQ, 2015). Many of the existing TMDLs that DEQ and other state agencies have issued attributed toxic pollutant discharges to seasonal variation, reporting higher concentrations during periods of high precipitation levels and stormwater flow, an indication of nonpoint source stormwater runoff. Furthermore, many of the organic pollutants detected in subbasin streams were correlated with suspended solids concentrations, where organics such as PCBs and chlorinated pesticides sorbed to solid matter and became entrained in stormwater runoff (DEQ, 1995, 2006b, 2006a, 2008b, 2008a, 2015; WA Ecology, $1999,2006)$. Correlations between high mercury concentrations and increased river flow were reported 
in the Lower Fox River (Wisconsin), adding observances of higher mercury concentrations in the presence of suspended particles as a result of resuspension from river dynamics (Hurley et al., 1998). These studies suggest that a variety of toxic pollutants are associated with nonpoint sources, attaching to soil and organic matter after release from their source and mobilizing with stormwater runoff, indirectly discharging to surface waters. Dissolved organic matter and suspended solids in water attract hydrophobic pollutants (i.e., PCBs, chlorinated pesticides, and some PAHs) but also some metals (iron, copper, mercury, and zinc). (Balasubramani et al., 2014; Bronner \& Goss, 2011; Cortes et al., 1991; Hegeman et al., 1995; Jaffé, 1991; Karickhoff et al., 1979; Tülp et al., 2009; Y. Yang et al., 2013; Yu et al., 2017). Sorption of hydrophobic pollutants to soil is dependent on the specific soil chemical characteristics. Pollutant uptake is enhanced as organic matter and solids increases, accumulating during transport and persisting at the site of release/deposition (Ter Laak et al., 2009).

Site-specific geology could also play a role in the spatial and temporal variation in metals-contaminated surface waters throughout the Basin. Arsenic and iron occur naturally in geologic soils and rocks and commonly exceed state water quality criteria in surface waters (DEQ, 2008b, 2015, 2018d). The geology of a watershed forms the background of water quality pollutants, with hydrogeochemical processes controlling the mobility and flow path of natural metals from upstream lands into surface waters (Nordstrom, 2011). Nevertheless, the magnitude of stormwater runoff transporting metals to the Basin's streams and rivers more than likely has altered over time due to altered land use practices, population fluctuations, changes to regulations of permitted discharges, and climatic factors (i.e., increases or decreases in precipitation) (DEQ, 2015).

\subsection{Chemical Characteristic Clustering}

\subsubsection{Evaluation of Cluster Results}

The results of the multivariate data analyses show that while chemical classification generally describes similarities in molecular structure (i.e., metals, PAHs, etc.), chemical characteristics more closely describes similarities in environmental behavior (i.e., soluble, hydrophobic, etc.). This distinction is more informative and applicable to TMDL development. Furthermore, results of the analyses illustrate patterns and relationships among the toxic pollutants associated to chemical characteristics.

Metals exhibit high magnitudes of solubility and the highest of all the toxic pollutants evaluated (although followed closely by VOCs). Metals exhibit considerable variation in vapor pressure, depending on individual chemical structures. Cluster 1 metals exhibit markedly higher values of solubility and lower values of volatility, compared to the Cluster 2 metals. Therefore, the discrimination of metals into two clusters is reasonable. The NMDS plot revealed Cluster 1 metals located closer together than the Cluster 2 metals. The Cluster 2 metals, however, are spaced slightly further apart. Particularly, arsenic and mercury are located at opposite ends of the NMDS space within the cluster, indicating a much higher and lower value of solubility, respectively. Based on the similarity of behaviors, metals in Clusters 1 and 2 would not be found in Clusters 3 or 4 .

The organochlorine and organophosphorus insecticides exhibit varied chemical characteristics, with exception for some similarities in vapor pressure values. Organophosphorus insecticides consisted of 
only two toxic pollutants, both exhibiting fairly similar chemical characteristics. Thus, these toxic pollutants were appropriately combined into a single cluster (Cluster 3 ). Six of the organochlorine toxic pollutants, however, were included in the same cluster as the organophosphorus toxic pollutants (Cluster 3). But these Cluster 3 organochlorine and organophosphorus insecticides exhibit fairly similar magnitudes of the five chemical characteristics, in particular vapor pressure. Furthermore, while the Cluster 3 and Cluster 4 organochlorine insecticides exhibit somewhat similar ranges in volatility (specifically vapor pressure), the Cluster 4 organochlorine insecticides exhibit higher values of $\mathrm{K}_{\mathrm{oc}}$ and $\mathrm{K}_{\text {ow }}$. Therefore, the placement of six organochlorine insecticides in Clusters 3 and the remaining five in Cluster 4 is justified. The NMDS plot indicates their similarities and supports the clustering analysis, as the Cluster 3 organochlorine insecticides are located closer to each other (although more widespread in the Cluster) compared to the Cluster 4 organochlorine insecticides. The Cluster 3 organochlorine insecticides surround the organophosphorus insecticides in the NMDS space, further suggesting more similarities to each other than to the Cluster 4 organochlorine insecticides.

PAHs exhibit a wide range of behaviors, owing to their chemical structure where there are sub-classes according to molecular weight. Given this, it is reasonable for PAHs to be included in two clusters (Cluster 3 and 4). Furthermore, because of their marked volatility and sorption (depending on the individual toxic pollutant), PAHs are clustered with pesticides and PCBs that exhibit similar characteristics, as expected. For example, individual PAH toxic pollutants with four to six aromatic rings have higher molecular weight and thus exhibit less volatility and stronger sorption capacity. These PAHs include benzo(a)anthracene and chrysene (among others) grouped in Cluster 4 with the more hydrophobic organochlorine insecticides DDT/DDE, as well as PCBs. The NMDS plot revealed the positioning of the PAHs attributable to these molecular weight differences: Cluster 4 PAHs are located closer together than Cluster 3 PAHs. Furthermore, Cluster 3 PAHs located further left within the NMDS space exhibit higher volatility and Cluster $3 \mathrm{PAHs}$ further right within the NMDS space exhibit less volatility and more sorption ( $\mathrm{K}_{\mathrm{ow}}$ and $\mathrm{K}_{\mathrm{oc}}$ ).

PCBs exhibit a wide range of chemical characteristic values, yet are predominantly the most hydrophobic of all the toxic pollutants (as a class). Because PCBs were evaluated as total PCBs, they were found only in Cluster 4. Based on sorption capacity and hydrophobicity ( $\mathrm{K}_{\mathrm{Oc}}$ and $\mathrm{K}_{\mathrm{ow}}$ ) values alone, the combination of PCBs with other toxic pollutants exhibiting similar characteristics in Cluster 4 is reasonable and total PCBs should not be found in any other cluster with opposite characteristic values. Given that chemical characteristics vary for the 209 PCB congeners, these congeners would likely be grouped into more than one cluster, sharing similarities with other toxic pollutants. The NMDS plot shows PCBs located furthest away from its Cluster 4 toxic pollutants, which was expected given that PCBs exhibit the highest $\mathrm{K}_{\mathrm{ow}}$ values (when evaluated as total PCBs).

VOCs exhibit the highest vapor pressures of all the toxic pollutants evaluated, and thus, are less hydrophobic $\left(\mathrm{K}_{\mathrm{OC}}\right)$. Yet, some VOCs also exhibit high solubility. Because of this, VOCs are accurately represented in Cluster 2 and in the NMDS space cluster (in the direction of the vapor pressure vector). Ammonia was considered a VOC and it exhibits magnitudes of water solubility and vapor pressure far greater than the Cluster 2 VOCs, but similar in magnitude as the three metals in its cluster (Cluster 1). Although six VOCs and six metals in Cluster 2 exhibit varying ranges of solubility, the clustering of these 
toxic pollutants is reasonable given the similar magnitudes of vapor pressure and $\mathrm{K}_{\mathrm{oc}}$, compared to the characteristics of the Cluster 1 metals. The NMDS plot revealed Cluster 2 VOCs are located fairly close to each other, indicating similarities, while ammonia is located the furthest away in Cluster 1 indicating its magnitude of behavioral differences to the other VOCs.

\subsubsection{Evaluation of Clustering Applications in Other Studies}

The evaluation and application of chemical characteristics in mass balance pollutant modeling has been widely studied (D. Mackay, 2013). Mackay describes the driving forces of chemical thermodynamic processes for environmental fate and transport modeling using simple mass balance models to predict the partitioning preferences of various pollutants (D. Mackay, 2013; D. Mackay et al., 2001, 1992; Donald Mackay et al., 1997; Wania \& Mackay, 1998; Webster et al., 2005). No studies were found in the literature that used statistical methodologies to group pollutants on the basis of chemical characteristics for application in surface water quality modeling intended for TMDL development. Methods applied in and results obtained from the cluster analysis in this Project were consistent with only a few studies evaluating chemicals on the basis of chemical characteristics (Gramatica et al., 2004; Servien et al., 2014).

In a 2014 study, the applicability of a method that could predict environmental behaviors of new chemicals that have not yet undergone rigorous toxicity assessments was tested using cluster analysis and other multivariate techniques (Servien et al., 2014). This 2014 study classified 215 organic chemicals (pesticides, PAHs, VOCs, and others) on the basis of their chemical and physical characteristics (Servien et al., 2014). Indicated by this current Project, and consistent with results from Servien et al (2014), evaluating a multitude of toxic pollutants for modeling applications is a time consuming process, yet it can be simplified using similarities in chemical behaviors well defined in the literature. Servien et al (2014), however, considered both molecular descriptors as well as behaviors, applying partial least squares (PLS) regression analysis to correlate the two variables (using $R$ and other software). Molecular descriptors included those used in QSAR assessments, including atomic structure, molecular surface, dipole moment, and others. Behaviors considered included those most common in environmental fate processes and data availability, including dissolution (using solubility and $\mathrm{K}_{\mathrm{ow}}$ ), volatilization (using vapor pressure and Henry's Law Constant), adsorption ( $\mathrm{K}_{\mathrm{OC}}$ ), degradation (using half-life), and bioaccumulation (using bioaccumulation factor). The methodology Servien et al (2014) applied resulted in the 215 chemicals grouped into six clusters (varying quantities in each), with each cluster dominated by different characteristics specific to behavior consistent with the literature. Servien et al (2014) concluded that the methodology applied had a high predictive quality of clustering chemicals together that exhibit similar behaviors and the behavior of new chemicals in the environment would be appropriately predicted.

The methodology applied and the results obtained in this Project are consistent with results from Servien et al (2014). All five of the chemical characteristics were similarly evaluated, with exception for degradation. Many of the same organic pollutant classes were evaluated (PCBs, PAHs, VOCs, and some pesticides). Degradation was not considered as a chemical characteristic for analysis in this Project, given the limited data found in the literature and also the wide ranges of values reported where data were available. Furthermore, molecular descriptors were not considered in this strategy in order to keep the methodology and data analysis as simple as possible. Finally, relationships identified by the cluster 
analysis and PLS results from Servient et al (2014) were similar (although PLS was not used in this Project): several groupings of chemicals were identified according to similarities of environmental behaviors shared and not grouping entirely by chemical classes.

Multivariate statistical methods were used in a Texas water quality study for proposing an efficient method of developing bacteria TMDLs for multiple watersheds (Paul, 2003). The methodology clustered Texas watersheds comprised of 110 bacteria-impaired stream segments on the basis of similar watershed characteristics and bacteria sources. The results of the clustering were applied to other watersheds in the same cluster where there was limited data. Cluster analysis and several other multivariate techniques were applied to evaluate numerous watershed variables likely to be affecting bacteria concentrations, resulting in five waterbody clusters. Watershed variables for clustering included: point and nonpoint sources (such as confined animal feeding operations and wastewater treatment plants), seasonal variability in bacteria concentrations, climate, land use, and stream density. The results indicated point and nonpoint sources most likely contributing to instream bacteria concentrations, differentiated by the clusters of bacteria concentrations. The results showed simulations of calibrated watersheds within a cluster yielded similar trends of bacteria reductions for the same model input parameters for other watersheds (with similar characteristics) in the same cluster. Out of 20 different surface water quality models reviewed, Paul (2003) concluded that HSPF was the only model that could simulate bacteria loading in all clustered streams. Limitations to accuracy and uncertainty in the model simulations indicated the need for improved knowledge in hydrologic input parameters and more specific information on the inputs of point/nonpoint sources. Although the Paul (2003) study evaluated bacteria stream impairments, the objectives and methodology applied were consistent with those outlined in this Project. Although the Paul (2003) study did not evaluate similarities in pollutants, the most intriguing aspect was the positive result indicating the feasibility of grouping watersheds based on similar characteristics and the use of the HSPF model for all watershed simulations.

Many research studies around the globe have utilized multivariate statistical techniques, particularly cluster analysis, to address water quality issues and make informed management decisions with the goal of improving water quality. Cluster analysis was used to evaluate water quality data in Taiwan to group stream gauge sites based on hydrologic similarities (Lin \& Wang, 2006). The similarities were used to evaluate nine hydrological factors with the objective of delineating 30 watersheds comprised of numerous ungauged sites. The results of the cluster analysis were used in a classification model that contained a set of regression models and assigned ungauged sites to clustered gauge sites according to the similar hydrological factors (Lin \& Wang, 2006). In the U.S., the USGS utilized cluster analysis to evaluate water quality data with the objective of delineating hydrologic-landscape regions across the U.S. (Wolock et al., 2011). Watersheds were clustered based on similar hydrogeological and climatic characteristics influencing water quality conditions and trends (Wolock et al., 2011). In Scotland, cluster analysis was used to evaluate water quality data to explain spatial and temporal water quality patterns throughout a geographic area (Haggarty et al., 2012; McNeil et al., 2005). The results of the cluster analysis supported environmental management directives under a regulatory framework. In China, cluster analysis was used to evaluate lake water quality by identifying pollutants associated with point 
and nonpoint sources (Y. H. Yang et al., 2010). The cluster analysis was based on spatial and temporal variations in a watershed, grouping lakes according to similarities in physicochemical properties and water quality conditions of conventional pollutants. The cluster analysis results helped identify correlations between water quality and specific seasons, in addition to conventional pollutant sources to temporal variations. The cluster analysis results provided lake management strategies for controlling pollutant source discharges (Y. H. Yang et al., 2010).

These global studies utilizing cluster analysis share commonalities in their research purpose: to strategically approach water quality management issues using simple multivariate statistical techniques. These techniques reduce large datasets into manageable sizes, allowing for efficient analyses and generalized interpretations to be made, leading to effective decision making. The results of these global studies suggest that clusters of environmental variables sharing similar traits (gauging sites, watersheds, water quality data, etc.) can be used to predict and evaluate unknown variables of interest, addressing a larger quantity of water quality issues more effectively and reducing level of effort. The cluster analysis results of this Project, therefore, can be used to inform strategic management decisions by DEQ TMDL developers and help guide the selection of surface water quality models to efficiently simulate loads of toxic pollutants based on groupings of similar chemical characteristics of toxic pollutants.

While clustering is a commonly used multivariate statistical method for data reduction and pattern recognition, identifying patterns of relationships has been shown to be more applicable to decision making through a relationship-based clustering approach (Liang et al., 2019). This approach is formulated on the basis of identifying ecological cause-and-effect relationships (based on stressorresponse relationships), concluding that multiple environmental factors must be considered to obtain comprehensive results. While this methodology is not applicable to this Project, this approach could be considered in the linkage analysis step that DEQ will conduct during TMDL development, where the objective is to evaluate cause-and-effect relationships between pollutant sources and waterbody responses (EPA, 2008a). Adding rank-based criteria to this approach could benefit source assessment efforts and subsequent decision making by incorporating numeric water quality standards exceedances as a contributing factor to the cause-and-effect relationships between pollutant sources and waterbody impairments (D. Mackay et al., 2001).

\subsubsection{Additional Chemical Characteristics to Consider}

While the five chemical characteristics evaluated in this Project (to determine the groupings of the Basin's 48 toxic pollutants) are those primarily driving fate and transport processes in the environment, and widely used in surface water quality modeling, there are other variables that characterize pollutants These additional characteristics, both chemical and physical, include: molecular weight, half-life (i.e., degradation or decay rate), bioaccumulation factor (BAF), and bioconcentration factor (BCF).

- Molecular weight describes the sum of the mass of atoms present in a molecule's structure; the structure and weight of a molecule are attributes that provide insight to a pollutant's behavior (Schwarzenbach et al., 2017). Revealed by the NMDS plot, it was apparent that the individual PAH toxic pollutants were discriminated into two clusters based on their molecular weight: toxic pollutants with lower molecular weights were grouped together and toxic pollutants with higher 
molecular weights were grouped together. Molecular weight of a chemical is considered in QSAR applications (Cronin et al., 2003).

- Degradation/decay of a pollutant can occur under several processes in the presence of varying environmental conditions (e.g., photodegradation and hydrolysis) (Hemond \& Fechner-Levy, 2000). As a thermodynamic process, decay rate is used in pollutant mass balance models to calculate and predict the pollutant's fate over time (Hemond \& Fechner-Levy, 2000; Schwarzenbach et al., 2017). As described by Servien et al (2014), degradation was a valuable variable in discriminating groups of chemicals. Degradation rates vary by environmental media for each toxic pollutant (e.g., atmospheric decay versus decay in soil) (Appendix D). Furthermore, degradation/decay rates are limited in the literature: some pollutants have no reported rates while some have a wide range of rates (e.g., the half-life of DDT ranges from 22 to greater than 672 days, varying in different soil profiles around the globe) (ATSDR, 2002b). Degradation/decay is considered in QSAR applications (Cronin et al., 2003).

- BAF and BCF are calculated ratios used to predict the toxicity of a pollutant in aquatic species to understand (and predict) its persistence and accumulation. Both characteristics are indicators of a pollutant's affinity to absorb in fatty tissues because in water, some organic pollutants are capable of partitioning from water to aquatic species (some more than others) (Hemond \& Fechner-Levy, 2000; Rand, 1995; Schwarzenbach et al., 2017). However, BAF and BCF values are limited in the literature: some pollutants have no reported value and some have a wide range of values, with the more hydrophobic pollutants characterized with higher BAF and BCF values (e.g., PCBs) (ATSDR, 2000). BCF is considered in QSAR applications (Cronin et al., 2003).

Therefore, these four additional characteristics could be considered in the cluster analysis to potentially strengthen the statistical groupings of the Basin's toxic pollutants, in addition to potentially strengthening the toxic pollutant load calculations in TMDL models. Given that water quality standards are developed according to the most sensitive beneficial uses (i.e., aquatic species and drinking water for toxic pollutants), BAF and BCF would, therefore, be considered the most valuable characteristic of these additional four. 


\section{Limitations and Data Gaps}

The compilation of point and nonpoint sources was retrieved from publicly available information on the internet from state and federal regulatory databases. Therefore, the status of facilities identified in the Basin may change, as of the date data were downloaded. Further, while point and nonpoint sources of the Basin's toxic pollutants were obtained from published databases, limitations in data availability created challenges in identifying all potential sources.

- The DEQ's 2012 Integrated Report GIS geodatabase displays information from the 2012 Integrated Report and 303(d) list as it was submitted for review to EPA in November 2014. EPA partially approved the 303(d) list in December 2016 (DEQ, 2012a). This geodatabase does not identify listings (or delistings) that were disapproved by EPA, nor does it include 303(d) listings that were added by EPA as a result of the disapproval.

- DEQ's Wastewater Permit Database was last updated on August 27, 2018 (as of the date of this report). Significant changes to the point sources identified by this Project are not expected. Pollutant masses in stormwater/wastewater discharges authorized in NPDES permits for DEQ facilities are not reported in this database.

- The DOGAMI's "Permit Data Spreadsheet" was collected and compiled by DOGAMI as early as July 1, 1972 (DOGAMI, 2017). Some permits are no longer issued and thus, not identified in the data spreadsheet (example: Vegetation Permit Mine [VPM] for metals). DOGAMI's "Permit Data Spreadsheet" was updated on January 11, 2018 (as of the date of this report). Significant changes to the point sources identified by this Project are not expected. Pollutant masses in stormwater/wastewater discharges authorized in NPDES permits for mining sites is not reported in this database.

- Not all NPDES-permitted facilities that discharge to surface waters are required to report their discharges to EPA via DMR and TRI monitoring forms. Industrial point sources are required to report information to EPA's TRI if the facility meets certain criteria relating to the NAICS code, quantity of employees, and quantity of TRI chemicals processed onsite (EPA, 2016c). Not all point sources identified in DEQ's Wastewater Permit database for this Project were identified in EPA's Water Pollution Search Pollutant Loading Tool database.

- Only government agencies, some districts, and some large-scale pesticide applications are required to submit reports to DEQ regarding their pesticide applications under NPDES permits (DEQ, 2016). Not all NPDES-permitted pesticide applicators were identified for the Basin, given the reporting criteria.

- New and existing information on ODOT's stormwater outfalls inventory is collected by ODOT's Stormwater Program to identify locations via GIS mapping (ODOT, 2016). ODOT has not yet inventoried all permitted outfalls throughout the state; therefore, not all outfalls located throughout the Basin were identified in this Project.

- Under the USGS NPSP, the EPest high rates treat unreported pesticide-by-crop-use as unsurveyed. The USGS reports EPest low rates if a pesticide was not reported in a surveyed Crop Reporting District. The USGS calculated EPest rates from adjoining/nearby Crop Reporting Districts when data were not available for all Crop Reporting Districts for a particular year. Not 
all farms are surveyed and only harvested acres, not planted acres, are surveyed. Surveyed pesticide-by-crop use rates may not reflect all agricultural use on all crops (USGS, 2015). Pesticide applications were evaluated only for the years 2000 to 2016. Survey data prior to 2015 included estimates with pesticide treated seed applications. Data beginning in 2015 does not include pesticide treated seed applications. The quantity of pesticides applied for seed treatment was not reported separately. Total amount of pesticides reported in each county was evaluated for all land cover designated as agriculture in the National Land Cover Dataset for Oregon (2011). Therefore, the area of pesticides applied in each county may likely be an overestimate, given that specific land areas of pesticide applications were not reported.

- Discharges of toxic pollutants from DEQ's ECSI and EPA's Superfund Sites databases would require in-depth evaluation of site-specific contamination (DEQ, 2017c; EPA, 2018c). In addition, contaminated groundwater contributions to a specific surface waterbody is a complex process requiring site-specific hydrologic assessments (Davie, 2002). Therefore, identifying the specific Basin waterbodies impacted by toxic pollutant releases from DEQ and EPA cleanup sites could only be evaluated qualitatively.

- A large proportion of the 303(d)-listed toxic pollutants impairing the Basin were not identified in point source discharges (i.e., EPA's pollutant loading database) evaluated in this Project. Table 36 lists these data gaps, illustrating the challenges DEQ will face during development of many of the Basin's toxic pollutant TMDLs. 


\section{Conclusions and Recommendations}

Approximately $6,000 \mathrm{~km}$ (3,750 miles) of streams and rivers flowing through the Basin are listed on DEQ's 2012 303(d) list as impaired with 48 toxic pollutants, requiring the development of TMDLs to meet CWA Section 303(d) requirements. Environmental processes (i.e., hydrologic, soil, climatic dynamics), coupled with the unique chemical characteristics exhibited by these toxic pollutants, have contributed to the presence and magnitudes of water quality standard exceedances in the Basin that require attention in the form of TMDLs.

\subsection{Summary of Results}

Based on available data, metals, PAHs, and VOCs can be attributed to both point and nonpoint sources while PCBs, organochlorine insecticides and organophosphorus insecticides can be attributed to nonpoint sources. These toxic pollutants were discharged into the Basin's streams and rivers via permitted stormwater and wastewater (including non-permitted stormwater and wastewater) and via direct as well as indirect inputs from contaminated hazardous waste sites.

\section{Summary of Sources by Activity}

- 2,050 NPDES-permitted facilities (69\% non-POTWs and $31 \%$ POTWs) comprised $55 \%$ of the Basin's point sources, authorized to discharge stormwater and wastewater offsite.

- The annual daily flow of stormwater/wastewater discharges reported to EPA by NPDESpermitted facilities from 2007 to 2016 totaled $1.8 \times 1^{-02}$ MGD. Only utilities and manufacturing reported total daily flow volumes (two of the seven industry categories). The POTWs discharged the most volume (98.5\%) for all years reported.

- 13 of the 48 toxic pollutants were discharged in stormwater/wastewater reported to EPA by NPDES-permitted facilities into the Basin's surface waters (2007 to 2015) that included only three of the six toxic pollutant classes: VOCs (ammonia, cyanide, and TCE), PAHs (benzo(g,h,i)perylene)), and metals (arsenic, cadmium, chromium, copper, lead, methyl mercury, mercury, silver, and zinc). The majority of the discharged toxic pollutant loads included ammonia (99\% of the total mass), with zinc $(0.20 \%)$ and copper $(0.031 \%)$ reported in far lesser amounts. Only utilities (97\%), manufacturing (3.1\%), and real estate/retail $(0.0012 \%)$ reported toxic pollutant loads (three of the seven industry categories).

- Flow of stormwater/wastewater discharged by NPDES-permitted facilities from 2007 to 2015 were reported to EPA only by major discharge facilities, with a higher volume reported by major

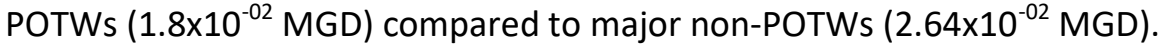

- 715 DOGAMI mining sites comprised $27 \%$ of the Basin's point sources, extracting metals and aggregate materials. Of this total, 51 mining sites (7.1\%), authorized to discharge stormwater/wastewater offsite.

- 522 ODOT outfalls comprised $14 \%$ of the Basin's point sources, authorized to discharge stormwater from state roadways. 
- 12,814 farms harvesting crops comprised 93\% of the Basin's nonpoint sources. Approximately 1.5 million $\mathrm{kg}$ ( 3.3 million Ibs) of 13 pesticides were applied to the Basin's agricultural land from 2000 to 2016, containing 1.1 million $\mathrm{kg}$ ( 2.5 million lbs, 77\%) of metals (copper and zinc), over $303,000 \mathrm{~kg}(668,000 \mathrm{lbs}, 20 \%)$ of organophosphorus insecticides (azinphos-methyl and chlorpyrifos), and over $36,700 \mathrm{~kg}$ ( $81,000 \mathrm{lbs}, 2.5 \%)$ of organochlorine insecticides (endosulfan).

- 927 ECSI Sites and 10 contaminated EPA Superfund Sites comprised 6.8\% of the Basin's nonpoint sources, contaminated with toxic pollutants (many located near/within surface waters).

\section{Summary of Sources by Geographic Area}

- Four of the 11 subbasins contained the most point sources at $12 \%$ to $18 \%$ of the total: Yamhill (17\%), Tualatin (16\%), McKenzie (14\%), and North Santiam (12\%).

- Three of the 11 subbasins contained the most nonpoint sources at $13 \%$ to $30 \%$ of the total: Upper Willamette (30\%), Middle Willamette (19\%), and Tualatin (14\%).

- Facilities reporting the most mass of toxic pollutant loads in offsite NPDES-permitted stormwater/wastewater discharges were located mostly in the Lower Willamette $(27.3 \%$ of the total), the Tualatin (26.5\%), and the Middle Willamette (26.2\%) subbasins. Pollutant loads of metals, PAHs, and VOCs were discharged from facilities located in a total of eight, one, and 11 subbasins, respectively.

- NPDES-permitted facilities reporting the most flow volume (in MGD) offsite were located mostly in the Tualatin (69\% of the total volume), the Middle Willamette $(8.5 \%)$, and the Lower Willamette $(7.3 \%)$ subbasins.

- ECSI sites were associated mostly with industrial/manufacturing (38\% of the total sites) and located mostly in the Lower Willamette $(60 \%)$, followed by dry cleaners/laundromats $(9.6 \%)$ located in the Lower Willamette (40\%), and "study areas" (7.3\%) located in the Lower Willamette (45\%). $37 \%$ of the ECSI sites were impacted by metals, $35 \%$ were impacted by VOCs, $13 \%$ were impacted by PAHs, $9.6 \%$ were impacted by $\mathrm{PCBs}$, and $4.8 \%$ were impacted by organochlorine insecticides. Sites impacted by metals, PAHs, PCBs, VOCs, and organochlorine insecticides were located in the Lower Willamette.

- Approximately $63 \%$ of the point source facilities were located on urban land, whereas $18 \%$ were located on agricultural land, and $13 \%$ were located on forest land.

- Approximately $93 \%$ of the number of nonpoint source facilities were located on agricultural land, whereas only $6.2 \%$ were located on urban land uses, and only $0.25 \%$ were located on forest land. However, when considering only the contaminated sites (DEQ ECSI Sites and EPA Superfund Sites), 91\% were located on urban land, whereas 3.6\% were located on forest land, and only $3.4 \%$ were located on agricultural land.

\subsection{Recommendations}

This Project proposed a strategy of grouping the Basin's 48 toxic pollutants listed on Oregon's 2012 CWA 303(d) list into clusters according to chemical characteristic similarities using multivariate statistical techniques. Cluster analysis results revealed that the Basin's 48 toxic pollutants could be addressed in four statistically significant groups of TMDLs for the Basin, discriminated by similarities in environmental 
behavior: soluble toxic pollutants (Cluster 1 ), more volatile toxic pollutants (Cluster 2), less volatile toxic pollutants (Cluster 3), and hydrophobic toxic pollutants (Cluster 4). NMDS analysis revealed the Basin's 48 toxic pollutants could be grouped by their chemical characteristic and generally not pollutant class. These toxic pollutant clusters form the basis of the proposed strategy for DEQ to develop grouped toxic pollutant TMDLs for the Basin (Figure 51). This Project illustrates that multivariate analytical techniques are useful tools for environmental management and can be applied to the development of multiple and concurrent TMDLs throughout a large-scale watershed. The results obtained from this Project indicate a significant (potential) reduction in time for developing 48 toxic pollutant TMDLs (Figure 52). Further analysis is required, however, through DEQ's calibration and assessment of a chosen TMDL surface water quality model to the cluster results in order to effectively simulate and determine the Basin's toxic pollutant loads. The model used for calculating pollutant reduction scenarios can be any of the three models DEQ intends to use, previously described in Section 2.3: HSPF, SWAT, or WASP. As listed in Table 3, there are numerous surface water quality models available and many are capable of simulating toxic pollutants (some are capable of only simulating pesticides and some are capable of simulating only metals). However, significant time and costs are associated with many of these other models (Table 4). A variety of models have been used by other state environmental agencies to calculate toxic pollutant load reductions for TMDLs (Section 2.3), but HSPF, SWAT, and WASP are commonly used in TMDL development, and DEQ has previously used these in existing Basin TMDLs to calculate load reductions.

\section{Recommendations on Approaches to TMDL Development}

EPA encourages the development of watershed TMDLs, which have been successfully developed by several state environmental agencies, emphasizing the importance of continued water quality monitoring after TMDLs are issued for successful implementation (EPA, 2008a). Water quality modeling complexity increases when pollutant transport is simulated across large watersheds, requiring additional hydrological inputs (such as climate data, soil property data, and vegetation cover, among others) (Shoemaker et al., 2005). Grouping watershed models by similar land characteristics (such as land cover, soil type, etc.) within subbasins and linking hydrological networks within the models could reduce simulation complexity. Hierarchical clustering has shown to be advantageous for TMDL development in grouping waterbodies or watersheds that display similar hydrologic characteristics, with model simulations producing reasonable agreements between observed and model-predicted in-stream concentrations. Rather than developing a basin-wide TMDL that may not capture all relevant details in terms of pollutant transport, hydrologic dynamics, as well as pollutant sources, DEQ management strategies should also consider developing toxic pollutant TMDLs by geographic area (such as at the subbasin level) according to statistically-evaluated similarities in watershed characteristics, potentially combined with similarities in pollutant impairments.

Additional efficiencies in development of the Basin's toxic pollutant TMDLs can be realized where modeling is conducted (and TMDLs are developed) only for the impaired subbasins. As illustrated in Figure 51, subbasins grouped by impairment of toxic pollutant class are associated with their corresponding toxic pollutant cluster. For example, VOC impairments are found only in three subbasins: Lower Willamette, Middle Willamette, and Tualatin. The clusters containing the Basin's VOCs are Clusters 1 and 2. Thus, modeling these clusters of VOCs to simulate and set toxic pollutant loads of VOCs 
comprises roughly one-third of the subbasins, resulting in roughly one-third the level of effort needed for developing the Basin's VOC TMDLs. Likewise, PAH impairments are found only in a single subbasin: the Lower Willamette. The clusters containing the Basin's PAHs are Clusters 3 and 4. Thus, modeling these clusters of PAHs only comprise approximately $9 \%$ of the subbasins, resulting in approximately $9 \%$ the level of effort needed for developing the Basin's PAH TMDLs. However, each toxic pollutant cluster will need to be modeled within each cluster, with results calibrated from one toxic pollutant to the remaining toxic pollutants in that cluster. Nevertheless, modeling clusters of toxic pollutants for only the impaired subbasins would greatly reduce the level of effort and resources required.

\section{Recommendations on Data Analysis for TMDL Development}

Many state environmental agencies use surrogates for developing pollutant TMDLs, in lieu of the actual pollutant requiring load reductions, which EPA approves the use of (EPA, 2018d). DEQ frequently uses surrogate measures to estimate pollutant allocations if the pollutant is difficult to measure and/or is highly variable, which is related to the target pollutant where correlations between the surrogate and target pollutants can be established (DEQ, 2011). Percent impervious cover was used as a surrogate for metals, organochlorine insecticides, organophosphorus insecticides, PCBs, and VOCs in Ohio, Maine, and Connecticut TMDLs (CDEP, 2007; MDEP, 2012; OEPA, 2012). Total suspended solids (TSS) was used as a surrogate for organochlorine insecticides and PCBs in Oregon, California and Washington TMDLs (Art Johnson, Brandee Era-Miller, Randy Coots, 2004; CRWQCB, 2008; DEQ, 2008a; WA Ecology, 2007a). Reductions in dissolved organic carbon was used as a surrogate for metals and a toxicity rule for fish tissue concentrations was used as a surrogate for PCBs in California TMDLs (CRWQCB, 2008). Aquatic organism toxicity response was used as a surrogate for organochlorine insecticides in California TMDLs (CRWQCB, 2008) (CRWQCB, 2005). And finally, Total Kjeldahl Nitrogen was used as a surrogate for ammonia in Ohio TMDLs (Kasich et al., 2013; OEPA, 2012).

Based on these surrogate examples developed by other environmental state agencies, TSS would be the most appropriate surrogate; reducing percent impervious cover in urbanized watersheds would not be feasible, especially when the population in metropolitan areas continues to increase. For these reasons, TSS should be considered as a surrogate for some of the Basin's toxic pollutant TMDLs to increase the efficiency in the grouped TMDL development approach. The organic toxic pollutants (most notably PCBs and pesticides) can be correlated with TSS which is aligned with the high $\mathrm{K}_{\mathrm{ow}}$ and $\mathrm{K}_{\mathrm{oc}}$ values exhibited, attaching to soil/sediment. The subbasins impaired by these organic pollutants include the following: Tualatin, Clackamas, Molalla-Pudding, Lower Willamette, Middle Willamette, Upper Willamette, and Yamhill (Figure 2). Given that these toxic pollutants are grouped primarily in Clusters 3 and 4, by developing TSS TMDLs as surrogates for these toxic pollutants and only in these seven subbasins, additional efficiencies can be gained in addressing multiple pollutants across multiple subbasins (Figure 43).

\section{Recommendations on Prioritization of the Basin's TMDLs}

Prioritization of the Basin's toxic pollutant TMDLs should consider: 1) pollutant toxicity risks to the Basin's beneficial uses and 2) geographic area of toxic pollutant impairments in the Basin. 
While all of the Basin's toxic pollutants are considered toxic and priority pollutants under the CWA, chlorpyrifos (an organophosphorus insecticide) is a "pesticide of concern" for the DEQ (DEQ, 2018a; EPA, 2014). Methylmercury is highly toxic, exhibiting bioaccumulation and persistence in aquatic environments (ATSDR, 1999). It's important to note that mercury impairments in the Basin are currently being addressed in an updated Basin-wide TMDL, scheduled to be completed by the end of 2019. PCBs and DDx are also highly bioaccumulative and persistent in aquatic environments (ATSDR, 2000, 2002b). EPA identified PCBs and DDx as "focus contaminants of concern" that are driving remedial cleanup of contaminated sediment in certain areas of the Portland Harbor Superfund Site, located in the Lower Willamette subbasin (EPA, 2017d). In addition to PCBs and DDx driving cleanup, EPA also identified carcinogenic PAHs (cPAHs) as "focus contaminants of concern" at this Superfund Site. PAHs classified as cPAHs include the following, which are toxic pollutants in the Basin: benzo(a)anthracene, benzo(a)pyrene, benzo(b)fluoranthene, benzo(k)fluoranthene, chrysene, dibenzo(a,h)anthracene, and indeno(1,2,3-c,d)pyrene (ATSDR, 1996c). Subbasins with toxic pollutant-impacted Superfund Sites should be considered a priority, given that many sites are impaired by a variety of (and many with multiple) toxic pollutants that have transport pathways to the Willamette River (Table 23).

For these reasons, the toxic pollutants posing the highest toxicological risks to aquatic organisms and humans should be given a higher priority, with the Lower Willamette subbasin prioritized first; the remaining subbasins with toxic pollutant-impacted Superfund Sites should be subsequently addressed (Table 37). Additional efficiencies in TMDL development can be gained with this prioritization approach, given that several of these higher priority toxic pollutants are grouped in the same cluster: CPAHs, DDx, and PCBs in Cluster 4 and the remaining PAHs and chloryprifos in Cluster 3 (Figure 51).

\section{Benefits of TMDLs}

In accordance with the CWA, TMDLs offer numerous benefits, given that their primary objective is to restore water quality for beneficial uses. With the strategized approach to develop the Basin's toxic pollutant TMDLs according to four clusters, a significant amount of time, level of effort, and required resources could be reduced. Through this approach, time and money saved could be directed to other efforts aligned with DEQ's water quality management objectives for the Basin (and the rest of the state). For example, the resources gained (staff time and money) could be used to further support and strengthen DEQ's adaptive management approach to TMDL development. This would allow for continuous improvement of internal processes, designating valuable time for the imperative interactions needed between local/state/federal agencies during TMDL implementation to address water quality issues and identify immediate solutions.

Developing grouped TMDLs according to this Project's strategy of toxic pollutant clusters would not only benefit DEQ's efforts, but efficiently addressing toxic pollutant impairments under a shortened schedule would most importantly expedite the improvement of water quality for an aquatic environment that is safe and healthy, benefiting humans and aquatic organisms dependent on surface water of exceptional quality. The improvement of the Basin's water quality under a shortened schedule would also promote the Basin's thriving economy, which relies on the many beneficial uses that promote health and business. Drinking water, fishing, and contact water recreation are beneficial uses of particular concern 
where toxic pollutant impairments are present in surface water. Furthermore, similar to EPA's objectives of Superfund Site cleanup, meeting CWA requirements by addressing the most sensitive beneficial uses in TMDLs ensures that the severity of adverse health effects (particularly cancer risks) are minimized or completely eliminated. Therefore, efficiently developing TMDLs for the Basin's 48 toxic pollutants through a clustered model approach by subbasin, based on similarities in chemical characteristics, could simultaneously meet requirements of the CWA and the needs of DEQ TMDL developers. 


\section{References}

Art Johnson, Brandee Era-Miller, Randy Coots, and S. G. (2004). A Total Maximum Daily Load Evaluation for Chlorinated Pesticides and PCBs in the Walla Walla River. Retrieved from https://fortress.wa.gov/ecy/publications/documents/0403032.pdf

ATSDR. (1990). Toxicological Profile for Silver. https://doi.org/10.1017/CBO9781107415324.004

ATSDR. (1992). Toxicological Profile for Thallium. Retrieved from https://www.atsdr.cdc.gov/toxprofiles/index.asp\#D

ATSDR. (1994a). Toxicological Profile for 1,1-Dichloroethene. https://doi.org/10.3109/15569529909037564

ATSDR. (1994b). Toxicological Profile for Chlordane. Retrieved from https://www.atsdr.cdc.gov/toxprofiles/index.asp\#D

ATSDR. (1996a). Toxicological Profile for 1,2-dichloroethene. Retrieved from https://www.atsdr.cdc.gov/toxprofiles/index.asp\#D

ATSDR. (1996b). Toxicological Profile for Endrin. https://doi.org/http://dx.doi.org/10.1155/2013/286524

ATSDR. (1996c). Toxicological Profile for PAHs. https://doi.org/10.3109/15569529909037564

ATSDR. (1997). Toxicological Profile for Chlorpyrifos. https://doi.org/http://dx.doi.org/10.1155/2013/286524

ATSDR. (1999). Toxicological Profile for Mercury. https://doi.org/10.1201/9781420061888_ch109

ATSDR. (2000). Toxicological Profile for PCBs. Retrieved from https://www.atsdr.cdc.gov/toxprofiles/index.asp\#D

ATSDR. (2002a). Toxicological Profile for Aldrin / Dieldrin. Retrieved from https://www.atsdr.cdc.gov/toxprofiles/index.asp\#D

ATSDR. (2002b). Toxicological Profile for DDT, DDE, and DDD. https://doi.org/CAS\#: DDT 50-29-3; DDE 72-55-9; DDD 72-54-8

ATSDR. (2004a). Toxicological Profile for Ammonia. Retrieved from https://www.atsdr.cdc.gov/ToxProfiles/tp126.pdf

ATSDR. (2004b). Toxicological Profile for Copper. https://doi.org/doi:10.1201/9781420061888_ch106

ATSDR. (2005). Toxicological Profile for Zinc. https://doi.org/http://dx.doi.org/10.1155/2013/286524

ATSDR. (2006). Toxicological Profile for Cyanide. https://doi.org/10.1201/9781420061888_ch68

ATSDR. (2007a). Toxicological Profile for Arsenic. https://doi.org/http://dx.doi.org/10.1155/2013/286524 
ATSDR. (2007b). Toxicological Profile for Heptachlor and Heptachlor Epoxide. Retrieved from https://www.atsdr.cdc.gov/toxprofiles/index.asp\#D

ATSDR. (2007c). Toxicological Profile for Lead. https://doi.org/doi:10.1201/9781420061888_ch106

ATSDR. (2008). Toxicological Profile for Guthion. Retrieved from https://www.atsdr.cdc.gov/toxprofiles/index.asp\#D

ATSDR. (2012). Toxicological Profile for Chromium. Retrieved from https://www.atsdr.cdc.gov/toxprofiles/index.asp\#D

ATSDR. (2014a). Toxicological Profile for Tetrachloroethylene. https://doi.org/http://www.atsdr.cdc.gov/toxprofiles/tp18.pdf

ATSDR. (2014b). Toxicological Profile for Trichloroethylene. https://doi.org/http://www.atsdr.cdc.gov/toxprofiles/tp19.pdf

ATSDR. (2015). Toxicological Profile for Endosulfan. https://doi.org/http://dx.doi.org/10.1155/2013/286524

ATSDR. (2017). Toxicological Profiles. Retrieved November 25, 2011, from https://www.atsdr.cdc.gov/toxprofiles/index.asp

Balasubramani, A., Howell, N. L., \& Rifai, H. S. (2014). Polychlorinated biphenyls (PCBs) in industrial and municipal effluents: Concentrations, congener profiles, and partitioning onto particulates and organic carbon. Science of the Total Environment, 473-474, 702-713. https://doi.org/10.1016/j.scitotenv.2013.12.105

Bicknell, B., Imhoff, J., Kittle, J., Jobes, T., \& Donigian, A. (2001). Hydrologic Simulation Program - Fortran HSPF Version 12 User's Manual. Retrieved from https://searchworks.stanford.edu/view/5650433

Boyacioglu, H., \& Boyacioglu, H. (2008). Water pollution sources assessment by multivariate statistical methods in the Tahtali Basin, Turkey. Environmental Geology, 54(2), 275-282. https://doi.org/10.1007/s00254-007-0815-6

Bronner, G., \& Goss, K. U. (2011). Sorption of organic chemicals to soil organic matter: Influence of soil variability and ph dependence. Environmental Science and Technology, 45(4), 1307-1312. https://doi.org/10.1021/es102576e

Carle, M. V., Halpin, P. N., \& Stow, C. A. (2005). Patterns of Watershed Urbanization and Impacts on Water Quality. Journal of the American Water Resources Association, 27669, 693-708.

CDEP. (2007). A Total Maximum Daily Load Analysis for Eagleville Brook, Mansfield, CT. Retrieved from percent impervious cover (\%25 IC

Chen, H., Teng, Y., \& Wang, J. (2012). A framework of characteristics identification and source 
apportionment of water pollution in a river: A case study in the Jinjiang River, China. Water Science and Technology, 65(11), 2071-2078. https://doi.org/10.2166/wst.2012.118

Chen, Q., Mei, K., Dahlgren, R. A., Wang, T., Gong, J., \& Zhang, M. (2016). Impacts of land use and population density on seasonal surface water quality using a modified geographically weighted regression. Science of the Total Environment, 572, 450-466.

https://doi.org/10.1016/j.scitotenv.2016.08.052

Clarke, K., \& Warwick, R. (2001). Change in Marine Communities: An Approach to Statistical Analysis and Interpretation (2nd ed.). Primer-E Ltd. Retrieved from http://www.vliz.be/imisdocs/publications/213560.pdf

Cortes, J. A., Riego, A., Paya-Perez, B., \& Larsen, B. (1991). Soil Sorption of Co-Planar and Non-Planar PCBs. Toxicological and Environmental Chemistry, 31-32, 79-86.

Cronin, M. T. D., Walker, J. D., Jaworska, J. S., Comber, M. H. I., Watts, C. D., \& Worth, A. P. (2003). Use of QSAR in international decison-making frameworks to predict ecologic effects and environmental fate of chemical substances. Environmental Health Perspectives, 111(10), 1376-1390. https://doi.org/10.1289/ehp.5759

CRWQCB. (2005). Diazinon and Pesticide-Related Toxicity in Bay Area Urban Creeks Water Quality Attainment Strategy and Total Maximum Daily Load. https://doi.org/10.1038/nrn2648

CRWQCB. (2006). Mercury in San Francisco Bay, Proposed Basin Plan Amendment and Staff Report for Revised TMDL and Proposed Mercury Water Quality Objectives.

CRWQCB. (2008). Total Maximum Daily Load for PCBs in San Francisco Bay: Final Staff Report for Proposed Basin Plan Amendment. San Francisco. Retrieved from https://www.waterboards.ca.gov/sanfranciscobay/water_issues/programs/TMDLs/sfbaypcbs/PCBs TMDL Final Staff Report April2017.pdf

CWP. (2003). Impacts of Impervious Cover on Aquatic Systems. Retrieved from https://clear.uconn.edu/projects/TMDL/library/papers/Schueler_2003.pdf

Dabrowska, L., \& Rosińska, A. (2012). Change of PCBs and forms of heavy metals in sewage sludge during thermophilic anaerobic digestion. Chemosphere, 88(2), 168-173. https://doi.org/10.1016/j.chemosphere.2012.02.073

Davie, T. (2002). Fundamentals of Hydrology. (Second, Ed.). Routledge.

DEQ. (n.d.). Oregon DEQ TMDL Modeling Review. Retrieved from https://www.oregon.gov/deq/FilterDocs/tmdlmodelsguide.pdf DEQ. (1995). Coast Fork Willamette TMDL. Retrieved from 
https://www.oregon.gov/deq/FilterDocs/CFWillametteTMDL.pdf

DEQ. (2003). Fact Sheet: Sources of Polychlorinated Biphenyls.

DEQ. (2006a). Chapter 3: Willamette Basin Mercury TMDL.

DEQ. (2006b). Chapter 5: Lower Willamette Subbasin TMDL.

DEQ. (2006c). Willamette Basin TMDL Ch 1 Overview. Retrieved from http://www.oregon.gov/deq/FilterDocs/chpt1overview.pdf

DEQ. (2008a). Molalla-Pudding Subbasin TMDL Chapter 4: Pesticides. https://doi.org/10.1016/S02732300(05)80020-0

DEQ. (2008b). Molalla-Pudding Subbasin TMDL Chapter 6: Iron, Manganese, Arsenic, 26. Retrieved from https://www.oregon.gov/deq/FilterDocs/MoPudChapter6Metals.pdf

DEQ. (2009). Willamette Basin Rivers and Streams Assessment. Oregon Department of Environmental Quality. Retrieved from pdf

DEQ. Chapter 340 Division 42 Total Maximum Daily Loads, Pub. L. No. ORS 468 (2011). Retrieved from https://secure.sos.state.or.us/oard/displayDivisionRules.action?selectedDivision=1459

DEQ. (2012a). 2012 Integrated Report Geographic Information System. Retrieved from https://www.oregon.gov/deq/Data-and-Reports/Pages/GIS.aspx

DEQ. (2012b). Oregon's 2012 Integrated Report Assessment Database and 303(d) List. Retrieved February 24, 2017, from http://www.deq.state.or.us/wq/assessment/rpt2012/search.asp DEQ. (2014). Portland Harbor Upland Source Control Summary Report.

DEQ. (2015). Statewide Water Quality Toxics Assessment Report. Retrieved from https://www.oregon.gov/deq/wq/Pages/WQ-Monitoring-Statewide.aspx

DEQ. (2016). Pesticide General Permit (2300A) Table 1. Retrieved from https://www.oregon.gov/deq/FilterPermitsDocs/2300aTable1.pdf

DEQ. OAR 340-041 Water Quality Standards, Pub. L. No. ORS 468 (2017). Retrieved from https://secure.sos.state.or.us/oard/displayDivisionRules.action?selectedDivision=1458

DEQ. (2017b). Total Maximum Daily Loads - Willamette Basin. Retrieved January 16, 2018, from http://www.oregon.gov/deq/wq/tmdls/Pages/TMDLs-Willamette-Basin.aspx

DEQ. (2017c). Wastewater Permits Database. Retrieved November 1, 2017, from https://www.deq.state.or.us/wq/sisdata/sisdata.asp

DEQ. (2017d). Water Quality Assessment. Retrieved January 16, 2018, from http://www.oregon.gov/deq/wq/Pages/WQ-Assessment.aspx DEQ. (2018a). About Water and Pesticides. Retrieved January 10, 2018, from 
https://www.oregon.gov/ODA/programs/Pesticides/Water/Pages/AboutWaterPesticides.aspx DEQ. (2018b). DEQ Stream Location Identification Tool. Retrieved October 6, 2018, from http://hdcgcx2.deq.state.or.us/HVR291/?viewer=wqslit

DEQ. (2018c). Environmental Cleanup Site Information Database. Retrieved May 18, 2018, from https://www.oregon.gov/deq/Hazards-and-Cleanup/env-cleanup/Pages/ecsi.aspx DEQ. (2018d). Fact Sheet Background Levels of Metals in Soils for Cleanups. Retrieved from https://www.oregon.gov/deq/FilterDocs/cu-bkgrmetals.pdf DEQ. (2018e). Fact Sheet Biosolids: A Beneficial Resource. Retrieved from https://www.oregon.gov/deq/FilterDocs/bio-05wq002biosolids.pdf DEQ. (2018f). Fact Sheet Water Quality Permits for Metal Mining Activities. DEQ. (2018g). Total Maximum Daily Loads - Implementation Guidelines and Tools. Retrieved March 26, 2019, from https://www.oregon.gov/deq/wq/tmdls/Pages/TMDLs-Implementation.aspx

DEQ. (2019). ECSI Site ID 1657 Black Butte Mine. Retrieved from https://www.deq.state.or.us/lq/ECSI/ecsidetail.asp?seqnbr=1657

DOGAMI. (2017). Mining Permit Viewer. Retrieved October 13, 2017, from http://www.oregongeology.org/mlrr/permitviewer.htm

DOGAMI. (2018a). Surface Mining Permitting Process. Retrieved June 30, 2018, from http://www.oregongeology.org/mlrr/surfacemining.htm DOGAMI. (2018b). Water Quality Permitting Process. Retrieved June 30, 2018, from http://www.oregongeology.org/mlrr/waterquality.htm

EPA. (1976). PCBs in the United States Industrial Use and Environmental Distribution. Retrieved from https://nepis.epa.gov/Exe/ZyPURL.cgi?Dockey=20001275.txt

EPA. (1991). Guidance for Water Quality-based Decisions : The TMDL Process. https://doi.org/EPA 440/491-001

EPA. (2001). The National Costs to Develop TMDLs Draft Report: Support Document \#1 for The National Costs of the Total Maximum Daily Load Program (Vol. EPA 841-D-).

EPA. (2003a). Protecting Water Quality from Urban Runoff. EPA 841-F-03-003. Retrieved from https://nepis.epa.gov/Exe/ZyPDF.cgi/20004PP1.PDF?Dockey=20004PP1.PDF

EPA. (2003b). Table of PCB Species by Congener Number. https://doi.org/papers://E3BD4C0C-74F541EB-A364-4F15648D10A8/Paper/p69

EPA. (2005a). National Management Measures to Control Nonpoint Source Pollution from Forestry. Retrieved from https://www.epa.gov/sites/production/files/2015- 
10/documents/2005_05_09_nps_forestrymgmt_guidance.pdf

EPA. (2005b). Protecting Water Quality from Agricultural Runoff. EPA 841-F-05-001. https://doi.org/DC 20460 www.epa.gov/nps

EPA. (2006a). Industrial Stormwater Fact Sheet Series, Sector A: Timber Products Facilities. Retrieved from https://www.epa.gov/npdes/industrial-stormwater-fact-sheet-series

EPA. (2006b). Industrial Stormwater Fact Sheet Series, Sector B: Paper and Allied Products Manufacturing Facilities. Retrieved from https://www.epa.gov/npdes/industrial-stormwater-factsheet-series

EPA. (2006c). Industrial Stormwater Fact Sheet Series, Sector J: Mineral Mining and Processing Facilities.

EPA. (2008a). Handbook for Developing Watershed TMDLs. Retrieved from http://www2.epa.gov/sites/production/files/201510/documents/2009_01_09_tmdl_draft_handbook.pdf

EPA. (2008b). Polycyclic Aromatic Hydrocarbons, 4. Retrieved from https://archive.epa.gov/epawaste/hazard/wastemin/web/pdf/pahs.pdf

EPA. (2011). Ore Mining and Dressing Preliminary Study Report. Retrieved from https://www.epa.gov/sites/production/files/201605/documents/ore_mining_study_sept_2011.pdf

EPA. (2012). Sustainable Futures / P2 Framework Manual 2012 EPA-748-B12-001 Chapter 5 Estimating Physical / Chemical and Environmental Fate Properties with EPI Suite ${ }^{T M}$. Retrieved from https://www.epa.gov/sites/production/files/2015-05/documents/05.pdf

EPA. (2014). Priority Polluant List. Retrieved from https://www.epa.gov/sites/production/files/201509/documents/priority-pollutant-list-epa.pdf

EPA. (2015). Water Quality Progress Report, San Francisco Bay - Mercury (Approved 2008).

EPA. (2016a). About NPDES. Retrieved March 16, 2019, from https://www.epa.gov/npdes/about-npdes

EPA. (2016b). Pesticide Product and Label System. Retrieved from https://iaspub.epa.gov/apex/pesticides/f?p=PPLS:1

EPA. (2016c). Toxic Chemical Release Inventory Reporting Forms and Instructions. Retrieved from https://ofmpub.epa.gov/apex/guideme_ext/guideme_ext/r/files/static/v3321/rfi/RY_2016_RFI.pdf

EPA. (2017a). Chemistry Dashboard. Retrieved November 1, 2017, from https://comptox.epa.gov/dashboard

EPA. (2017b). Enforcement and Compliance History Online, Facility Search - Enforcement and Compliance Data. Retrieved December 1, 2017, from https://echo.epa.gov/facilities/facility-search 
EPA. (2017c). Industrial Stormwater Fact Sheet Series. Retrieved October 27, 2018, from https://www.epa.gov/npdes/industrial-stormwater-fact-sheet-series

EPA. (2017d). Portland Harbor Superfund Site Record of Decision. Retrieved from https://cumulis.epa.gov/supercpad/SiteProfiles/index.cfm?fuseaction=second.docdata\&id=100215 5

EPA. (2017e). Program Overview: Impaired Waters and TMDLs. Retrieved February 2, 2018, from https://www.epa.gov/tmdl/program-overview-impaired-waters-and-tmdls

EPA. (2017f). Summary of the Clean Water Act. Retrieved from https://www.epa.gov/lawsregulations/summary-clean-water-act

EPA. (2017g). Water Pollution Search, Water Pollutant Loading Tool. Retrieved October 24, 2017, from https://echo.epa.gov/trends/loading-tool/water-pollution-search

EPA. (2018a). Impaired Waters and TMDLs Program in your EPA Region, State or Tribal Land. Retrieved March 19, 2019, from https://www.epa.gov/tmdl/impaired-waters-and-tmdls-program-your-eparegion-state-or-tribal-land

EPA. (2018b). National Pollutant Discharge Elimination System (NPDES). Retrieved August 24, 2018, from https://www.epa.gov/npdes

EPA. (2018c). National Priorities List and Superfund Alternative Approach Sites Search. Retrieved January 10, 2018, from https://www.epa.gov/superfund/search-superfund-sites-where-you-live

EPA. (2018d). Program Overview: Total Maximum Daily Loads (TMDL). Retrieved January 28, 2018, from https://www.epa.gov/tmdl/program-overview-total-maximum-daily-loads-tmdl

EPA. (2018e). Superfund: CERCLA Overview. Retrieved July 23, 2018, from https://www.epa.gov/superfund/superfund-cercla-overview

Erickson D., M. (1997). Analytical Chemistry of PCBs (Second).

ESRI. (2017). ArcMap version 10.5.1. Retrieved from http://desktop.arcgis.com/en/arcmap/

Fitzpatrick, M. L., Long, D. T., \& Pijanowski, B. C. (2007). Exploring the effects of urban and agricultural land use on surface water chemistry, across a regional watershed, using multivariate statistics. Applied Geochemistry, 22(8 SPEC. ISS.), 1825-1840. https://doi.org/10.1016/j.apgeochem.2007.03.047

Gamble, A., \& Babbar-Sebens, M. (2012). On the use of multivariate statistical methods for combining in-stream monitoring data and spatial analysis to characterize water quality conditions in the White River Basin, Indiana, USA. Environmental Monitoring and Assessment, 184(2), 845-875. https://doi.org/10.1007/s10661-011-2005-y 
Göbel, P., Dierkes, C., \& Coldewey, W. G. (2007). Storm water runoff concentration matrix for urban areas. Journal of Contaminant Hydrology, 91(1-2), 26-42. https://doi.org/10.1016/j.jconhyd.2006.08.008

Gotelli, N., \& Aaron, E. (2013). A Primer of Ecological Statistics (Second). Sinauer Associates, Inc. Gramatica, P., Papa, E., \& Battaini, F. (2004). Ranking and classification of non-ionic organic pesticides for environmental distribution: A QSAR approach. International Journal of Environmental Analytical Chemistry, 84(1-3), 65-74. https://doi.org/10.1080/0306731031000149732

Guzmán, N. de, Gabriela T. Hapeman, Cathleen J. Prabhakara, K., Codling, E. E., Shelton, D. R., Rice, C. P., Hively, W. D., ... Torrents, A. (2012). Potential pollutant sources in a Choptank River (USA) subwatershed and the influence of land use and watershed characteristics. Science of the Total Environment, 430(May 2009), 270-279. https://doi.org/10.1016/j.scitotenv.2012.03.056

Haggarty, R. A., Miller, C. A., Scott, E. M., Wyllie, F., \& Smith, M. (2012). Functional clustering of water quality data in Scotland. Environmetrics, 23(8), 685-695. https://doi.org/10.1002/env.2185

Hall, K. K. (2012). Application of Multivariate Statistical Methodology to Model Factors Influencing Fate and Transport of Fecal Pollution in Surface Waters. East Tennessee State University.

Hegeman, W. J. M., Van Der Weijden, C. H., \& Gustav Loch, J. P. (1995). Sorption of Benzo[a]pyrene and Phenanthrene on Suspended Haihor Sediment as a Function of Suspended Sediment Concentration and Salinity: A Laboratory Study Using the Cosolvent Partition Coefficient. Environmental Science and Technology, 29(2), 363-371. https://doi.org/10.1021/es00002a012

Helmreich, B., Hilliges, R., Schriewer, A., \& Horn, H. (2010). Runoff pollutants of a highly trafficked urban road - Correlation analysis and seasonal influences. Chemosphere, 80(9), 991-997. https://doi.org/10.1016/j.chemosphere.2010.05.037

Hemond, H. F., \& Fechner-Levy, E. J. (2000). Chemical Fate and Transport in the Environment (2nd ed.). Hernandez, L., Probst, A., Probst, J. L., \& Ulrich, E. (2003). Heavy metal distribution in some French forest soils: Evidence for atmospheric contamination. Science of the Total Environment, 312(1-3), 195219. https://doi.org/10.1016/S0048-9697(03)00223-7

Holvoet, K. M. A., Seuntjens, P., \& Vanrolleghem, P. A. (2007). Monitoring and modeling pesticide fate in surface waters at the catchment scale. Ecological Modelling, 209(1), 53-64. https://doi.org/10.1016/j.ecolmodel.2007.07.030

Hope, B. K. (2008). A Model for the Presence of Polychlorinated Biphenyls (PCBs) in the Willamette River Basin (Oregon). Environmental Science and Technology, 42(16), 5998-6006. https://doi.org/10.1021/es8000213 
Huang, Y., Li, T., Wu, C., He, Z., Japenga, J., Deng, M., \& Yang, X. (2015). An integrated approach to assess heavy metal source apportionment in peri-urban agricultural soils. Journal of Hazardous Materials, 299, 540-549. https://doi.org/10.1016/j.jhazmat.2015.07.041

Hurley, J. P., Cowell, S. E., Shafer, M. M., \& Hughes, P. E. (1998). Partitioning and Transport of Total and Methyl Mercury in the Lower Fox River, Wisconsin. Environmental Science and Technology, 32(10), 1424-1432. https://doi.org/10.1021/es970685b

Imamoglu, I., \& Christensen, E. R. (2002). PCB sources, transformations, and contributions in recent Fox River, Wisconsin sediments determined from receptor modeling. Water Research, 36(14), 34493462. https://doi.org/10.1016/S0043-1354(02)00050-7

Jaffé, R. (1991). Fate of Hydrophobic Organic Pollutants in the Aquatic Environment: A review. Environmental Pollution, 69(2-3), 237-257. https://doi.org/10.1016/0269-7491(91)90147-0

K. R. Clarke. (1993). Non-parametric multivariate analyses of changes in community structure. Australian Journal of Ecology, 18, 117-143. https://doi.org/10.1071/WR9840181

Kalkstein, L. S., Tan, G., \& Skindlov, J. A. (1987). An Evaluation of Three Clustering Procedures for use in Synoptic Climatological Classification. Journal of CLimate and Applied Meteorology, 26, 717-730. https://doi.org/10.1017/СВ09780511486883

Karickhoff, S. W., Brown, D. S., \& Scott, T. A. (1979). Sorption of Hydrophobic Pollutants on Natural Sediments. Water Research, 13, 241-248. https://doi.org/0043-1354790301-0241502.00

Kasich, J. R., Taylor, M., \& Nally, S. J. (2013). Total Maximum Daily Loads for the Grand River (upper) Watershed. Retrieved from https://www.epa.ohio.gov/Portals/35/tmdl/GrandUpper_TMDLReport_Final.pdf

Kim, J. H., Kim, R. H., Lee, J., Cheong, T. J., Yum, B. W., \& Chang, H. W. (2005). Multivariate statistical analysis to identify the major factors governing groundwater quality in the coastal area of Kimje, South Korea. Hydrological Processes, 19(6), 1261-1276. https://doi.org/10.1002/hyp.5565

Kingrani, S. K., Levene, M., \& Zhang, D. (2017). Estimating the number of clusters using cross-validation. Artificial Intelligence Research, 7(1), 15-22. https://doi.org/10.5430/air.v7n1p15

Liang, Z., Liu, Y., Chen, H., \& Ji, Y. (2019). Is ecoregional scale precise enough for lake nutrient criteria? Insights from a novel relationship-based clustering approach. Ecological Indicators, 97(October 2018), 341-349. https://doi.org/10.1016/j.ecolind.2018.10.034

Lin, G. F., \& Wang, C. M. (2006). Performing cluster analysis and discrimination analysis of hydrological factors in one step. Advances in Water Resources, 29(11), 1573-1585. https://doi.org/10.1016/j.advwatres.2005.11.008 
Mackay, D. (2013). Dr. Donald Mackay Publications 1960-2012. Retrieved from https://www.trentu.ca/academic/aminss/envmodel/DMackayPubs.html

Mackay, D., McCarty, L. S., \& MacLeod, M. (2001). On the validity of classifying chemicals for persistence, bioaccumulation, toxicity, and potential for long-range transport. Environmental Toxicology and Chemistry, 20(7), 1491-1498. https://doi.org/10.1002/etc.5620200711

Mackay, D., Paterson, S., \& Shiu, W. Y. (1992). Generic Models for Evaluating the Regional Fate of Chemicals. Chemosphere, 24(6), 695-717.

Mackay, Donald, Di Guardo, A., Paterson, S., \& Cowan, C. E. (1996). Evaluating the environmental fate of a variety of types of chemicals using the EQC model. Environmental Toxicology and Chemistry, 15(9), 1627-1637. https://doi.org/10.1002/etc.5620150929

Mackay, Donald, Shiu, W.-Y., \& Ma, K.-C. (1997). Illustrated Handbook of Physical-Chemical Properties and Environmental Fate for Organic Chemicals: Volume V Pesticide Chemicals. Lewis Publishers.

Mackay, Donald, Shiu, W. Y., Ma, K.-C., \& Lee, S. C. (2006). Illustrated Handbook of Physical-Chemical Properties and Environmental Fate for Organic Chemicals: Vol I, II, III, IV (Second). CRC Press.

Mackay, Donald, Shiu, W. Y., \& Ma, K. C. (1993). Illustrated Handbook of Physical-Chemical Properties and Environmental Fate for Organic Chemicals: Volume III Volatile Organic Chemicals. CRC Press.

McCune, B., \& Grace, J. (2002). Analysis of Ecological Communities. MjM Software Design.

McNeil, V. H., Cox, M. E., \& Preda, M. (2005). Assessment of chemical water types and their spatial variation using multi-stage cluster analysis, Queensland, Australia. Journal of Hydrology, 310(1-4), 181-200. https://doi.org/10.1016/j.jhydrol.2004.12.014

MDEP. (2012). Maine Impervious Cover Total Maximum Daily Load Assessment (TMDL) for Impaired Streams. Retrieved from https://www.maine.gov/dep/water/monitoring/tmdl/2012/IC TMDL_Sept_2012.pdf

Meijer, S. N., Ockenden, W. A., Sweetman, A., Breivik, K., Grimalt, J. O., \& Jones, K. C. (2003). Global Distribution and Budget of PCBs and HCB in Background Surface Soils : Implications for Sources and Environmental Processes, 667-672. https://doi.org/10.1021/es025809|

Miller, M. M., Wasik, S. P., Huang, G. L., Shlu, W. Y., \& Mackay, D. (1985). Relationships between Octanol-Water Partition Coefficient and Aqueous Solubility. Environmental Science and Technology, 19(6), 522-529. https://doi.org/10.1021/es00136a007

Moore, J. N., \& Luoma, S. N. (1990). Hazardous wastes from large-scale metal extraction: A case study. Environmental Science and Technology, 24(9), 1278-1285. https://doi.org/10.1021/es00079a001 NAICS. (2018). NAICS Identification Tools. Retrieved July 1, 2018, from https://www.naics.com/search/ 
Neitsch, S. L., Arnold, J. G., Kiniry, J. R., Srinivasan, R., \& Williams, J. R. (2002). Soil and Water Assessment Tool User's Manual Version 2000. https://doi.org/10.1002/mrm.20747

Nicholson, F. A., Smith, S. R., Alloway, B. J., Carlton-Smith, C., \& Chambers, B. J. (2006). Quantifying heavy metal inputs to agricultural soils in England and Wales. Water and Environment Journal, 20(2), 87-95. https://doi.org/10.1111/j.1747-6593.2006.00026.x

NLM. (2017). PubChem Substance and Compound Databases. Retrieved November 1, 2017, from https://pubchem.ncbi.nlm.nih.gov/

Nordstrom, D. K. (2011). Hydrogeochemical processes governing the origin, transport and fate of major and trace elements from mine wastes and mineralized rock to surface waters. Applied Geochemistry, 26(11), 1777-1791. https://doi.org/10.1016/j.apgeochem.2011.06.002

NRCS. (2007). Watersheds, Hydrological Units, Hydrological Unit Codes, Watershed Approach, and Rapid Watershed Assessments. Retrieved from https://www.nrcs.usda.gov/Internet/FSE_DOCUMENTS/stelprdb1042207.pdf

Nziguheba, G., \& Smolders, E. (2008). Inputs of trace elements in agricultural soils via phosphate fertilizers in European countries. Science of the Total Environment, 390(1), 53-57.

https://doi.org/10.1016/j.scitotenv.2007.09.031

ODA. (2019). Oregon Fertilizer Program Guide.

ODOT. (2016). Stormwater Outfall Inventory Management. Retrieved from https://www.oregon.gov/ODOT/GeoEnvironmental/Pages/Stormwater.aspx

OEPA. (2012). Flow-Based Surrogate TMDLs , A Case Study in Ohio Lower Grand River TMDL, (January), 3. Retrieved from https://epa.ohio.gov/portals/35/tmdl/GrandLower_SurrogateTMDLFactSheet.pdf OSDL. (2011). Oregon NLCD Land Cover 2011. Retrieved April 15, 2018, from http://spatialdata.oregonexplorer.info/geoportal/details;id=81916ee1b2b741c0aacb814ee8e73af9 OSDL. (2015a). Oregon Counties. Retrieved June 1, 2018, from http://spatialdata.oregonexplorer.info/geoportal/details;id=361c06fee9de4e24a72e280fb386a771 OSDL. (2015b). Oregon Land Management 2015. Retrieved April 15, 2018, from http://spatialdata.oregonexplorer.info/geoportal/details;id=9b644e0f7a7d4124a50f6b35c05626ae OSDL. (2017). Oregon Watershed Boundary Dataset. Retrieved December 13, 2017, from http://spatialdata.oregonexplorer.info/geoportal/details;id=4b1b008d5a764a209b2df040689c077 9

OSU. (2018). Get a leg up on fruit tree problems with dormant oils. Retrieved November 20, 2017, from 
https://extension.oregonstate.edu/news/get-leg-fruit-tree-problems-dormant-oils

Paul, S. (2003). Bacteria Total Maximum Daily Load: Development and Evaluation of a New Classification Scheme for Impaired Waterbodies of Texas. Texas A\&M University. https://doi.org/10.16309/j.cnki.issn.1007-1776.2003.03.004

Piwoni, M. D., \& Keeley, J. W. (1990). Basic Concepts of Contaminant Sorption at Hazardous Waste Sites. Ground Water Issue -EPA/540/4-90/053. https://doi.org/10.1056/NEJMoa030660

Plummer, J. D., \& Long, S. C. (2009). Identifying sources of surface water pollution: A toolbox approach. Journal / American Water Works Association, 101(9).

R Development Core Team. (2016). The R Project for Statistical Computing. Retrieved from http://www.rstudio.com/.

Rand, G. M. (1995). Fundamentals of Aquatic Toxicology: Effects, Environmental Fate, and Risk Assessment (2nd ed.).

Reckhow, K. H., Donigian Jr., A. S., Karr, J. R., McDonald, S. H., Novotny, V., Smith, R. A., \& Yoder, C. O. (2001). Assessing the TMDL Approach to Water Quality Management. https://doi.org/10.17226/10146

Rodenburg, L. A., \& Ralston, D. K. (2016). Historical Sources of Polychlorinated Biphenyls to the Sediment of the New York/New Jersey Harbor. Chemosphere, 169, 450-459. https://doi.org/10.1016/j.chemosphere.2016.11.096

Sabin, L. D., Jeong, H. L., Stolzenbach, K. D., \& Schiff, K. C. (2005). Contribution of trace metals from atmospheric deposition to stormwater runoff in a small impervious urban catchment. Water Research, 39(16), 3929-3937. https://doi.org/10.1016/j.watres.2005.07.003

Schueler, T. R. (2000). The importance of Imperviousness. Watershed Protection Techniques, 100-111, 12. https://doi.org/Doi: 10.1016/0021-9517(74)90218-8

Schwarzenbach, R. P., Gschwend, P. M., \& Imboden, D. M. (2017). Environmental Organic Chemistry (Third). John Wiley \& Sons, Inc.

Servien, R., Mamy, L., Li, Z., Rossard, V., Latrille, E., Bessac, F., ... Benoit, P. (2014). TyPol - A new methodology for organic compounds clustering based on their molecular characteristics and environmental behavior. Chemosphere, 111, 613-622. https://doi.org/10.1016/j.chemosphere.2014.05.020

Shoemaker, L., Dai, T., Koenig, J., \& Hantush, M. (2005). TMDL Model Evaluation and Research Needs. Retrieved from https://www.epa.gov/sites/production/files/2015-07/documents/600r05149.pdf Shrestha, S., \& Kazama, F. (2007). Assessment of surface water quality using multivariate statistical 
techniques: A case study of the Fuji river basin, Japan. Environmental Modelling and Software, 22(4), 464-475. https://doi.org/10.1016/j.envsoft.2006.02.001

Soto-Varela, F., Rodríguez-Blanco, M. L., Taboada-Castro, M. M., \& Taboada-Castro, M. T. (2015). Metals discharged during different flow conditions from a mixed agricultural-forest catchment (NW Spain). Hydrological Processes, 29(6), 1644-1655. https://doi.org/10.1002/hyp.10282

Spromberg, J. A., Baldwin, D. H., Damm, S. E., Mcintyre, J. K., Huff, M., Sloan, C. A., ... Scholz, N. L. (2016). Coho salmon spawner mortality in western US urban watersheds: Bioinfiltration prevents lethal storm water impacts. Journal of Applied Ecology, 53(2), 398-407. https://doi.org/10.1111/13652664.12534

SRC. (2013). FatePointers Search Module, PhysProp. Retrieved December 1, 2017, from http://esc.srcinc.com/fatepointer/search.asp

Ter Laak, T. L., Ter Bekke, M. A., \& Hermens, J. L. M. (2009). Dissolved organic matter enhances transport of PAHs to aquatic organisms. Environmental Science and Technology, 43(19), 72127217. https://doi.org/10.1021/es803684f

Tülp, H. C., Fenner, K., Schwarzenbach, R. P., \& Goss, K. U. (2009). pH-dependent sorption of acidic organic chemicals to soil organic matter. Environmental Science and Technology, 43(24), 91899195. https://doi.org/10.1021/es902272j

U.S. Census Bureau. (2019). American FactFinder, Annual Estimates of the Resident Population. Retrieved March 7, 2019, from https://factfinder.census.gov/faces/tableservices/jsf/pages/productview.xhtml?pid=PEP_2017_PE PANNRES\&prodType=table

Uhrich, M. A., \& Wentz, D. A. (1999). Environmental Setting of the Willamette Basin, Oregon.

US Census Bureau. (2010). 2010 FIPS Code Files for Counties and County Equivalent Entities. Retrieved October 29, 2017, from https://www.census.gov/geo/reference/codes/cou.html

US Labor Department. (2019). US Inflation Calculator. Retrieved May 30, 2019, from https://www.usinflationcalculator.com/

USDA. (2012a). 2012 Census of Agriculture, County Data, Table 24 Selected Crops Harvested. Retrieved from https://www.nass.usda.gov/Publications/AgCensus/2012/Full_Report/Volume_1,_Chapter_2_Cou nty_Level/Oregon/st41_2_024_024.pdf

USDA. (2012b). 2012 Census of Agriculture, County Data, Table 25 Field Crops 2012 and 2007. Retrieved from 
https://www.nass.usda.gov/Publications/AgCensus/2012/Full_Report/Volume_1,_Chapter_2_Cou nty_Level/Oregon/st41_2_025_025.pdf

USDA. (2012c). 2012 Census of Agriculture, County Data, Table 27 Other Crops 2012 and 2007. Retrieved from

https://www.nass.usda.gov/Publications/AgCensus/2012/Full_Report/Volume_1,_Chapter_2_Cou nty_Level/Oregon/st41_2_027_027.pdf

USDA. (2012d). 2012 Census Volume 1 Chapter 1 State Level Data Oregon. Retrieved July 19, 2018, from https://www.agcensus.usda.gov/Publications/2012/Full_Report/Volume_1,_Chapter_1_State_Lev el/Oregon/

USDA. (2012e). Census of Agriculture Table 8 Farms, Land in Farms, Value of Land and Buildings, and Land Use: 2012 and 2007. Retrieved from https://www.agcensus.usda.gov/Publications/2012/Full_Report/Volume_1,_Chapter_2_County_Le vel/Oregon/

USDA. (2012f). Census of Agriculture Table 9 Harvested Cropland by Size of Farm and Acres Harvested: 2012 and 2007. Retrieved from https://www.agcensus.usda.gov/Publications/2012/Full_Report/Volume_1,_Chapter_2_County_Le vel/Oregon/

USGS. (1996). Occurence of Selected Trace Elements and Organic Compounds and their Relation to Land Use in the Willamette River Basin, 1992-94.

USGS. (2007). Pesticides in the Nation's Streams and Groundwater, 1992-2001. Retrieved from http://pubs.usgs.gov/circ/2005/1291/pdf/circ1291.pdf

USGS. (2015). Estimated Annual Agricultural Pesticide Use for Counties of the Conterminous United States, 1992-2009. https://doi.org/10.1890/03-0410

USGS. (2017). National Water Quality Assessment Project, Pesticide National Synthesis Project. Retrieved July 8, 2018, from https://water.usgs.gov/nawqa/pnsp/usage/maps/county-level/ Velleux, M., \& Endicott, D. (1994). Development of a Mass Balance Model for Estimating PCB Export from the Lower Fox River to Green Bay. Journal of Great Lakes Research, 20(2), 416-434. https://doi.org/10.1016/S0380-1330(94)71159-X

Verhaar, H. J. M., J., V. L. C., \& Hermens, J. L. M. (1992). Classifying Environmental Pollutants 1: Structure-Activitiy Relationships for Prediction of Aquatic Toxicity. Chemosphere, 25(4), 471-491.

WA Ecology. (1999). Spokane River Dissolved Metals Total Maximum Daily Load Submittal Report Spokane River Dissolved Metals Total Maximum Daily Load. 
WA Ecology. (2006). Walla Walla River Chlorinated Pesticides and PCBs Total Maximum Daily Load (Water Cleanup Plan).

WA Ecology. (2007a). Characterizing Stormwater for Total Maximum Daily Load Studies A Review of Current Approaches. Retrieved from https://fortress.wa.gov/ecy/publications/publications/0703006.pdf

WA Ecology. (2007b). Spokane River PCB TMDL Stormwater Loading Analysis Final Technical Report. Retrieved from https://fortress.wa.gov/ecy/publications/documents/0703055.pdf

WA Ecology. (2010). Yakima River Pesticides and PCBs Total Maximum Daily Load, Volume 1 Water Quality Study Findings. Retrieved from https://fortress.wa.gov/ecy/publications/documents/1003018.pdf

WA Ecology. (2014). Green/Duwamish River Watershed Pollutant Loading Assessment Technical Approach. Retrieved from https://www.ezview.wa.gov/Portals/_1962/Documents/DGPLA/GrnDuwamishPLAtechApproachFinal10172014.pdf

Walker, C. (2001a). Influence of the Properties of Chemicals on their Environmental Fate. In Organic Pollutants: An Ecotoxicological Perspective (Second, pp. 64-71). CRC Press.

Walker, C. (2001b). Organometallic compounds. In Organic Pollutants: An Ecotoxicological Perspective (Second, pp. 148-164). CRC Press. https://doi.org/10.1038/179987d0

Walker, C. (2001c). Organophosphorus and Carbamate Insecticides. In Organic Pollutants: An Ecotoxicological Perspective (Second, pp. 177-203). CRC Press.

Walker, C. (2001d). Polychlorinated biphenyls and polybrominated biphenyls. In Organic Pollutants: An Ecotoxicological Perspective (Second, pp. 121-137). CRC Press.

Walker, C. (2001e). Polycyclic Aromatic Hydrocarbons. In Organic Pollutants: An Ecotoxicological Perspective (Second, pp. 165-176). CRC Press.

Walker, C. (2001f). The Organochlorine Insecticides. In Organic Pollutants: An Ecotoxicological Perspective (Second, pp. 91-120). CRC Press.

Wang, X., Chen, T., Ge, Y., \& Jia, Y. (2008). Studies on land application of sewage sludge and its limiting factors. Journal of Hazardous Materials, 160(2-3), 554-558. https://doi.org/10.1016/j.jhazmat.2008.03.046

Wang, Y., Wang, Y., Ran, M., Liu, Y., Zhang, Z., Guo, L., ... Wang, P. (2013). Identifying potential pollution sources in river basin via water quality reasoning based expert system. In Fourth International Conference on Digital Manufacturing \& Automation (pp. 671-674). https://doi.org/10.1109/ICDMA.2013.159 
Wania, F., \& Mackay, D. (1998). The evolution of mass balance models of persistent organic pollutant fate in the environment. Environmental Pollution, 100(1-3), 223-240. https://doi.org/10.1016/S0269-7491(99)00093-7

Ward Jr., J. H. (1963). Hierarchical Grouping to Optimize an Objective Function. Journal of the American Statistical Association, 58(301), 236-244. https://doi.org/10.1016/j.genhosppsych.2010.09.005

Webster, E., Mackay, D., Wania, F., Arnot, J., Gobas, F., Gouin, T., ... Chenier, R. (2005). Development and Application of Models of Chemical Fate in Canada Modelling Guidance Document. Ontario.

Wenning, R. J., \& Erickson, G. A. (1994). Interpretation and analysis of complex environmental data using chemometric methods. Trends in Analytical Chemistry, 13(10), 446-457. https://doi.org/10.1016/0165-9936(94)85026-7

Wolock, D. M., Winter, T. C., \& McMahon, G. (2011). Delineation and Evaluation of HydrologicLandscape Regions in the United States Using Geographic Information System Tools and Multivariate Statistical Analyses. Environmental Management, 34, 71-88. https://doi.org/10.1007/s00267-003-5077-9

Wool, T., Ambrose, R., Martin, J., \& Comer, E. (2009). Water Quality Analysis Simulation Program (WASP) Version 6.0 Draft: user's Manual.

WSU. (2015). Pesticide Ingredient: Horicultural Oil. Retrieved from http://cru.cahe.wsu.edu/CEPublications/FS184E/FS184E.pdf

Yang, Y. H., Zhou, F., Guo, H. C., Sheng, H., Liu, H., Dao, X., \& He, C. J. (2010). Analysis of spatial and temporal water pollution patterns in Lake Dianchi using multivariate statistical methods. Environmental Monitoring and Assessment, 170(1-4), 407-416. https://doi.org/10.1007/s10661009-1242-9

Yang, Y., He, Z., Wang, Y., Fan, J., Liang, Z., \& Stoffella, P. J. (2013). Dissolved organic matter in relation to nutrients ( $\mathrm{N}$ and $\mathrm{P}$ ) and heavy metals in surface runoff water as affected by temporal variation and land uses - A case study from Indian River Area, south Florida, USA. Agricultural Water Management, 118, 38-49. https://doi.org/10.1016/j.agwat.2012.12.001

Younos, T. (2005). Total Maximum Daily Load: Approaches and Challenges.

Yu, J., Yi, H., Wang, J., Deng, R., Zeng, G., Ren, X., ... Ye, S. (2017). Sorption, transport and biodegradation - An insight into bioavailability of persistent organic pollutants in soil. Science of The Total Environment, 610-611, 1154-1163. https://doi.org/10.1016/j.scitotenv.2017.08.089

Zambelli, A. (2016). A Data-Driven Approach to Estimating the Number of Clusters in Hierarchical Clustering. https://doi.org/10.12688/f1000research.10103.1 